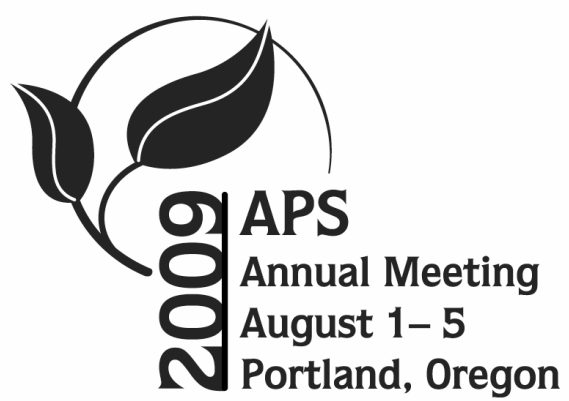

\title{
2009 APS Annual Meeting Abstracts of Special Session Presentations
}

\section{Biology of Plant Pathogens}

\section{Coordinated Regulation of Fungal Development and Secondary Metabolism During Pathogenesis}

\begin{abstract}
Aspects of habitat important to Fusarium verticillioides during pathogenesis of maize kernels

C. P. Woloshuk

Dept. Botany \& Plant Pathology, Purdue University, West Lafayette, IN 47907

Phytopathology 99:S152

Fusarium verticillioides has at least two discernible interactions with its host. The most obvious is the destruction of host tissues: causing root rot, stalk rot, and kernel/ear rot. In a second type of interaction, the pathogen grows as an endophyte without visible signs or symptoms. Evidence suggests that $F$. verticillioides responds to its microenvironment during colonization of the maize kernels. The responses are triggered by plant metabolites within kernel, often resulting in a modification of the kernel environment by the fungus. The most noted change is $\mathrm{pH}$. Fungal growth on germ tissues leads to alkalinization of the tissue, in contrast to endosperm tissues, which becomes acidic during colonization. Alkalinization also occurs when the fungus infects blister stage kernels and high-amylose genotypes of maize. Production of fumonisin B1 (FB1) is also part of the fungal response to its host environment. In mature kernels, the starch-rich tissue of the endosperm supports higher levels of FB1 than germ tissue. The uptake and subsequent utilization of sugars derived from starch in endosperm may drive kernel acidification, which is conducive for FB1 biosynthesis. Recently, we have identified several genes that appear to have roles in the perception of and/or the response to inducers in the kernel. We are investigating the potential mechanisms responsible for regulating FB1 production during the destructive or endophytic states of the pathogen.
\end{abstract}

Regulation of morphogenesis, secondary metabolism, and pathogenicity by the VeA system in Aspergillus and Fusarium species

A. M. Calvo

Dept. Biological Sciences, Northern Illinois University, Dekalb, IL 60115

Phytopathology 99:S152

A number of biological processes are intimately connected to an organism's developmental program. This is true of processes such as production of toxins and other secondary metabolites in pathogenic fungi. In many cases the signaling pathways involved in these cellular processes are very complex and often the cross-talk between them is not well understood. Here we describe the role of the VeA regulator in morphogenesis, secondary metabolism and pathogenesis in two agriculturally important fungal genera: Aspergillus and Fusarium. We showed that the veA gene positively regulates sterigmatocystin production in Aspergillus nidulans and aflatoxin production in A. parasiticus and A. flavus, species often found infecting oil seed crops worldwide. In addition, $v e A$ is required for the production of resistant structures called

The abstracts are published as submitted. They were formatted but not edited at the APS headquarters office. sclerotia in these fungi. Furthermore, our recent studies revealed that virulence of A. flavus on peanut, corn and cotton was reduced in the absence of the veA gene product. Whether veA homologs have a role in regulating secondary metabolism and pathogenicity in other fungal genera was unknown. In our studies, we examined the role of the veA homolog, FvVE1, on the production of two mycotoxin families, fumonisins and fusarins, in the important maize pathogen Fusarium verticillioides. We found that FvVE1 deletion completely suppressed fumonisin and fusarin production on natural substrates, such as corn and rice. Moreover, deletion of $F v V E 1$ resulted in strains unable to cause disease symptoms on corn, and unable to produce fumonisins in plant tissue. Leaf lesion incidence and severity correlated with fumonisin presence and disruption of sphingolipid metabolism.

Bioprotective secondary metabolites from fungal endophytes of cool season grasses

C. Young

The Samuel Roberts Noble Foundation, Ardmore, OK 73401

Phytopathology 99:S152

The epichloae (Epichloë and Neotyphodium species) are important fungal symbionts that form mutualistic associations with cool season grasses. They are capable of producing a range of bioprotective alkaloids, such as peramine, lolines, ergot alkaloids and lolitrems, with anti-insect and anti-mammalian properties that help protect their grass host. The genes required for the synthesis of these four classes of alkaloids have been cloned and characterized from a number of endophytes found in agriculturally important grasses. As seen with other fungal secondary metabolite biosynthesis genes, the genes for three of the four alkaloids are present as co-regulated gene clusters. The lolitrem (ltm) biosynthesis genes from Neotyphodium lolii, an endophyte of perennial ryegrass (Lolium perenne), are found in a complex gene cluster interspersed with AT rich repetitive regions that are preferentially and highly expressed in planta. Metabolic profiles using HPLC and LC-MS/MS, and characterization of the indole-diterpene biosynthetic pathway using gene knockouts and naturally occurring isolates with variation at the LTM locus has shown that lolitrem B is produced by a complex biosynthetic grid rather than linear pathway.

Elicitors to toxins: Plant interactions with Trichoderma virens C. Kenerley

Dept. Plant Pathology \& Microbiology, Texas A\&M University, College Station, TX 77843

Phytopathology 99:S152

As a ubiquitous soil inhabitant capable of developing symbiotic associations with plant roots, Trichoderma virens can provide significant protection against pathogens through induced systemic resistance (ISR). The activation of this response in maize and cotton roots colonized by $T$. virens is mediated through the elicitor SM1, a small secreted, cysteine-rich protein and a member of the cerato-platanin family $(\mathrm{CP})$. We have established the role of glycosylation in elicitation properties and this property appears distinct for some members of the CP family. Crystallization of SM1 has further provided a model for comparison to the phytotoxic members of the $\mathrm{CP}$ family. A bioinformatic survey of the T. virens genome has revealed the presence of more than 200 
proteins with putative elicitation properties; many of these are root-induced. In order to establish the role of non-ribosomal peptide synthetases (NRPSs) in ISR, we have studied the expression of over 30 putative genes encoding NRPSs, and estimated that approximately half are expressed during interactions between maize roots and the fungus. A reverse genetic approach has demonstrated the involvement of several NPRSs in siderophore, peptaibol, and gliotoxin production. One peptaibol initiates ISR whereas other biosynthesized compounds affect developmental stages. However, the majority of the metabolites encoded by these NRPSs remain to be identified.

Light and pathogenesis among Cercospora: Evidence for coordinated responses to photoperiod?

B. Bluhm

Dept. Plant Pathology, University of Arkansas, Fayetteville, AR 72701

Phytopathology 99:S153

The fungal genus Cercospora is a diverse and destructive group of foliar fungal pathogens. During infection, many species of Cercospora display an extraordinary ability to orient hyphal growth in the direction of the nearest stomate, whereupon they form appressoria to initiate entry. After penetrating leaves, many Cercospora species produce the phytotoxin cercosporin, a photosensitizing perylenequinone. Light strongly induces cercosporin biosynthesis, thus underscoring a relationship between photobiology and virulence in this group of pathogens. We recently discovered that the maize foliar pathogen C. zeae-maydis requires light in order to find stomata and produce appressoria, and that blue light induces cercosporin biosynthesis. These findings led us to characterize CRPI in C. zeae-maydis, a member of the white collar-1 family of blue-light photoreceptors that regulate circadian rhythms in filamentous fungi. Disruption of CRPI almost completely abolished appressorium formation, resulting in a concomitant loss of virulence. Intriguingly, the basal regulation of stomatal aperture is circadian, governed by an endogenous molecular clock that is entrained by daily cycles of day and night. We hypothesize that coordinated, light-dependent signal transduction pathways dictate the outcome of interactions between C. zeae-maydis and maize. As the first gene known to regulate non-thigmotropic stomatal infection in fungi, CRPI provides a key foothold to unravel the molecular dialogue underlying light-dependent pathogenesis.

\section{'New' Nuances in Virus-Vector Biology}

Elucidating the functional role of Crinivirus capsid proteins in mediating semi-persistent virus transmission by whitefly vectors

J. Ng

Department of Plant Pathology \& Microbiology, University of California, Riverside, CA 92521

Phytopathology 99:S153

Semi-persistently transmitted viruses include the aphid-transmitted Cauliflower mosaic caulimovirus (CaMV) and members of the whitefly-transmitted genus Crinivirus. Evidence suggests that semi-persistently transmitted viruses are borne in the vector foregut, although virion retention in the aphid stylet has also been reported for CaMV. Studies of Lettuce infectious yellows crinivirus (LIYV) and Lettuce chlorosis crinivirus (LCV) showed that whitefly, Bemisia tabaci biotype A, pre-fed with high concentrations of LIYV virions followed by decreasing concentrations of LCV virions drastically reduced or, in most cases, abolished the transmission of LCV, suggesting that vector acquisition of LIYV interfered with some aspects of LCV-vector interaction. One objective of our study was to use immunofluorescent localization to determine if acquired LIYV virions are retained in the vector foregut, and if this corresponds with virus transmission. Our results revealed that fluorescence was seen in the foregut of viruliferous vectors, and virus transmission occurred when the signal was observed in $>20 \%$ of the whiteflies. This is only the first step; many issues remain unexplored. Are virions retained in the foregut of non-vector whiteflies? What is/are the viral protein(s) that mediate(s) foregut retention? Do LIYV and LCV share a similar retention site? These and other developments will be discussed.

\section{-Omics for exploring whitefly-begomovirus interactions}

J. Brown

Department of Plant Sciences, The University of Arizona, Tucson, AZ 85721 Phytopathology 99:S153

Whiteflies are pests and vectors of plant viruses. The most damaging viruses are members of the genus Begomovirus (Geminiviridae), which are transmitted by the Bemisia tabaci complex (Gennadius) in a persistent and circulative manner. Such tight specificity is suggestive of co-evolved proteinprotein interactions. We are focused on elucidating both conserved and specific molecular and cellular mechanisms that underlying circulative types of virus-vector transmission. Using a proteomics approach, we identified a suite of whitefly proteins (putatively) involved in 'stress' and 'defense' pathways, and in macromolecular transport. A large-scale 5' expressed sequence tag (EST) project was undertaken in which non-normalized (Leshkowitz et al. 2006) and normalized (Sarapalli et al., in press) whitefly (B biotype) cDNA libraries were sequenced. Non-subtracted EST consensi were re-annotated, and normalized ESTs were annotated for the first time against available insect sequences $(12+$ genomes) in public databases. BLASTN hits were predominantly to genes of A. pisum and $M$. persicae, a result that supports the close taxonomic relatedness of whiteflies and aphids, e.g. homopterans in the Sternorrhyncha. The translated ESTs were assigned Gene Ontology functions (www.geneontology.org), and candidates were selected for validation. Determining the genome sequence for B. tabaci, a subtropical, hompteran hallmark, is now imperative.

Vector and virus proteins contributing to the regulation of Yellow dwarf virus (Luteoviridae) transmission by aphids

F. Gildow (1), S. Gray (2)

(1) Department of Plant Pathology, Pennsylvania State University, University
Park, PA 16802; (2) USDA-ARS, Department of Plant Pathology, Cornell University, Ithaca, NY 14853

Phytopathology 99:S153

The circulative transmission pathway of luteoviruses through their aphid vectors requires that the virus be actively transported across both gut and salivary tissues as well as survive in the hostile environments of the gut and the hemocoel. This journey is orchestrated by two virus proteins and an unknown number of aphid proteins. The transmission of two related viruses that cause yellow dwarf disease of cereals by Schizaphis graminum is controlled by two distinct, but overlapping sets of aphid genes. Aphid genes regulating the transmission of both viruses segregate independently as do genes regulating the transport of virus through gut and salivary tissues. A proteomic analysis of vector and nonvector genotypes has identified numerous aphid and endosymbiont proteins that are involved in cell surface binding, endocytosis, macromolecular transport and trafficking, and immune defense responses. These proteins are correlated with vector and nonvector genotypes or specific tissue types and ultrastructural studies suggest sites of protein function influencing virus transmission. Several of these proteins have been shown to bind to virus particles. Several proteins have also been shown to be allelic in nature, differing between vector and nonvector genotypes. This is the first system to allow the identification of specific aphid proteins involved in the genetic regulation of virus transmission.

\section{Exploiting vector specificity to inhibit tospovirus transmission}

T. German

Department of Entomology, University of Wisconsin, Madison, WI 53706

Phytopathology 99:S153

Arthropods can be significant pests of humans, animals and plants directly and in their role as vectors of viral pathogens. More than $70 \%$ of viruses infecting plants and $40 \%$ of viruses infecting mammals are transmitted by arthropod vectors. We are addressing this problem using Tomato spotted wilt virus (TSWV), the prototypic member of the genus Tospovirus within the family Bunyaviridae. TSWV is a prominent plant pathogen with a worldwide distribution and a large host range. TSWV is transmitted by at least seven species of thrips (Thysanoptera: Thripidae) in a persistent, replicative manner. Vector specificity (which virus can be transmitted) and efficiency (usually measured as per-cent transmission) are determined by (i) the acquisition of virus from an infected host; (ii) passage of virus through the insect midgut; (iii) entry into the salivary glands; (iv) delivery of virus in a viable form into another host. Each of these steps is governed by specific molecular interactions between the virus and the vector and every step represents possible barriers to successful transmission. We have shown that a truncated version of a viral surface protein specifically attaches to thrips mid-gut cells and significantly interferes with transmission of TSWV. Our objective is to use this information to develop a practical, bio-rational means to specifically target peptides derived from viral proteins to vectors of TSWV that will inhibit virus transmission.

Molecular and cellular interactions between rhabdoviruses and their insect hosts

A. Whitfield

Department of Plant Pathology, Kansas State University, Manhattan, KS 66502 Phytopathology 99:S153

Plant rhabdoviruses are transmitted in a persistent propagative manner by their arthropod vectors. These viruses must cross several tissue layers in the arthropod for successful transmission to occur. Studies have demonstrated that the 
insect gut serves as an important barrier for rhabdovirus transmission, and in other insect-microbe interactions, it has been shown that a substantial number of genes are differentially regulated upon pathogen invasion of midguts, including immune-response genes. In recent years, significant advancements have been made towards identifying the essential viral components of virusvector interactions, but the molecules that determine vector competence remain largely uncharacterized. Our goal is to identify proteins that facilitate virus acquisition and/or innate immune responses during infection of the insect midgut. We hypothesize that Maize mosaic virus (MMV) infection of the planthopper vector, Peregrinus maidis, alters the insect midgut transcriptome. To that end, we sequenced the $P$. maidis midgut transcriptome and identified 200 ESTs that are predicted to play a role in innate immune response. Two possible virus receptor transcripts were identified in our EST collection based on sequence similarity to receptors for animal-infecting rhabdoviruses. These sequence resources provide us with the necessary tools to identify insect proteins that play a role in virus transmission.

\section{Quorum Sensing and Biofilm Formation in Plant-Associated Bacteria}

\author{
Quorum sensing in the plant pathogenic bacteria: The Pantoea stewartii \\ paradigm \\ S. von Bodman \\ University of Connecticut, Storrs, CT \\ Phytopathology 99:S154
}

In Pantoea stewartii subsp. stewartii the major stewartan exo- and capsular polysaccharide (EPS/CPS) virulence factor is governed by the EsaI/EsaR cellcell communication system together with the environmental sensing Rcs phosphorelay. The integration of these regulatory networks ensures the cell density-dependent synthesis of stewartan, but only under the appropriate environmental conditions. The strict regulation of stewartan synthesis is absolutely essential for $P$. stewartii to cause Stewart's vascular wilt in maize. In fact, the premature or constitutive synthesis of stewartan diminishes the virulence potential of the pathogen significantly. One of the reasons for this is that stewartan production interferes with microbial adhesion to surfaces, including maize tissue, thereby compromising the organism's ability to aggregate and form biofilms. P. stewartii is motile and exists in the xylem as cell wall-adherent biofilms. We also resolved a related, long-standing question showing that stewartan CPS synthesis coincides with stewartan EPS synthesis supporting our hypothesis that various surface glycoplymers provide different functions during the $P$. stewartii life-cycle. We will correlate our findings to the disease biology of the pathogen.

Polar attachment, a unipolar polysaccharide adhesin and cellular asymmetry determinants of Agrobacterium tumefaciens

C. FUQUA, P. M. Merritt, J. Kim, J. Xu

Indiana University, Bloomington, IN

Phytopathology 99:S154

Agrobacterium tumefaciens is well known for its ability to genetically modify plants through transfer of a segment of DNA (T-DNA) into the plant nucleus. T-DNA genes direct rapid cell proliferation and production of opine nutrients that are utilized by the infecting bacteria. Despite extensive studies of the TDNA transfer, there is minimal understanding regarding productive attachment to plant surfaces. A. tumefaciens attaches and forms complex biofilms on a variety of surfaces. We have identified a cell surface adhesin that associates with the pole of the cell which contacts surfaces, including plant tissues and abiotic structures. The adhesin can be visualized with fluorescently-tagged lectins on single cell poles, suggesting that it is at least partially comprised of polysaccharide, and hence we describe it as the unipolar polysaccharide (UPP). The A. tumefaciens UPP bears facile similarity to the holdfast adhesin of Caulobacter crescentus. UPP elaboration requires the upp gene cluster, which encodes putative polysaccharide biosynthetic functions, and is conserved and syntenous among several rhizobia. Elaboration of the UPP is required for $A$. tumefaciens polar attachment to abiotic surfaces and binding to Arabidopsis root tissues. Co-localization of the UPP with flagellar basal bodies reveals that this adhesin is on the opposite end of the cell from the flagellar tuft in $A$. tumefaciens. Several presumptive polar development genes of A. tumefaciens are required for or influence proper cell septation, flagellar placement and motility, biofilm formation, pellicle generation and UPP localization.

The role of quorum sensing and phenazine antibiotics in biofilm formation by Pseudomonas chlororaphis 30-84

E. Pierson

University of Arizona

Phytopathology 99:S154

Pseudomonas chlororaphis $30-84$ is a rhizosphere-colonizing bacterium that is able to control take-all disease of wheat caused by the fungal pathogen Gaeumannomyces graminis var. tritici (Ggt). P. chlororaphis produces primarily two different phenazine (PZ) compounds, phenazine-1-carboxylic acid (PCA) and 2-hydroxy-PCA (2OHPCA). Production of PZs by strain 3084 is the primary mechanism of pathogen inhibition and contributes to the persistence of strain $30-84$ in the rhizosphere. $\mathrm{PZ}$ production is regulated by a complex sensory pathway that includes the PhzR/I quorum-sensing system (QS). Using flow cells, we demonstrated that QS and PZ are involved in biofilm formation. Derivatives of $P$. chlororaphis were constructed that produced only PCA or more efficiently converted PCA into 2OHPCA. These derivatives produced similar levels of PZs and PZ gene expression was controlled by QS. We found that the PZ-altered derivatives of $P$. chlororaphis differed from the wild type in initial attachment, biofilm architecture, and dispersal. The PCA-only derivative produced thicker, denser biofilms than the wild type, whereas the 2OHPCA enhanced strain adhered more rapidly than either the wild type strain or the PCA-only derivative. The PZ-altered derivatives also differed in their ability to inhibit Ggt. Preliminary microarray data suggested that PZs themselves serve as signaling mechanisms. Our findings demonstrate that $\mathrm{PZ}$ play multiple roles in the ecology of $P$. chlororaphis.

Plant factors and other bacterial residents modulate iron levels on leaves thereby influencing quorum sensing controlled epiphytic fitness and virulence in Pseudomonas syringae

S. Lindow

University of California, Berkeley

Phytopathology 99:S154

The majority of cells of Pseudomonas syringae are found in relatively large (>100 cells) cell aggregates on the surface of healthy leaves, facilitating quorum sensing (QS) via its production of 3-oxo-hexanoyl homoserine lactone (AHL). QS enhances epiphytic fitness but suppresses swarming motility of $P$. syringae. The increased numbers of lesions incited by QS mutants on bean compared to wild-type strains was associated with increased rates of invasion of leaves, apparently due to incessant movement of cells on plants. As many as $8 \%$ of the bacterial residents of healthy leaves produced an AHL to which $P$. syringae responded and reduced the numbers and size of lesions incited when co-inoculated onto plants with $P$. syringae. QS in $P$. syringae is directly related to levels of ferric iron and about $9 \%$ of bacteria on leaves produced iron sequestering compounds that inhibited QS and increased lesions size and numbers when co-inoculated with $P$. syringae. Invasion of leaves by $P$. syringae and disease incidence is suppressed by topical applications of iron and stimulated by tannins that bind ferric ions. Thus considerable cross-talk appears to occur between $P$. syringae and other residents on leaves which may alter the likelihood of disease from an existing $P$. syringae population. Pathogen confusion by bacteria that alter signal perception by plant pathogens and modulating iron availability on plants may be important new strategies of disease control.

\section{DSF signalling and biofilm formation in Xanthomonas campestris}

J. Max Dow (1), M. R. Marano (2), A. A. Vojnov (3)

(1) University College Cork, Ireland; (2) University of Rosario, Argentina; (3) Fundacion Pablo Cassara, Buenos Aires, Argentina

Phytopathology 99:S154

Xanthomonas campestris pathovar campestris (Xcc) is the causal agent of black rot of crucifers. The ability of Xcc to incite disease depends on cell-cell signaling involving the diffusible factor DSF. The synthesis of DSF depends upon RpfF and perception and signal transduction involves the RpfC/RpfG two-component system. Mutations in $r p f C$ lead to DSF over-production. In certain liquid media, $r p f F, r p f G$ and $r p f C$ mutants grow as large multicellular aggregates rather than the dispersed planktonic form of the wild type. Addition of DSF causes dispersal of aggregates formed by $r p f F$ strains but not $r p f G$ or $r p f C$ strains. Strains carrying additional mutations in $g u m B$, which is required for biosynthesis of xanthan, are unable to form aggregates indicating that this polysaccharide is a component of the bacterial matrix. In minimal medium without shaking a different picture emerges. Wildtype Xcc forms microcolonies that develop into a structured biofilm, whereas $r p f F$ and $r p f C$ mutants form only unstructured arrangements of bacteria. A gumB mutant is unable to develop the typical wildtype biofilm. Mixed cultures of gumB and $r p f F$ mutants form a typical biofilm; in contrast, the $r p f C$ mutant prevents the formation of the structured biofilm by the wildtype. These findings suggest that DSF signaling is finely balanced during biofilm formation. 


\section{Schroth Faces of the Future Symposium in Bacteriology}

\section{Erwinia amylovora IQ and gene regulatory network (GRN)}

Y. Zhao

Department of Crop Sciences, University of Illinois at Urbana-Champaign, Urbana, IL

Phytopathology 99:S155

Microbes are in constant contact with their environment, and the ability of a bacterium to monitor the ever-changing environmental conditions is a prerequisite for its survival. Two-component signal transduction systems (TCSTs) are the most elaborate sensory systems in bacteria to monitor dramatic fluctuations in their environment and to elicit adaptive responses through changes in gene expression. It has been proposed that TCSTs can be used to measure the ability of an organism to adapt to diverse conditions as the bacterial intelligence quotient (IQ). Recent advances in genome sequencing have provided a unique platform to identify and decode bacterial IQs. In this study, we used a systems approach to identify and characterize TCSTs in Erwinia amylovora, a serious pathogen of apples and pears. Bacterial genetics, comparative genomics and bioinformatics approaches were employed. Our results revealed that TCSTs in E. amylovora play major roles in virulence and in regulating critical virulence gene expression, suggesting the presence of regulatory networks governing expression of major virulence genes; and multiple TCSTs may form complex, highly connected circuits and signaling networks in this important pathogen. Deciphering gene regulatory networks using functional genomics such as microarray and computational models will be our next goal. Here, I will highlight our findings including discovery of new global regulators and our future directions of this project.

\section{Xylella fastidiosa transmission by vectors - from molecules to models} R. P. P. Almeida

Department of Environmental Science, Policy and Management, University of California, Berkeley, CA

Phytopathology 99:S155

Xylella fastidiosa is a xylem-limited vector-borne bacterium that causes disease in several crops of economic importance, including grape, almond, citrus and coffee. As with other vector-borne plant pathogens, developing practices that may reduce the impact of $X$. fastidiosa diseases requires interdisciplinary approaches, ranging from molecular- to field-based studies, integrating pathogen, vector, host plants and the environment. We will argue that research approaches used decades ago are still valuable methodological tools and can be used to address new questions. Likewise, technological advances permit us to revisit and challenge paradigms, and explore novel research venues. Using $X$. fastidiosa transmission as a model system, we will discuss recent research from the molecular characterization of pathogenvector interactions to the role of host plant, pathogen strain and vector species in determining transmission rates, and how these factors may affect disease epidemiology. We hope to provide evidence that interdisciplinary research is more than the sum of its parts, and that the future of bacteriology and development of disease management practices lies in the integration of classic and novel, molecular and ecological approaches.

\section{Individual-based ecology of plant-associated bacteria}

J. H. J. Leveau

Department of Plant Pathology, University of California, Davis, CA

Phytopathology 99:S155

Ecology is the study of an organism's interactivities with its biotic and abiotic environment. Little is known about how individual bacteria perceive and respond to their local surroundings, or how far their sphere of perception and influence reaches beyond their own micrometer dimensions. To address this question and determine to what degree individual variation in perception contributes to the structure and activity of bacterial communities, our lab employs bioreporters for high-resolution habitat characterization. We focus on the phyllosphere, or leaf surface, as a model microbial habitat, and are using novel GFP-based bioreporter strains to quantify the experience, behavior and reproductive success of individual bacteria in relation to their whereabouts on the leaf surface. The overall objective of this work is to come to a better appreciation of the world from a bacterial perspective, using an individualbased, experimental ecology approach. More specifically, we aim for an enhanced understanding of the establishment, (inter)activities, and fate of plant-associated pathogens and nonpathogens at the microscale, so as to improve our ability at the macroscale to predict and manage plant disease and health in natural and/or agricultural systems.

\section{Biology of Enterobacter cloacae and its association with onions}

B. K. Schroeder

Department of Plant Pathology, Washington State University, Pullman Phytopathology 99:S155

The bacterium, Enterobacter cloacae, is the causal agent of Enterobacter rot of onion bulbs in storage. Evaluation of naturally infected bulbs from onion fields and storages in the Pacific Northwest identified that the incidence of $E$. cloacae was greater than previously thought. E. cloacae was found to be present in $\sim 50 \%$ of the infected onion bulbs assayed and coinfecting onion bulbs with another bacterial plant pathogen such as Burkholderia cepacia, Burkholderia gladioli, Pantoea ananatis or Pectobacterium spp. $\sim 25 \%$ of the time. This indicates that E. cloacae could be causing more onion bulb rot than previously thought. Evaluation of curing temperature and duration determined that E. cloacae is favored by higher temperatures $\left(>35^{\circ} \mathrm{C}\right)$ and a longer exposure time at the higher temperatures significantly impacts disease progression of E. cloacae in onion bulbs. Artificial inoculation of onion plants with E. cloacae does not result in a phenotypic response. This supports the hypothesis that the pathogen is present as a latent infection when onion bulbs are placed in storage. Investigations into movement of E. cloacae in onion leaves demonstrate that the pathogen can move as quickly as $1 \mathrm{~cm}$ or more per week through the phloem and xylem. This indicates that the timing of the infection of the plant and the pathogen entering the bulbs as a latent infection could be quite small. Finally, the roll of exopolysaccharide in the biology of E. cloacae will be discussed.

\section{Disease of Plants}

\section{APS - ISF Collaboration to Implement a System to Standardize Naming of Plant Pathogen Races and Strains}

\section{Overview of proposed system P. Himmel \\ Seminis Vegetable Seeds, a division of Monsanto Phytopathology 99:S155}

Inconsistency in protocols used to name plant pathogen races and strains can undermine the value of disease resistance claims made for specific cultivars, particularly in specialty crops such as vegetables. A broader understanding of the impact of naming pathogen races and strains on the vegetable industry is needed. For example, inconsistencies in naming of races, pathotypes and or strains of the downy mildew pathogens of spinach and lettuce, as well as the Fusarium wilt pathogens of tomato, melon and watermelon, cause continuing confusion for growers, the vegetable seed industry and academia. There is no internationally recognized authority on nomenclature for new races and strains. Readily available sets of differential host cultivars and reference cultures of pathogen races and strains are needed to help standardize the nomenclatural system and provide clarity for claims of disease resistance. Members of APS, the American Seed Trade Association and the International Seed Federation are collaborating to implement a network of private and public research laboratories and seed companies in the U.S. for the mainten- ance, storage, multiplication and distribution of reference pathogen cultures and seed of differential host cultivars, to facilitate standardizing the naming of plant pathogen races and strains. The proposed system should complement existing systems in Europe (i.e., Naktuinbouw in the Netherlands and GEVES in France) and comply with U.S. regulatory requirements. The complexity and challenges of implementing this system, demand for such a system, and proposed protocols will be discussed in the symposium. Feedback from the APS community is critical to development of a system of reference pathogen cultures and differential host sets for naming of pathogen races and strains with guidelines that are accepted globally by the scientific community.

\section{Current European systems}

C. van Ettekoven

Naktuinbouw, Roelofarendsveen, The Netherlands

Phytopathology 99:S155

Disease resistance is a primary goal in vegetable breeding. In Europe, governmental scientific institutes traditionally have been responsible for the maintenance, nomenclature and distribution of pathogen reference cultures. Due to changing priorities in financing these institutes, the pathogen collections became lower priority, resulting in poorer quality control. Affected seed companies in France and the Netherlands joined with Plant Breeders Rights testing authorities at GEVES (Group for Control and Testing of Varieties and Seeds) and Naktuinbouw, respectively. Different strategies were developed. 1) 
In the French system, GEVES, INRA and seed companies created a network, MATREF (Reference Materials) based on the mutualization of differentials, controls and pathogen strains. Seed companies produce seeds of host differential cultivar sets that are stored at GEVES. Seed health tests are performed by seed companies or GEVES-SNES on the regenerated seeds. Pathogen reference cultures are maintained at GEVES and distributed to participants of the MATREF network. A duplication of pathogen strains is ensured by the members of MATREF. The differential seeds and pathogen reference cultures are distributed freely to members of MATREF and sold to non-member participants. 2) In the Netherlands, the focus is on maintenance of pathogen reference cultures. Seed companies maintain pathogen reference cultures that are sent to Naktuinbouw for verification of identity and pathogenicity, and then distributed to seed company member participants or sold to non-member participants. In each of these programs, clear identification and nomenclature of pathogen races/strains is critical. The definition and maintenance of host differential sets is also crucial for accurate pathogen race or strain identification. The International Seed Federation (ISF) Resistance Code Working Group has taken the lead in developing this at a global level. Public scientists, private industry, and regulatory authorities are essential to these programs to ensure quality sources of pathogen reference cultures and host differential sets to improve efficiency and quality control in developing resistant plant cultivars.

Proposed U.S. Permitting Strategy for pathogen race and strain distribution

R. Dunkle

American Seed Trade Association, Alexandria, VA 22314-2875

Phytopathology 99:S156

The USDA Animal and Plant Health Inspection Service (APHIS) regulates plant pathogens and other organisms that are of limited distribution or do not occur in the U.S. For an individual to import and maintain cultures of regulated pathogens, APHIS issues permits with safeguarding requirements based on the potential risk of the organisms in question to agriculture and the environment. For organisms classified as "widely prevalent", APHIS issues permits that have standardized and comparatively minimal permit conditions. At the request of the APS-ISF ad hoc committee on naming plant pathogen races/strains, three sets of pepper differentials with associated reference pathogen races or strains classified as "widely prevalent" were presented to APHIS to begin developing a pilot permitting system. This system will enable identification and/or calibration of pathogen races and strains using reference pathogen cultures and differential host cultivar sets. Under this system, laboratory facilities will be certified by APHIS for maintenance of reference pathogen races or strains, and electronic permits will be issued for distribution of pathogen cultures for resistance testing. Seeds of the host differential sets will be stored, catalogued in the GRIN database, and distributed by the USDA Agricultural Research Service with associated reference cultures of pathogen races or strains. This presentation will provide detailed information on this template permit system and demonstrate how the system will function.

Naming of Spinach downy mildew races, a case study

J. C. Correll (1), S. T. Koike (2), S. Smilde (3)

(1) Department of Plant Pathology, University of Arkansas, Fayetteville 72701; (2) University of California Cooperative Extension, Salinas, CA 93901; (3) Naktuinbouw, Roelofarendsveen, Netherlands

Phytopathology 99:S156

Spinach downy mildew, caused by Peronospora farinosa f. sp. spinaciae, is an economically important disease of spinach worldwide. In recent years, there has been a dramatic expansion in both spinach production and consumption. With this increase in production, there has been an increase in the number and frequency of new races of the spinach downy mildew pathogen. There are now 11 described races of the pathogen, with three races (races 1-3) having been identified between 1824 and 1990 (166 years) and eight races (races 4-11) identified between 1990 and 2008 (18 years). Because of the globalization of spinach production and the need for independent verification of reportedly resistant spinach cultivars, standardized race identification, and clear communication on race development, an international committee known as the International Working Group on Peronospora (IWGP) was organized. The committee, administered by Plantum in Gouda, the Netherlands, is composed of public and private sector spinach research personnel. The committee provides an important and objective balance to the demands of scientific discovery, company proprietary concerns, and industry, breeder, and grower imperatives. The continued effectiveness of the committee will depend on periodic review of the committee objectives, operating procedures, and communication methods with various international stakeholders. Specific examples will be discussed illustrating the practical needs in dealing with the development and nomenclature of new races of the downy mildew pathogen on spinach. The committee continues to evolve, and the benefits to industry and the challenges the committee faces will be discussed.

\section{Current Status of Citrus Huanglongbing Research and Control}

\section{Citrus HLB, its pathogens and vectors \\ R. Lee \\ USDA-ARS, Riverside, CA \\ Phytopathology 99:S156}

Huanglongbing (HLB) has been known for over 100 years, probably originating in Asia. The disease was named after the symptoms associated with the declining trees; in China it was commonly called yellow shoot disease, likubin decline in Taiwan, citrus dieback in India, citrus leaf mottle yellows in the Philippines, citrus vein-phloem degeneration in Indonesia, and blotch mottle or greening in South Africa. Even to the present, Koch's postulates have not been fulfilled for HLB. Based on diagnosis of conserved regions of prokaryotic DNA, usually the 16S rRNA gene, three species of Candidatus Liberibacter have been associated with HLB: asiaticus, africanus, and americanus. In Brazil and China, Phytoplasmas have been associated with HLB symptoms in trees where $\mathrm{Ca}$. Liberibacter sp. tested negative. In African, HLB is vectored by Trioza erytreae, African citrus psyllid, while in Asia and the Americas, the Asian citrus psyllid, Diaphorina citri, is the vector. Control of HLB currently depends on psyllid control, planting healthy plants in block plantings, and timely removal of symptomatic trees. Growers having to adapt to these practices to stay in production complain about the high costs. Generally, the economic benefits of programs which result in avoiding large economic losses are hard to document. Available literature will be reviewed which document the economics of living with HLB.

\section{Historical and current status of HLB in China}

X. Deng, P. Zhang, R. Liu

South China Agricultural University, Guangzhou, Guangdong, China

Phytopathology 99:S156

Citrus Huanglongbing (HLB, yellow shoot disease) was first observed in Chaoshan area of Guangdong Province, China over 100 years ago. As inferred by the name, typical symptoms of HLB are leaf/shoot chlorosis. HLB was first systematically studied in Chaoshan during the 1930-40's, when HLB was epidemic there. The disease was found to be spread probably by unknown biological vector(s). The infectious nature of HLB was further demonstrated and confirmed in the 1950's. Since then, HLB management has focused on pathogen elimination and vector control. Efforts to identify HLB pathogen(s) has, however, met with great challenges. Suspected causal agents include Fusarium, water damage, nutrient deficiency, nematode, virus, mycoplasmalike organism, Rickettsia-like organism and bacteria-like organisms. Currently, "Candidatus Liberibacter asiaticus" is confirmed to be associated with HLB. A strain of " $\mathrm{Ca}$. phytoplasma asteri" has recently been identified. However, Koch's postulates have not been fulfilled. Citrus psyllid (Diaphorina citri) was proved to transmit HLB. No HLB-resistant citrus cultivar has so far been identified. Presently, HLB remains as a critical threat to the booming citrus industry in China. HLB control includes: 1) Strict implementation of quarantine procedures; 2) Production and utilization of disease-free seedlings; 3) Control of insect vector(s); 4) Prompt elimination of affected trees; and 5) Optimization of orchard management.

\section{Current HLB research in Brazil}

S. Lopes

Fundecitrus, Araraquara, Sao Paulo, Brazil

Phytopathology 99:S156

Huanglongbing (HLB) is a destructive and fast spreading citrus disease associated with Candidatus Liberibacter americanus (Lam) and $\mathrm{Ca}$. L. asiaticus (Las), both transmitted by Diaphorina citri. Lam and Las also infect orange jasmine trees. A phytoplasma of group 16SrIX has also been detected in citrus trees showing typical HLB symptoms, but free of Liberibacter. HLB was first found in 2 locations in São Paulo State in March 2004, and has been reported in 241 municipalities in São Paulo, Paraná and Minas Gerais States as of March, 2009. Lam and Las differ in ability to grow in planta and in sensitivity to high temperature, which helps to explain their uneven spatial and temporal progress. Since pruning is not effective in removing all infected tissues, disease management relies on symptomatic tree elimination and 
repeated insecticide applications. Success has been dependent on the intensity of inoculum pressure in adjacent areas. To improve HLB management, current research focuses on determining: (i) the role of asymptomatic citrus and orange jasmine as sources of inoculum, (ii) feeding and dispersion patterns of D. citri, (iii) the efficacy of systemic insecticides in preventing Liberibacter transmission, (iv) the best frequency and timing of orchard inspection and insecticide application, (v) the relative importance of these practices in HLB management, and (vi) the temperature limits for Lam and Las multiplication in citrus and in the insect vector.

\section{Research on HLB in South Africa}

J. da Graca (1), G. Pietersen (2), S. P. van Vuuren (3)

(1) Texas A\&M University-Kingsville, Citrus Center, Weslaco, TX; (2) University of Pretoria, Pretoria; (3) Citrus Research International, Nelspruit, S. Africa

Phytopathology 99:S157

Citrus Huanglongbing (HLB = citrus greening) was first observed on citrus in South Africa during the 1920s. It was shown later to be transmitted by the psyllid, Trioza erytreae, and to be caused by the phloem-limited bacterium Candidatus Liberibacter africanus. The disease is currently managed by a certified disease-free budwood program, nursery location, total psyllid control in nurseries and timed control in orchards, and infected tree removal. Current research is directed towards host range studies of indigenous and wild rutaceae, surveys for variants of $\mathrm{Ca}$. L. africanus and the presence of other species, and resistance to HLB through embryo recovery from chimeric mutants. Vepris lanceolata and Clausena anisata have been identified as indigenous hosts of the bacterium, while Calodendrum capense has been shown to be widely infected by a sub-species, $C a$. L. africanus ssp. capensis. No other species have been detected thus far in any plants. Two clones of Valencia orange seedlings derived from asymptomatic fruit chimeras are undergoing field testing for resistance/tolerance.

\section{Huanglongbing in India}

K. L. Manjunath

USDA-ARS, Riverside, CA

Phytopathology 99:S157

The earliest evidence of the presence of huanglongbing (also known as citrus greening) in India probably comes from the detailed descriptions of symptoms associated with Asian citrus psyllids (ACP, Diaphorina citri) in Punjab state (Husain and Nath, 1927). The symptoms were suspected to be caused by a toxin secreted by the psyllid at that time. In India, the symptoms associated with ACP were known as "Indian citrus dieback". Fraser (1966) associated the dieback symptoms with the South African citrus greening. She found widespread incidence of this disease throughout India. At the same time, Capoor's laboratory in Poona established, for the first time, that D. citri is the vector of the disease. In the 1970s, a phytoplasma was reported to be associated with citrus greening, but was soon thought to be an error because of later research on association of a bacterium with the disease. In India, the disease appeared to have spread slowly because of several cultural and environmental factors. The effect of disease on the industry in several citrus growing regions is discussed.

\section{HLB diagnosis \\ J. Hartung \\ USDA-ARS, Beltsville, MD \\ Phytopathology 99:S157}

Initial diagnosis of huanglongbing is based on symptoms of phloem dysfunction, which can be caused by diseases and disorders other than huanglongbing. Diagnosis of huanglongbing must be confirmed by PCR testing. Both standard format and real-time PCR tests are available, most based on the 16S RNA gene or the rRNA operon. PCR products are sequenced for final diagnostic confirmation. Several species of $\mathrm{Ca}$. Liberibacter have been identified from citrus, and these can be differentiated on the basis of these tests. A difficult challenge in PCR-based diagnosis is the collection of the samples from the tree. Symptomatic mature leaves are preferred, although even in trees with established infections, the distribution and titer of the pathogen can be erratic. For this reason multiple leaf samples should be collected, and if huanglongbing is suspected, negative tests should be repeated. Although hundreds of real-time PCR tests can be completed in a day, extraction of DNA in quantity and quality from midribs or petioles for PCR testing is very laborious and determines the rate at which samples can be tested. Judgment is required in the review of PCR test data. A 'positive' result with a high $\mathrm{Ct}$ value may be valid or may result from laboratory contamination. Negative controls and internal controls for DNA quality are both essential. As with any test, lab-to-lab variation exists. Ultimately the results must be interpreted with the sample source and test purpose in mind.

\section{Epidemiology of HLB in U.S.}

\section{T. Gottwald}

USDA-ARS, Fort Pierce, FL

Phytopathology 99:S157

Results from studies on the increase in HLB incidence and spread in China and Reunion Island indicate a rate of disease increase leading to a multi-year epidemic requiring 7 to 10 years for infection to approach an asymptote of $100 \%$. In contrast, more recent studies in Brazil, Vietnam, and Florida suggest a much more rapid rate of disease increase and spread. An HLB epidemic was examined in a plantation of over 4,800 ha in South Florida where no new citrus had been introduced for $10 \mathrm{y}$ and thus spread was entirely dependent on psyllid transmission. The level of psyllid infestation was unprecedented compared to previously recorded psyllid infestations. The psyllid vector was relatively newly introduced to Florida and thus lacks the biological and environmental constraints found in its native range. Consequently the HLB epidemic in Florida is undoubtedly one of the worst on record. Stochastic Markov-Chain Monte Carlo models indicated a prevalence of secondary spread with occasional primary spread from outside the plots. Interpretations of the stochastic models combined with survival analyses show spread over multiple scales from local to regional are occuring simultaneously and continually in Florida. Edge effects analyses indicate a prevalence of infections that accumulate at the transition of plantings and areas devoid of citrus such as the plantation perimeter, internal roads, canals, ponds, etc. This edge effect diminishes rapidly toward the interior of the planting and is generally well described by an inverse power function.

\section{Isolation, cultivation, and Koch's postulates of the HLB bacterium}

N. Schaad, A. Sechler, E. Schuenzel

USDA-ARS, Ft. Detrick, MD

Phytopathology 99:S157

Huanglongbing (HLB) is a serious bacterial disease of citrus, world-wide. One of the three suspected pathogens of HLB, Candidatus Liberibacter asiaticus, emerged in 2005 in Florida. Recent findings of the psyllid (Diaphorina citri) vector of HLB in Southern California pose a potential threat of introducing the pathogen into California. The suspected causal agents $\mathrm{Ca}$. L. asiaticus, $\mathrm{Ca}$. L. americanus, and $\mathrm{Ca}$. L. africanus are phloem-limited bacteria and have been only recently grown in pure culture (Sechler et al., 2009, Phytopathology, In Press). Isolations from infected tissue were made by streaking extracts of sterilized leaf petioles onto Liber A agar. Plates were sealed and incubated for $3-4 \mathrm{~d}$ at $28^{\circ} \mathrm{C}$, until colonies were visible with a binocular microscope. The colonies were $0.1 \mathrm{~mm}$ or less in diameter and irregular shaped after $7 \mathrm{~d}$. Cells were 0.3 to $0.4 \times 0.5$ to $0.8 \mu \mathrm{m}$ with numerous fimbriae. Inoculation of citrus seedlings and trees with cultured bacteria resulted in typical symptoms of HLB. The symptomatic tissue and typical isolated bacteria were positive by a $C a$. L. asiaticus-specific real-time PCR assay.

\section{Genome sequencing of " $\mathrm{Ca}$. Liberibacter asiaticus"}

Y. Duan, L. Zhou, T. Gottwald

USDA-ARS, Fort Pierce, FL

Phytopathology 99:S157

Citrus huanglongbing is the most destructive disease of citrus worldwide. It is spread by citrus psyllids (Diaphorina citri and Trioza erytreae) and is associated with a low-titer, phloem-limited infection by any of three uncultured species of alpha-Proteobacteria: 'Candidatus Liberibacter asiaticus'; (Las), ' $\mathrm{Ca}$. L. americanus'; and 'Ca. L. africanus'. A complete circular Las genome has been obtained by metagenomics using the DNA extracted from a single Las-infected psyllid. The genome of 1,227,204 bps has an average $36.5 \% \mathrm{GC}$ content. Annotation revealed a high number of genes involved in both cell motility (4.5\%) and active transport in general (92 genes), which may contribute to its virulence. Las appears to have a limited ability for aerobic respiration and is likely auxotrophic for at least 5 amino acids, all of which contribute to its fastidious nature. Consistent with its intracellular nature, Las lacks Type III and Type IV secretion systems as well as typical free living or plant-colonizing extracellular degradative enzymes. Las appears to have all Type I secretion system genes needed for both multidrug efflux and repeats in toxin effector secretion. Multiprotein phylogenetic analysis confirmed $\mathrm{Ca}$. L. asiaticus as an early-branching and highly-divergent member of Rhizobiaceae. This is the first genome sequence of an uncultured alpha-Proteobacteria that is both an intracellular plant pathogen and insect symbiont/parasite. 


\section{Perplexing Potato Problems}

\section{Potato early dying}

A. MacGuidwin

University of Wisconsin-Madison, Madison, WI

Phytopathology 99:S158

Potato early dying (PED) is a chronic disease endemic to many potato production regions. Chlorosis and premature senesce of foliage with reduced tuber yield characterize PED. The primary pathogen of PED and Verticillium wilt is the soilborne fungus Verticillium dahliae. The PED disease is distinguished from Verticillium wilt by a more rapid and extensive progression of symptoms in the field, and the coinfection of plants by Pratylenchus penetrans or various fungi. It is generally agreed that detection of $V$. dahliae is diagnostic for PED, but criteria for soil inoculum thresholds, symptoms, or epidemiology vary as do conclusions about the significance and role of other pathogens in PED. Controlled inoculations of $V$. dahliae and $P$. penetrans cause PED, but potato fields are typically infested with other nematode species and soil fungi such as Colletotrichum coccodes. A perplexing problem for scientists and producers is to construct models that reflect combinatoric interactions manifested as PED in potato fields. Root infection by fungi and nematodes is a continuous process with physiological impacts on the crop that may take weeks to manifest. No single sampling scheme or assay is adequate to represent fungal and nematode population biology. The complexity of PED and the push towards control measures more specific than soil fumigation justify a multidisciplinary approach towards this most perplexing potato disease.

\section{Impact of nematodes on potato quality}

R. E. Ingham (1), N. L. David (2), B. A. Charlton (3), P. B. Hamm (4)

(1) Oregon State University, Corvallis, OR; (2) North Dakota State University, Fargo, ND; (3) Oregon State University, Klamath Falls, OR; (4) Oregon State University, Hermiston, OR

\section{Phytopathology 99:S158}

While nematodes that reduce plant growth can cause significant yield reduction, nematodes that impact crop quality can result in complete loss of crop value. Root-knot nematodes infect tubers and develop to adult females. These infection sites produce brown spots that are considered a quality defect. Only a few spots can degrade a tuber to a cull and if a field contains 5-15\% culls the crop may be devalued or rejected. Some species produce galls on the tuber surface which can also cause tubers to be graded as culls. The most damaging species is Meloidogyne chitwoodi (Columbia root-knot nematode) which can cause crop rejection at densities of $1 / 250 \mathrm{~g}$ soil or less. Tobacco rattle virus (TRV) is vectored to potato by stubby-root nematodes, SRN (Paratrichodorus spp. and Trichodorus spp.). TRV causes corky ring spot disease (CRS) which produces necrotic arcs, rings and/or diffuse spots in tubers. If more than $5 \%$ of the tubers in a field have excessive CRS, that crop may be rejected. SRN as low as $3 / 250 \mathrm{~g}$ soil have resulted in rejected crops. Fumigation with 1,3-dicloropropene (1,3-D) is generally effective for both nematodes. Metam sodium (MS) applied through irrigation (chemigation) is not effective but shanked-in MS may be adequate in fields with low disease pressure. Best control is with 1,3-D followed by MS. Oxamyl can be effective but timing of applications is critical. Crop rotation and green manure crops can suppress root-knot nematode but are less effective for SRN.
Important soilborne fungal diseases of potato

P. B. Hamm

Hermiston Agricultural Research \& Extension Center, Hermiston, OR Phytopathology 99:S158

Soilborne fungi caused a number of important disease problems in potatoes. Three that are arguably the most important in North America are: Pythium ultimum (leak), Rhizoctonia solani (Rhizoctonia canker and black scurf) and Helminthosporium solani (silver scurf). The former disease causes a tuber rot in the field that can further develop in storage. Losses in the field are usually minor but losses due to secondary problems in storage can be severe. This disease is controlled by a combination of cultural (i.e. watering, harvest conditions, and/or storage temperatures) and chemical (Mefenoxam) methods. Recent reports of resistance to Mefenoxam may result in reduced control. Rhizoctonia solani inoculum can originate in the soil or be seedborne, and infect stems, roots and stolons (canker diseases) or infect the surface of tubers (black scurf). Yield loss can result or in the case of black scurf, the formation of sclerotia on tubers may prevent fresh marketing. Infection is controlled by cultural (crop rotation, planting conditions, soil moisture) and chemical (seed and in-furrow treatments) methods. Silver scurf infects tubers in the field and causes a surface discoloration but no rot. However field and secondary infection in storage can result in total crop losses. Control of silver scurf requires the use of both cultural (seed selection, quick harvest) and chemical (seed and pre and post storage treatment) methods and even then adequate control may not be achieved.

Detection and control of infestation foci of potato cyst nematodes (Globodera rostochiensis and G. pallida)

C. Schomaker, T. H. Been

Plant Research International, Wageningen, The Netherlands

Phytopathology 99:S158

A computer software program 'SAMPLE' was developed to evaluate sampling methods for the detection of infestation foci of potato cyst nematodes (Globodera rostochiensis and G. pallida). In "SAMPLE" the distribution patterns of potato cyst nematodes at different scales are integrated: - The models describing the expected medium scale infestation foci; - Bivariate models for the variation of the parameters of the focus; $\bullet$ The Negative Binomial Distribution giving the probability of finding a certain number of cysts in a core, given the core size; $\bullet$ The growth of the infestation foci as a function of time. The methods to be evaluated are a.o.: the new EU method and some deviations, the Dutch AMI-50 and AMI-100 method, some Australian and New Zealand sampling methods. In the software package "NemaDecide", the detection algorithms of SAMPLE are included, providing the possibility to evaluate the effect of control measures on the detection of a focus, for instance: (partial) resistant cultivars, soil fumigation, crop rotation, non fumigants, trap crops and 30 years growth of non-hosts. NemaDecide contains models and parameters of: $\bullet$ Population dynamics of the nematodes under host and non-host crops; - Plant growth and yield as a function of nematode density; • Dose/effect of control measures on the model parameters. Further NemaDecide has a cultivars list with all relevant quantitative information and is connected with financial data and sampling data. SAMPLE and NemaDecide are used for governments to develop detection methods for legislation, quarantine and export protection, for farmers and agro business to give recommendations for optimum control measures leading to maximum returns and for bio-tech companies to evaluate resistant crops.

\section{Epidemiology/Ecology/Environmental Biology}

\section{9th I. E. Melhus Graduate Student Symposium: Integrating Pre- and Post-Harvest Views of Yield and Quality Loss}

Aflatoxins in Kenyan maize: Etiology holds clues to recurrent human aflatoxin poisonings

C. Probst (1), P. J. Cotty $(1,2)$

(1) Department of Plant Sciences, The University of Arizona, Tucson, AZ; (2) USDA-ARS

Phytopathology 99:S158

Aflatoxins are secondary metabolites produced by members of the fungal genus Aspergillus. Immunosuppressive and carcinogenic activities of these toxins negatively impact human health especially in emerging and developing countries. Severity of contamination is influenced by both fungal community structure and the environment to which the crop is exposed both prior to and after harvest. Consumption of maize contaminated with lethal levels of aflatoxins has resulted in repeated epidemics of human death in the Eastern Province of Kenya. Analysis of fungal community structures revealed that the $\mathrm{S}$ strain morphotype of Aspergillus flavus, previously unknown in Africa, was the causal agent of aflatoxin contamination events associated with lethal aflatoxicosis from 2004 through 2006. The S strain dominated fungal communities in contaminated maize and occurred at lower frequencies or not at all in adjacent provinces. Reduced intraspecific competition resulting from the unusual fungal community structure may have contributed to the extreme aflatoxin. Selectively increasing native atoxigenic fungal competitors could break the dominance of the S strain in Kenya and result in reduced aflatoxin levels in maize. Identification of specific causal agent(s), a traditional early step in development of plant disease management, has been underemphasized for aflatoxin contamination events. Improved etiologic knowledge may result in new opportunities to limit aflatoxin contamination. 
Distinct roles of VeA and LaeA in Aspergillus flavus

S. Amaike (1), N. P. Keller (1,2,3)

(1) Department of Plant Pathology; (2) Department of Medical Microbiology and Immunology; (3) Department of Bacteriology, University of WisconsinMadison, Madison, WI 53706

Phytopathology 99:S159

Aspergillus flavus, a mycotoxigenic filamentous fungus, colonizes several important agricultural crops, such as maize and peanuts. Two proteins, VeA and LaeA known to form a nuclear complex in A. nidulans, have been found to positively regulate developmental processes in several Aspergillus species. In A. flavus both proteins are required for aflatoxin and sclerotial formation. Here an examination of near-isogenic A. flavus mutants differing in copy number of $v e A$ and $l a e A$ alleles $(0,1$ or $2+$ each) revealed critical roles for $\mathrm{VeA}$ and LaeA in A. flavus development and seed colonization. Both null mutants were unable to metabolize host cell lipid reserves and were inhibited in growth by oleic acid, a primary component of peanut seed. Copy number of LaeA but not VeA appeared critical for a density dependent sclerotial-toconidial shift as the MClaeA strain produced relatively constant sclerotial numbers with increasing population size rather than the decrease in sclerotia seen in both wildtype and MCveA strains. The MCveA/laeA strain yielded an intermediate phenotype. This study revealed unique roles of VeA and LaeA in seed pathogenesis and fungal biology, distinct from their cooperative regulatory functions in aflatoxin and sclerotial development.

Development of biological control strategies for management of pre- and postharvest diseases of apple in Pennsylvania

A. M. Poleatewich (1), P. A. Backman (1), J. W. Travis (2)

(1) Dept. Plant Pathology, Penn State University, University Park, PA 16802;

(2) Penn State Fruit Res. \& Ext. Center, Biglerville, PA 17307-0330

Phytopathology 99:S159

Disease prevention is an essential for producing quality fruit. Fungicides are widely used for controlling pre- and postharvest diseases of apples and development of pathogen resistance has resulted in fewer fungicides available for disease control. The objective of this research is the development of biological control agents for foliar and fruit diseases that can be implemented into existing conventional, reduced risk and potentially organic apple production systems to reduce the use of fungicides. Bacteria were collected from abandoned, low input, organic and conventionally managed orchards in PA and screened for the ability to produce chitinase enzymes, endospores and endophytically colonize apple leaves and fruit. Following preliminary screening, field experiments were conducted to determine the effectiveness of selected bacterial isolates to suppress preharvest and postharvest diseases on apple. Isolates applied at full bloom along with successive later season sprays reduced apple scab (Venturia inaequalis) severity on 'Rome Beauty' and 'Golden Delicious' leaves. Several isolates also reduced severity of scab on 'Rome Beauty' fruit up to $40 \%$ compared to untreated controls. Evaluation of application timing indicated a synergistic effect of combining pre-harvest and postharvest applications on the reduction of bitter rot (Colletotrichum acutatum) disease severity. Successful results will improve the use of biocontrol for management of apple diseases.

Trichothecene dynamics and Fusarium graminearum infection patterns in wheat heads

K. T. Willyerd, G. A. Kuldau

Department of Plant Pathology, The Pennsylvania State University, University Park, PA

Phytopathology 99:S159

The primary causal agent of Fusarium Head Blight of wheat in North America is Fusarium graminearum. Shortly after infection, the fungus produces trichothecene mycotoxins, including deoxynivalenol (DON), which contaminate floral tissue and grain. However, the relationship between toxin production and fungal growth is not fully understood. The objective of this research was to study the effects of temperature on fungal biomass, estimated by ergosterol, and DON accumulation in wheat heads. Two spring wheat cultivars were used in this study: Alsen (moderately resistant) and Wheaton (susceptible). A central spikelet was inoculated during mid-anthesis. Plants were incubated at 15 or $22^{\circ} \mathrm{C}$. Spikelets, each containing two florets, were harvested daily until 12 days post-inoculation. One floret was placed on Nash agar to determine $F$. graminearum incidence. DON and ergosterol were extracted from the remaining floret and analyzed simultaneously by gas chromatography. This method was also designed to detect deoxynivalenol-3glucoside, a conjugated mycotoxin. Fungal colonization of spikelets beyond the inoculated point and DON translocation to spikelets not colonized by the pathogen were both observed by three days post-inoculation. During early stages of infection, DON production appeared to be stimulated by $15^{\circ} \mathrm{C}$, whereas fungal growth was slightly inhibited by the cooler temperature. Toxin accumulation was observed more frequently in Wheaton florets, but Alsen florets contained higher DON concentrations. This suggests that DON production is a cultivar specific response. Results indicate DON production is a mechanism the fungus uses to adapt to stressful environmental conditions, such as temperature and resistant host.

Pre-harvest moisture impacts wheat quality through Fusarium head blight (FHB) development and deoxynivalenol (DON) accumulation P. Gautam, R. Dill-Macky

Department of Plant Pathology, University of Minnesota, St. Paul, MN Phytopathology 99:S159

Field experiments (split-split-plot) were conducted to examine the effect of moisture on the production and accumulation of deoxynivalenol (DON) in Fusarium-infected wheat. Main plot treatments were length of mist-irrigation after inoculation $(14,21,28$ and 35 days after inoculation [DAI]); sub-plot were wheat cultivars: Alsen (moderately resistant), 2375 (moderately susceptible) and Wheaton (susceptible); and sub-sub-plots were Fusarium graminearum isolates (5) differing in aggressiveness and DON production capacity. Plots were inoculated at anthesis with $F$. graminearum $\left(1 \times 10^{5}\right.$ conidia ml-1). Heads were harvested (10/plot) at $0,7,11,14,21,28$ and 41 DAI for DON analysis. Disease severity was assessed at 21 DAI (20 heads/plot) and the percentage of visually scabby kernels (VSK) and DON was determined on samples of grain harvested at maturity. Across all isolates and mist-irrigation treatments, the susceptible cultivar Wheaton had significantly higher FHB severity, VSK and DON. VSK was significantly lower in all treatments receiving the least amount of mist-irrigation (14 DAI). DON was significantly lower in the longest mist-irrigation treatment (35 DAI) compared to all other treatments. The reduction of DON observed with increased moisture duration was also evident in the sampled heads. The reduction of DON was larger in Wheaton than the other cultivars. This suggests that DON may be reduced by late season moisture, either from mistirrigation or rainfall, despite increased damage to grain. Leaching of DON from plant tissues may explain the observed reductions in DON.

\section{Resistance in winter wheat to Fusarium head blight}

P. Horevaj, E. A. Milus

Department of Plant Pathology, University of Arkansas

Phytopathology 99:S159

Fusarium head blight (FHB), caused by Fusarium graminearum, is an important disease of wheat because of mycotoxins in grain. Developing cultivars with adequate resistance has been difficult because resistance is controlled by several genes with small effects on five components of resistance that are difficult to quantify. The objective of this research was to improve methods for quantifying the five components and to fully characterize the resistance in 15 diverse lines. Quantifying resistance to initial infection was improved by standardizing inoculum and environmental conditions, and a new method was developed for quantifying resistance to spread within a spike in the same experiment. Injecting florets with deoxynivalenol (DON), the principal mycotoxin, demonstrated that $F H B 1$, the most-studied resistance gene, has a unique mode of action and that measuring relative yield loss after DON injection may be useful for identifying lines with tolerance to FHB in the field. Late-season epidemics are being investigated as a means of separating resistances to kernel infection and DON accumulation from interactions with other components, and a real-time PCR technique has been developed to quantify kernel colonization. Some of the methods developed in this research are already being used to evaluate breeding lines for resistance. Results of this research should be useful for phenotyping lines in mapping studies to identify markers for genes controlling resistance components.

\section{Forensic Plant Pathology: Science in the Courtroom}

Critical issues in determining if disease outbreaks were deliberate attacks on U.S. agriculture

J. Fletcher

Oklahoma State University

Phytopathology 99:S159
Most plant diseases are naturally occurring, and producers, Extension agents, crop consultants and plant disease diagnosticians are appropriately focused on identifying a pathogen to the extent necessary to effectively manage the disease, and then moving quickly to limit the damage. New concerns about the possibility of a rare intentional plant pathogen introduction, however, have resulted in a need to discriminate between natural and human-assisted plant diseases. Because law enforcement personnel would become involved only in 
cases involving criminal activity, guidelines are needed for rapid assessment of the likelihood that illegal activity has occurred. Features of a disease event that could arouse concern about the nature of its introduction include current and recent weather, pathogen identity and geographical range, crop species and cropping history, soil conditions, disease pattern, presence or absence of vector insects (if involved), physical evidence, and other factors. We have created a decision tool consisting of a series of key questions and/or assessments, each of which is assigned a numerical point value that is weighted to reflect its significance. The tool helps non-plant pathologists to focus on the most relevant criteria, and the final point values add a quantitative aspect that can be used to rank the probability of intent or to compare two disease events.

\section{Engaging plant pathologists to meet law enforcement needs B. Budowle \\ FBI, DOJ \\ Phytopathology 99:S160}

Because of the availability of pathogenic microorganisms and the relatively low cost of preparing and disseminating bioweapons, there is a continuing threat of biocrime and bioterrorism. Thus, enhanced capabilities are needed that enable the full and robust forensic exploitation and interpretation of microbial evidence from acts of bioterrorism or biocrimes. To respond to the need, greater resources and efforts are being applied to the burgeoning field of microbial forensics. Microbial forensics is a discipline dedicated to the characterization, analysis and interpretation of evidence for attributional purposes from a bioterrorism act, biocrime, hoax or inadvertent agent release. The goal of attribution is the identification of those involved in the perpetration of the event, which is necessary for criminal prosecution, or for actions that may be taken as a result of national policy decisions. The forensic information sought in bioterrorism and biocrime cases evolves over the course of the investigation, but begins as soon as an attack or potential attack is realized. Farmers and agricultural health officials will likely be the first ones involved with initial analyses using traditional diagnostic approaches. First responder data are invaluable and will be used in a microbial forensic investigation. A major component of a microbial forensic case is trace-back to a cause and source. In this sense, a search for commonalities and clustering of the primary sources of infection to be employed in microbial forensics is no different from that of the standard epidemiologic methods. A microbial forensic investigation encompasses many aspects that are beyond those pertaining to health management. Detailed characterization assays are required for clues regarding the origin of a pathogen or vector. All pertinent evidence can be exploited, i.e., materials directly and indirectly associated with the biological weapon, processes used to prepare and disseminate the weapon, and evidence found at the crime scene. These include both traditional forensic evidence and biological, physical, and chemical characteristics of the microorganism and associated materials related to weapon preparation, purification, stabilization and/or dissemination.

Role of imagery, spatial pattern analyses, and sampling in plant pathogen forensics

F. W. Nutter, Jr.

Iowa State University

Phytopathology 99:S160

One of the most critical decisions needed early-on following the detection of a new, threatening plant pathogen is whether or not to treat the new threat as a biocrime (deliberate, human-assisted introduction) or as a natural or accidental introduction. This decision could be made (in near-real time) if a $10 \times 10 \mathrm{~km}$ high-resolution satellite or aerial image of the affected agricultural area could be obtained and analyzed for the presence of pathogen-specific signatures/patterns. Such imagery could provide forensic data concerning the spatial patterns of a new biothreat within and among agricultural fields. Within-field focal gradients, their spatial patterns, and temporal and spatial expansion rates can provide diagnostic and quantitative forensics data. By determining GPS coordinates of initial disease foci, forensics personnel will know where to search for key forensic evidence to support or refute that the new threat was as a result of a biocrime. Imagery also provides timeinsensitive, quantitative data that can be analyzed and re-analyzed by experts to obtain scientifically-valid geospatial evidence. Knowledge concerning the GPS location of initial fields, and disease foci within fields, ensures the collection of sufficient, geospatially-referenced pathogen isolates to detect population genetics anomalies atypical of natural events. A protocol for image acquisition, image processing, spatial analyses, and gradient analyses involving the wheat-leaf rust pathosytem will be presented.

New molecular tools for microbial forensics investigations

J. Burans

NBFC, DHS

Phytopathology 99:S160

The National Bioforensic Analysis Center (NBFAC) was established as the lead federal agency to conduct and coordinate the scientific analyses of evidentiary samples from biocrime and bioterror investigations in support of the lead federal investigative agency. The NBFAC since its inception in 2004 has been a leader in the develop of techniques to identify and characterize biological threat agents in evidentiary samples associated with biocrime and bioterror investigations. The NBFAC identifies and characterized biological threat agents using overlapping complementary techniques such as culture, molecular analyses, antigenic analyses and electron microscopy. With the advent of new techniques such as inexpensive rapid sequencing, microarrays and binformatic analyses, bioforensic analytical capabilities are becoming more comprehensive and capable of more rapidly identifiying and characterizing new emerging agents and genetically engineered agents. The various commonly used bioforensic approaches for identifying and characterizing biological threat agents and new approaches for the future will be discussed.

Forensics in the trenches: Learning through exercises

C. Thomas

UC Davis

Phytopathology 99:S160

The cross roads of criminal forensics and plant pathology meet many challenges in the field due to differences in traditional primary objectives and paradigms. This presentation will discuss similarities and differences in the approaches taken by these two different communities, using real-world and exercise cases. Seamless, coordinated standard operating procedures for detection, chain-of-custody, chain-of-communications, response and recovery in the event of a suspect criminal activity involving plant health are essential to a successful investigation. Lessons learned from exercise efforts, including a recent field training event in Oklahoma, and actual events will be presented. Focus will be on a likely progression of engagement that could involve a plant health professional, such as yourself, should the need arise. Potential roles and responsibilities of the university - including extension, industry, and government at the local, state and national levels will be discussed.

\section{Globe Trotting Plant Pathogens and Factors Making a Difference in Management Outcomes}

Globalization and new waves of immigration of plant pathogens J. H. McBeath

University of Alaska, Fairbanks, AK

Phytopathology 99:S160

Immigration of plant pathogens across national borders and geographic boundaries through trade has been present throughout much of human history. Recent movements through internationalization of trade by merging the world into one market unhampered by state boundaries/borders has greatly facilitated free trade, but also effectively enhanced long distance dissemination of plant pathogens. To combat this unwanted consequence of free trade, countries have paid increasing attention to collecting information on the emergence or re-emergence of plant diseases around the world. Pest risk assessment, phytosanitary clearance negotiation and plant quarantine are major tools used by trading partners in the prevention of entry of invasive pathogens. Plant materials, agricultural and forestry products and soils infested with exotic fungi, bacteria, viruses or nematodes are intercepted at the border and regularly denied entry. Within the country, elaborate surveillance systems are used to monitor diseases of economic, quarantine and national security significance. The development of new, sophisticated diagnostic tools and methods provides rapid and accurate diagnosis of pathogens and further aids the gathering of new information on diseases which might have been misdiagnosed or unknown previously. The new disease information, in turn, has a significant impact on mitigation; phytosanitary protocol negotiations and trade restrictions among countries.

Invasive bacterial pathogens with vectors: Management success and failure

S. Miller, R. Lee

The Ohio State University-OARDC, Wooster, OH \& USDA ARS National Clonal Germplasm Repository for Citrus and Dates, Riverside, CA Phytopathology 99:S160

Many bacterial diseases are intractable due to the lack of effective bactericides, durable host resistance or other management tactics. We present two 
examples of economically important invasive bacterial pathogens, citrus huanglongbing (HLB) and banana xanthomonas wilt (BXW), dependent on vectors for spread. HLB, vectored by two psyllid species, was first found in the Western hemisphere in 2004 and is now in Brazil, Florida, Cuba, and Louisiana. Management of the disease depends on psyllid control, planting healthy plants, and timely removal of symptomatic trees. Management is hampered by the lack of diagnostic methods for early detection of the associated Candidatus Liberibacter species in plants. Quantitative PCR (qPCR) for the detection of the bacterium in the vectors in Florida demonstrated the usefulness of this approach for early detection of HLB. We report the use of this approach for monitoring the effectiveness of different management systems in Brazil. BXW, caused by Xanthomonas campestris pv. musacearum, was first reported in Uganda in 2001. BXW has spread rapidly in East and Central Africa. The bacterium is spread by infected planting materials, contaminated tools and insects that visit infected fruit and flowers. A robust PCR assay based on the $h r p B$ operon of the $h r p$ gene cluster of $X$. campestris pv. musacearum has been developed. This assay was tested in African laboratories for detection of the pathogen and to determine the distribution of the bacterium in pseudostems in banana mats, resulting in refinement of sanitation recommendations.

\section{Advance of the fungi in a world without borders \\ D. Huber \\ Purdue University, Lafayette, IN \\ Phytopathology 99:S161}

Invasive fungal pathogens cause serious crop losses and environmental damage that can eliminate entire species and impose serious economic hardship on a society. Historical examples include Dutch elm disease and Chestnut blight, but current threats may be just as damaging. Reduced production efficiency from direct damage, increased costs of control, and imposed crop management changes often threaten sustainability of a society's necessary agricultural infrastructure and the health and well-being of populations far removed from the actual event. With regionalization of production, a disease in one area impacts the entire world community. Control of exotic fungal threats such as witches broom of cacao (Crinipellis perniciosa), laural wilt of red bay and avocado (Rafiella spp.), downey mildews of corn, sorghum, and sugarcane (Peronosclerospora philippinensis/P. sacchari), and late wilt of corn (Harpophora maydis); and reemerging diseases such as late blight of tomato and potato (Phytophthora infestans), take-all of cereals (Geaumannomyces graminis), and fusarium wilts (Fusarium oxysporum) require international understanding and cooperation in a global economy. Innovative approaches integrated into the crop production system are needed to meet fungal challenges to agriculture and the environment of the 21 st century.

\section{Capsids with wings}

J. Brown, C. Herron

University of Arizona, Tucson, AZ \& IITA-Tanzania, Dar es Salaam, Tanzania

Phytopathology 99:S161

Exotic, insect-vector borne plant viruses and viroids are among the most difficult pathogens to manage, owing to their propensity to hitchhike on plants and plant parts, mediated by human activities. In other instances vectorpathogen complexes invade new locales, deployed by natural weather phenomena. Many such vector-pathogen complexes exhibit invasive traits, are more fit than their endemic counterparts, and lack natural enemies in the invaded zone. Despite quarantine programs, the use of genetically similar (and susceptible) cultivars, together with expanded production in mild climatic zones have added fuel to the fire. Here, we will discuss very recent vectorpathogen invasions that have caused untold economic losses, including the whitefly-transmitted viruses: Cassava brown streak virus (Ipomovirus; Potyviridae), Cucurbit yellow stunting disorder virus (Crinivirus; Closteroviridae), Cowpea mild mottle virus (Carlavirus), severe African cassava mosaic disease complex, Tomato yellow leaf curl virus, and Squash leaf curl virus (Begomovirus; Geminiviridae). In addition the Tomato chlorotic dwarf viroid (Pospiviroid; Pospiviroidae) poses a serious threat to tomato production in controlled environment systems. These new and emergent pathogens and their insect vectors challenge the resilience of food and fiber production systems worldwide.

\section{Stealth invaders: Lessons on nematode dissemination}

\section{J. O. Becker}

University of California, Riverside, CA

Phytopathology 99:S161

Plant parasitic nematodes present major economic constraints to agriculture, horticulture and forestry production. Many of these disease problems are the consequence of invasions by non-native nematode species. Nematodes have evolved many strategies that favor their dissemination. Active mobility of individual nematodes allows for only limited movement. Passive dispersal by physical forces or biological vectors may operate within a field or on a limited regional scale. However, human activities have been the main vehicles for nematode dissemination from local to intercontinental scales. The spread of exotic nematodes relies foremost on their ability to survive the transport from their origin to the new location. Establishing and maintaining their population requires suitable host plants and environmentally conducive conditions. Ecosystem requirements and the nematode's ability to adapt and to thrive under such conditions ultimately determine the success of the pathogen's introduction and its disease potential. Awareness of the means of nematode dissemination and their anticipated consequences allows risk assessment and provides information for potential regulatory action and nematode management strategies.

Lessons learned for successful management of invasive pathogens K. Garrett, M. M. Roca

Kansas State University, Manhattan, KS \& Zamorano University, Tegucigalpa, Honduras

Phytopathology 99:S161

Some epidemics spread across continents, while others slow and come to a stop. Of the many strategies and tactics available for stopping epidemics of invasive pathogens, which have been most successful? The U.S. developed an extensive monitoring plan in response to the introduction of soybean rust, including deployment of sentinel plots to indicate the annual northern movement of the pathogen from overwintering sites to the south. Chrysanthemum white rust and Karnal bunt have been successfully restrained to date in the U.S. through quarantine programs and monitoring. The new stripe rust race UG99, with virulence to previously undefeated resistance genes, has been spreading, but it appears possible that efforts to restrict its movement will pay off before it reaches all vulnerable countries. Invasive diseases of palm caused by viruses and phytoplasmas offer less promising examples, where many epidemiological features still need more study to optimize management. We evaluate the strategies and tactics that have been employed for these and other pathogens of all taxonomic groups. As a function of the life history characteristics of hosts, pathogens, and vectors, we compare the utility of management efforts based on exclusion, eradication, containment, inspection, monitoring, and the use of pesticides and biological control.

\section{Meta-Analysis for Evidence Synthesis in Plant Disease Epidemiology and Management}

Introduction: What is meta-analysis and how is it used for evidence synthesis?

L. Madden

Ohio State University, Dept. of Plant Pathology, Wooster, $\mathrm{OH}$ Phytopathology 99:S161

Meta-analysis is the analysis of the results of multiple independent studies in order to synthesize the evidence from many possible sources in a formal probabilistic manner. In a simple sense, the outcome of each study becomes a single observation in the meta-analysis of all available studies. The discipline developed originally in the social sciences, based on earlier pioneering contributions by Fisher and Pearson, and has now been embraced within many scientific disciplines, especially in medical research. Since 1980 , over 25,000 journal articles have been published on the topic; however, only a handful of articles have been published in plant pathology and related fields utilizing this methodology. After reviewing basic concepts and approaches, the advantage of meta-analysis will be presented in terms of the high statistical power that can be achieved for detecting significant effects of treatments or significant relationships between variables. Meta-analytical results can be biased, however, if the analysis is based on a nonrepresentative sample of study results. Therefore, novel approaches for characterizing the upper bound on the bias will be discussed, in order to show the robustness of the approach to possible violation of assumptions.

How should one measure the effect of a treatment (effect size) and obtain this information from published and unpublished studies?

P. Paul, L. Madden

Ohio State University, Dept. of Plant Pathology, Wooster, OH

Phytopathology 99:S161

Like many other areas of statistics or data synthesis, meta-analysis begins with a question, and it is that question that determines what information is sought in published or unpublished studies or databases. The question may be related 
to the effect of some treatment or the association among variables; hence, information is gathered that allows for a quantitative synthesis of the magnitude, direction, and significance of that effect or association in the form of a variable called an effect size. There are several different types of effect sizes for continuous and discrete data, including correlation coefficients, regression coefficients, mean differences, standardized mean differences, response ratios, and $\log$ odds ratios. These may be readily available in published literature or may be (easily) calculated from available raw data. However, in many cases, the effect size of interest may not be available in the desired form in all studies; it may be hidden in some other information or statistic that is provided in the literature or database. Some effect sizes are interrelated, and as such, it may be possible to estimate one effect size from another. Methods for estimating effect sizes from available data or statistics, the interconnection between effect sizes, their relationship with properties of the synthesized studies (moderator variables), and interpretation of results for different effect sizes will be discussed.

\section{Effect of foliar fungicides used to control soybean rust}

P. Esker (1), H. Scherm (2)

(1) University of Wisconsin, Madison, WI; (2) University of Georgia, Athens, GA

\section{Phytopathology 99:S162}

Since the discovery of soybean rust (Phakospora pachyrhizi) in South America in 2001 and in the United States in 2004, there has been a tremendous increase in the number of foliar fungicide trials conducted in both regions. The goal for many of these trials was to improve management of soybean rust, however, in the United States, many of these trials were conducted under cropping conditions where soybean rust was not observed. Thus, it is important to improve our understanding of the conditions where the use of a foliar fungicide may be warranted. The focus for this talk will be the application of meta-analysis to address the use of foliar fungicides for soybean. In particular, a discussion of the current results from Brazil in comparison to results from the United States will be presented. Furthermore, in this talk special emphasis will be placed on how specific questions were formulated to screen foliar fungicide trials for inclusion in analyses and also a brief discussion of fixed and random effects as applied in metaanalysis.

\section{What is the best treatment for biocontrol of fire blight?}

H. Ngugi

Penn State University, Dept. of Plant Pathology, Biglerville, PA

Phytopathology 99:S162
Fire blight caused by Erwinia amylovora remains an important disease limiting the productivity of apples. Several biocontrol products have been evaluated for fire blight control but their efficacy in the eastern U.S. has been inconsistent. A multi-treatment random effects meta-analysis was performed using data obtained from 47 trials carried out in the eastern U.S. from 1999 to 2007. Treatments included in the meta-analysis had been applied solely, or in a sequential combination of two products. A method for estimating the least significance difference (LSD) for studies with at least three significant mean separations was developed and used to derive the within-study variances for weighting the effect sizes. Based on this method, the estimated LSD was an excellent predictor $\left(r^{2}=0.994, P<0.0001, n=35\right)$ of the observed LSD for 35 studies for which the raw data was available. Except for a treatment combining products based on Pseudomonas fluorescens and Pantoea agglomerans, all other treatments significantly reduced $(P<0.01)$ fire blight relative to the untreated control. The best control was noted for treatments combining the antibiotic streptomycin with a product based on P. agglomerans (56\% disease reduction) or Bacillus subtilis (53\% reduction). Disease suppression was 34, 25 , and $24 \%$, respectively, for products based on B. subtilis, P. agglomerans, and $P$. fluorescens, suggesting that the higher efficacy of the combination treatments was due to the antibiotic.

A Bayesian approach to meta-analysis

A. Mila (1), H. Ngugi (2)

(1) North Carolina State University, Raleigh, NC; (2) Penn State University, Biglerville, PA

Phytopathology 99:S162

This presentation reviews the use of Bayesian methods in meta-analysis of plant pathology studies. The use of meta-analysis has exploded over the last few years, as well as the use of Bayesian methods, facilitated by recent advances in computational technology. Whilst in most cases meta-analyses have been carried out using frequentist methods, there are a number of specific advantages conferred by the Bayesian approach. These include: full allowance for all parameter uncertainty in the models, the ability to include other pertinent information that would otherwise be excluded, and the ability to extend the models to accommodate more complex, but frequently occurring, scenarios. In the present paper the applications and advantages of Bayesian methods will be discussed and demonstrated with data assessing the evidence that application of a Systemic Acquired Resistance agent provides control against fire blight of apples, caused by Erwinia amylovora. Effect sizes computed with a frequentist approach will be compared with those obtained using a Bayesian approach. This evidence is available through synthesis of several experiments with meta-analysis methods.

\section{Phytophthoras in Forests: New Paradigms for an Old Genus}

Phytophthora in forests: New species, new threats, and new questions

E. Hansen

Dept Botany and Plant Pathology, Oregon State University

Phytopathology 99:S162

Phytophthora defines the science, the history, and the promise of plant pathology, from the potato famine to the new world of pathological genomics. Many Phytophthora species are known as pathogens of agricultural crops, but their origins lie in wild ecosystems. Speakers in this session look to forests for new insights into the evolutionary history of the genus. New ideas about population genetics and speciation are coming from forest populations of both indigenous and invasive species. Agricultural fields are too flat, and agronomic crops too genetically uniform to hold our attention for long in studies of epidemiology or pathogenesis. Crop losses in agriculture can be neatly measured by yield, but in the forest, the impacts of Phytophthora ripple through the entire ecosystem. New species are being described at an accelerating rate. Some are aggressive plant pathogens and threaten new diseases in new places in this era of global trade. Others appear to be benign, or even saprophytic in the wild. New pathogens are being reported in each of the major phylogenetic clades. ITS clade 6 encompasses much of the behavioral complexity in the genus. It includes the well-known $P$. megasperma, which is often not what it appears to be, and $P$. gonapodyides, ubiquitous despite its sterility. The full complexity of this clade is only beginning to be sorted out.

Progress in understanding Phytophthora evolutionary biology: 1983 revisited

C. Brasier

Forest Research Agency, UK

Phytopathology 99:S162
In the 1983 APS golden volume 'Phytophthora: its Biology Taxonomy Ecology and Pathology' the author reviewed the evolutionary biology of the genus and, perhaps unwisely, presented a tentative Phytophthora phylogenetic tree based solely on morphological and behavioural characters. At the time only about 50 Phytophthora species were known and molecular variation was assessed mainly by protein and isozyme polymorphism. Today, in 2009, we have more than 100 known Phytophthora species and maybe another 100-500 species are still to be discovered. We also have the ability to construct molecular phylogenies and to probe the environment for Phytophthora biodiversity. Natural ecosystems are being sampled more frequently for endemic Phytophthora species than ever before. While at the same time the international plant trade is unwittingly distributing previously unknown Phytophthora taxa and promoting interspecific hybridisation. The significance of these developments for understanding Phytophthora evolutionary biology will be discussed. Some issues highlighted in 1983, including Phytophthora phylogeny, will be assessed from a current perspective.

Examining the population diversity of Phytophthora species in natural and agricultural ecosystems

K. Ivors

Dept. of Plant Pathology, North Carolina State University, Mills River, NC Phytopathology 99:S162

Their virulence and ability to spread rapidly throughout the world establish Phytophthora species as some of the most important groups of plant pathogens. Species in this genus are receiving increased attention as causal agents of emerging forest diseases and commercial plant trade has been implicated in their introduction and movement. In recent years, numerous types of molecular techniques have been used to investigate the intraspecific population diversity of Phytophthora spp. known to infect plants in both agricultural and natural ecosystems. In general, $P$. ramorum and $P$. cinnamomi are known to exist as a limited number of distinct clonal lineages of asexually reproducing populations, as these lineages are represented mostly by single 
mating types. Recent research has indicated the A2 mating type as the oldest type in P. cinnamomi, while the A1 EU lineage may be older than the A2 NA lineages of $P$. ramorum. Often, their limited genetic and phenotypic diversity is presumed to be the result of founder events and used to support their exotic origin. While studies of some Phytophthora spp. have detected significantly higher genotypic diversity among nursery populations, isolates collected from forests have been mainly limited to terrestrial ecosystems. Researchers in numerous states and countries are currently investigating inter- and intraspecific diversity of Phytophthora spp. collected from watercourses in natural ecosystems and finding intriguing discoveries.

\section{Phytophthora in forests: Feedbacks between pathogen and plan communities in forests \\ D. M. Rizzo \\ Department of Plant Pathology, University of California, Davis, CA 95616 Phytopathology 99:S163}

Understanding the ecology of Phytophthora in forests requires integrating feedback among hosts, pathogens and their environment. Because generalist pathogens, such as $P$. ramorum or $P$. cinnamomi, infect many woody and herbaceous plant species, linkages between positive and negative feedback loops will be complex. Which plant species will be successfully recruited in the face of these pathogens and how successional patterns will develop are important questions for forest managers. In the sudden oak death system, pathogen-mediated competition between California bay laurel and tanoak appears to be a key component of plant community structuring. Transmission and pathogen impacts are asymmetric between the two hosts; bay laurel can support up to ten times greater sporulation and suffers no mortality compared to tanoak. Positive feedback may result in population increases for both bay laurel and $P$. ramorum. In contrast, as tree mortality increases, site associated environmental changes may create negative feedbacks on Phytophthora species. Opening of forest canopy gaps may result in unfavorable microclimatic changes for pathogen establishment, reproduction and survival. On sites with very high levels of pathogen caused tree mortality, accumulations of coarse woody debris (CWD) may be many times higher than in pathogen free areas. Contribution of CWD to wildfire severity may then lead to negative feedback on pathogen populations. The variety of Phytophthora species found in forests offer many opportunities to test hypotheses that will contribute to our understanding of disease ecology.

Landscape epidemiology of Phytopthora ramorum: Measuring, mapping, and modeling spread

R. Meentemeyer

University of North Carolina, Charlotte, NC

Phytopathology 99:S163

Landscape- to regional-scale models of plant epidemics are direly needed to predict large-scale impacts of disease and assess practicable options for control. While landscape heterogeneity is recognized as a major driver of disease dynamics, epidemiological models are rarely applied to realistic landscape conditions due to computational and data limitations. Here we describe a stochastic susceptible-infectious epidemic model, applied to temporally and spatially heterogeneous landscape parameters, to predict the spread of the invasive forest pathogen Phytophthora ramorum in California (1990-2030). Three epidemiological processes (production of inoculum, dispersal, and infection) are modeled on a weekly time step across a $250 \mathrm{~m}$ by $250 \mathrm{~m}$ lattice composed of variable susceptible and infected host units. We describe how field, lab, and geospatial data were combined to parameterize and map the key system variables affecting transmission of $P$. ramorum, including weather conditions, host infectiousness and availability, and a Markov Chain Monte Carlo estimated dispersal kernel. Replicated 1000 times to examine stochastic variability in epidemic outcomes, model predictions have a high degree of correspondence with 784 field plot observations that were collected across the pathogen's potential geographic range to validate model performance. Results show that most disease spread occurs via local dispersal $(<250 \mathrm{~m})$ but infrequent long-distance dispersal events can substantially accelerate epidemic spread in regions with large amounts of highly suitable habitat, such as the northern coastal forests. While the epidemic is currently well established, model predictions show that, under no control, epidemic spread will increase ten-fold by 2030 with most infection along the north coast to Oregon. In addition, results also show that wetter than normal weather conditions between 2009 and 2030 would double the rate of this spread. This research illustrates how stochastic epidemiological models can be applied to realistic geographies and be used gain a predictive understanding of plant disease dynamics in heterogeneous landscapes.

\section{Pathogenicity of Phytophthora ramorum}

D. K. Manter

USDA-ARS Soil-Plant-Nutrient Research, Fort Collins, CO 80526

Phytopathology 99:S163

Phytophthora spp. infect an extremely diverse array of host plants resulting in a variety of diseases, ranging from root rots to foliar blights. In particular, Phytophthora ramorum, has the ability to infect more than 100 plant species. This talk will present a broad overview of the Phytophthora secretome and its potential contribution to host susceptibility and $P$. ramorum pathogenicity. Topics include the potential contribution of Phytophthora spp. toxins (e.g., NPP1) and effectors (e.g., elicitins) on disease development. Greater detail will focus on our own work exploring the contribution of elicitins to $P$. ramorum pathogenicity. In one study, we have examined elicitin production, virulence, and sporulation in 15 P. ramorum isolates belonging to the three clonal lineages (EU1, NA1 and NA2). The EU1 and NA2 isolates are generally more virulent, produce more sporangia, and produce more elicitin in vitro than NA1 isolates. Plants possess a number of defense pathways that also interact with elicitins, contributing directly and indirectly to $P$. ramorum pathogenicity. For example, elicitins may trigger a hypersensitive response in some hosts, which depending upon the timing and degree of this process may lead to complete resistance or physiological impairment (i.e., reduced photosynthesis and/or cell death) without limiting Phytophthora colonization. Finally, research on the potential contribution of plant tannins on elicitin activity, $P$. ramorum growth and sporulation will also be discussed.

\section{Molecular/Cellular Plant Microbe Interactions}

\section{Application of Advanced Sequencing and Gene Expression Technologies for Characterization of Phytopathogens}

Integrating molecular and computational methods to evaluate the Pseudomonas syringae transcriptome I and II

\section{J. FILIATRAULT, P. STODGHILL}

USDA-ARS, Plant-Microbe Interactions Research Unit, Cornell University, Ithaca, NY. Both authors contributed equally to the work.

Phytopathology 99:S163

Much information can be gathered from the genomic sequence of a bacterium. However, to more fully understand the coding potential of the genome, experimental identification of the transcribed fraction is required. In particular, strand-specific information is essential to thoroughly characterize transcriptional activity. Several methods exist for capturing the complete set of transcripts in a cell, using deep-sequencing technologies, however, most of these techniques have been limited to the study of eukaryotes and lack strand specific information. We will present combined computational and experimental approaches for precisely evaluating the transcriptome of the plant pathogen Pseudomonas syringae using RNA-Seq. The power of this approach is demonstrated by the fact that a single experiment has generated a number of important questions regarding gene expression in $P$. syringae for future investigations. The establishment of RNA-Seq for analyzing bacterial transcriptomes on a global scale significantly impacts bacterial genome annotation as well as the study of bacterial gene regulation. In Part I, we will describe the molecular methods used to prepare RNA samples and the development of a strand-specific protocol to sequence RNA using the Illumina Genome Analyzer. Next, the computational methods developed to analyze the vast amount of sequence data will be discussed. Then, we will show the application of transcriptome sequencing to the identification of polymorphisms and candidate transcriptional start sites. For Part II, we will describe a unique classification method developed to qualitatively assess transcriptional activity that combines RNA-Seq with proteomics data. Using this approach, we are able to identify transcriptional activity in areas of the genome inconsistent with the genome annotation and transcriptional activity in un-annotated areas of the genome, allowing for transcript discovery. Specific examples of areas in the genome that display unusual transcriptional activity will be highlighted.

Genomic perspectives on plant-associated enterobacteria J. D. GLASNER, N. T. Perna

Genome Center of Wisconsin, University of Wisconsin-Madison Phytopathology 99:S163

The family Enterobacteriaceae includes plant-associated bacteria of the genera Benneria, Dickeya, Erwinia, Pantoea and Pectobacterium. We are using a 
combination of Sanger, 454 and Illumina sequencing approaches to obtain complete and draft genome sequences from multiple representatives of each of these lineages. Comparisons of the sequences are assisted by reordering and alignment of genomes using the Mauve program and annotation using the ASAP database. Our analyses reveal core components conserved across lineages as well as features specific to particular species, genera and other groups of evolutionarily or phenotypically related pathogens. The sequences are used to design species-specific ORF or tiled microarrays for transcriptional profiling and chromatin immunoprecipitation experiments under varying growth conditions. These multi-omic datasets are integrated in the ASAP database and used to reconstruct the evolutionary history of genetic and regulatory networks among these bacteria.

GeoChip: A high throughput genomics technology for characterizing microbial functional community structure

J. ZHOU

Institute for Environmental Genomics and Department of Botany and Microbiology, University of Oklahoma

Phytopathology 99:S164

Microarray technology provides the opportunity to identify thousands of microbial genes or populations simultaneously. A comprehensive functional gene array (GeoChip) was developed to detect and monitor microbial communities important to various biogeochemical, ecological and environmental processes. Based on the second generation of GeoChip, a new generation, GeoChip 3.0, has been developed with several new features. First, GeoChip 3.0 contains $\sim 25,000$ probes and covers $\sim 47,000$ sequences for 292 gene families. Second, the homology of automatically retrieved sequences by key words is verified by HUMMER using seed sequences so that the sequence retrieving process is automated. Third, a universal standard has been implemented so that data normalization and comparison of different microbial communities can be conducted. Fourth, a genomic standard is used to quantitatively determine absolute gene abundance. In addition, GeoChip 3.0 includes phylogenic markers, such as gyrB. Finally, a software package has been developed to facilitate the management of such a complicated array, especially for data analysis and future update. GeoChips were successfully used to analyze microbial functional structure from a variety of environments such as wastewater treatment, microbial fuel cells from hydrogen production, hydrothermal vents, uranium-contaminated groundwater, the distribution of microbial functional communities across different oil fields, and grassland microbial communities in response to elevated $\mathrm{CO} 2$ and soil warming. New insights and implications in these systems were obtained. The results also indicated GeoChip is a novel, powerful high throughput, quantitative genomics technology for characterizing microbial functional community structure from a variety of natural habitats.

\section{Comparative and functional genomics of oomycete infection}

B. M. TYLER (1), S. Tripathy (1), S. D. Kale (1), L. Zhou (1), A. Ferreira (1), D. Dou (1,2), F. D. Arredondo (1), S. X. Mideros (3), L. Bao (1), K. Krampis (1), A. Jerauld (1), K. Cooper (1), W. Qunqing (2), H. Changzhi (2), B. Gu $(1,4)$, R. Anderson (1), R. Hanlon (1), W. Xiaoli (2), Y. Xiaoli (2), L. Tiuli (2), Y. Yao (2), W. Xinle (2), D. Suomeng (2), Z. Zhengguang (2), Z. Xiaobo (2), C. Evans (1), W. Shan (4), Y. Wang (2), S. K. St. Martin (3), M. A. Saghai Maroof (1), I. Hoeschele (1), A. E. Dorrance (3), J. McDowell (1)

(1) Virginia Polytechnic Institute and State University; (2) Nanjing Agricul- tural University, China; (3) Ohio State University; (4) Northwest Agricultural and Forestry University, China

Phytopathology 99:S164

Oomycete pathogens, including Phytophthora and Pythium species and many downy mildews, cause billions of dollars of damage to crops, forestry and ornamental plantings each year. Draft genome sequences have been developed so far for Phytophthora sojae, P. ramorum, P. infestans, P. capsici, Hyaloperonospora arabidopsidis and Pythium ultimum, and Illumina survey sequences of $P$. phaseoli, P. mirabilis, $P$. andina and Albugo candida have been produced. We have also compared the genome sequences of the four major genotypes of $P$. sojae using 454 pyrosequencing. Comparisons among these genome sequences have identified large numbers of rapidly evolving genes, including toxin and effector genes, that are likely involved in the interaction with host plants. Closer examination of the sequences has revealed highly conserved members of effector families that may play key roles in infection. We have also used transcriptional profiling, including both Affymetrix GeneChips and $454 \mathrm{cDNA}$ sequence tags, to identify $P$. sojae and soybean genes that may play an active role in promoting or impeding infection, respectively. Transcriptional profiling revealed that very large numbers of host and pathogen mRNAs change in level during infection; in the case of soybean, more than $98 \%$ of the genes were transcriptionally reprogrammed. Combining information about the transcriptional program of $P$. sojae effector gene expression with high throughput functional screens for plant defense suppression has revealed a coordinated interplay among the effectors to maximize defense suppression.

Comparative genomics, sequence mining and transcript profiling of cyst nematodes during plant parasitism

A. A. ELLING (1), T. J. Baum (2)

(1) Department of Plant Pathology, Washington State University; (2) Department of Plant Pathology, Iowa State University

Phytopathology 99:S164

Genomic approaches have begun to unravel the responses of plants to nematode infection but information about pathogenesis-related gene expression changes in plant-parasitic nematodes themselves is still scarce. Highthroughput sequencing of expressed sequence tags (EST) and microarray analyses are powerful approaches to study nematode infection of plants from the parasite's perspective. Concerted efforts enabled the generation of a life stage-specific EST set of close to 22,000 sequences, representing up to 6,860 unique genes, for the soybean cyst nematode Heterodera glycines. EST sequence mining led to the pre-selection of candidate genes for secreted effector proteins, including a putative histone deacetylase. Secreted effectors allow cyst nematodes to establish a feeding site within their hosts. Furthermore, this EST set has been incorporated into the Affymetrix Soybean Genome Array GeneChip. Using this microarray, life stage-specific transcript profiling of $\mathrm{H}$. glycines revealed distinct shifts in transcript abundance during pathogenesis. Comparative genomics between $H$. glycines and the model nematode Caenorhabditis elegans showed that developmental arrest might be based on different mechanisms in these two species. Together, large scale transcript profiling of plant-parasitic nematodes and comparative genomics will aid in determining what defines the parasitic nature of certain nematodes and enable the development of novel control strategies to protect crops.

\section{Evolutionary \& Functional Genomics of Virus-Plant Interactions}

\section{Small RNA-directed silencing pathways in plants}

\section{J. C. Carrington}

Oregon State University, Corvallis, OR 97331

Phytopathology 99:S164

Plants possess several posttranscriptional silencing systems involving distinct small RNA biogenesis and effector components. We have explored biogenesis, effector and specificity mechanisms of miRNA, trans-acting siRNA (tasiRNA), antiviral siRNA, and other small RNA classes using Arabidopsis thaliana. Small RNA are formed through the activity of four DICER-LIKE (DCL) proteins, and sorted among 10 ARGONAUTE (AGO) proteins through AGO-specific $5^{\prime}$ nucleotide and size preferences. For example, the vast majority of miRNA possess a $5^{\prime} \mathrm{U}$, which directs association with AGO1. RNA silencing in response to viruses involves a set of DCL, amplification and AGO factors that partially overlap those required for tasiRNA, which form through an RNA-dependent RNA polymerase6 (RDR6)-mediated mechanism after initial processing of primary transcripts by miRNA-guided cleavage. Analysis of the tasiRNA biogenesis pathway has been particularly informative about mechanisms that direct a target RNA through the RDR6 amplification pathway, and has revealed the importance of specific small RNA-AGO complexes in recruiting RDR6 for dsRNA production. Antiviral silencing, however, involves additional factors, which have been revealed through analysis of silencing suppressor-defective mutant viruses. These and other features of Arabidopsis posttranscriptional and antiviral silencing pathways will be discussed.

Mechanisms of plant resistance to viruses

S. P. Dinesh-Kumar

Department of Molecular, Cellular and Developmental Biology, Yale University, New Haven, CT 06520-8103

Phytopathology 99:S164

Resistance (R) proteins are components of a plant surveillance system that serves to recognize pathogen-encoded effector proteins from organisms including viruses, bacteria, fungi and even nematodes. The majority of $\mathrm{R}$ immune receptors contain nucleotide binding (NB) and leucine-rich repeat (LRR) domains which are both present in mammalian intracellular pattern recognition receptors (PRRs) required for animal innate immunity. However, despite the structural similarities with animal innate immunity molecules, plant immune receptors recognize specific pathogen effectors while mammalian receptors recognize non-specific MAMPs. Intriguing questions in 
the last few years in the innate immunity field is how plant $\mathrm{R}$ proteins recognize the presence of pathogen-derived effector proteins and activate downstream signaling. To this end, we are using $\mathrm{N}$ immune receptor that confers resistance to tobacco mosaic virus (TMV) as a model system. I will discuss our recent findings on how $\mathrm{N}$ immune receptor recognizes TMV and activates defense signaling.

\section{The diverse routes of plant virus evolution}

E. V. Koonin

National Center for Biotechnology Information, National Library of Medicine, NIH, Bethesda, MD 20894

Phytopathology 99:S165

Each major lineage of cellular life forms supports the reproduction of diverse viruses. The repertoire of viruses infecting a given group of hosts depends on the internal dynamics of the virus world and on the unique cellular and tissue organization of the host. The plant virome is heavily dominated by positivestrand RNA viruses with smaller contributions from double-stranded RNA, negative-strand RNA, retroid, and single-stranded DNA viruses. Doublestranded DNA viruses that are dominant in prokaryotes and common in animals are conspicuously absent from plants, conceivably, owing to their inability to pass through plasmodesmata. Comparative-genomic analysis shows that the plant virome was shaped by a multitude of evolutionary processes of which perhaps the most prominent one is gene exchange among diverse viruses that is not limited to plant viruses but also involves viruses of fungi and bacterial plasmids. The radiation of the major superfamilies of positive-strand RNA viruses, most likely, occurred concomitantly with eukaryogenesis, and representative of all superfamilies were inherited by plants. In contrast, the small DNA viruses of plants (geminiviruses and circoviruses) were originally derived from bacterial plasmids. The subsequent evolution of plant viruses was defined primarily by intervirus gene exchange under common selective pressures as exemplified by the spread of homologous movement proteins among diverse viruses.

TMV MP gates plasmodesmata via ANK, a tobacco ankyrin-repeat protein which down-regulates callose deposits

S. Ueki, V. Citovsky

Department of Biochemistry and Cell Biology, State University of New York, Stony Brook, NY 11794-5215

Phytopathology 99:S165

For decades, TMV MP has been known to increase plasmodesmal permeability and traffic between cells, but how it achieves these goals remains an enigma. We have identified a tobacco ankyrin-repeat protein, designated ANK, which, when transiently overexpressed in tobacco leaf epidermal cells, enhanced the TMV MP cell-to-cell movement. On the other hand, in transgenic plants with native ANK expression decreased by RNAi-based knockdown, the TMV MP movement was dramatically suppressed. ANK contains a conserved glycosyl hydroxylase catalytic motif at its C-terminus. Point mutation of the glutamic acid residue, known to be critical for the glycosyl hydroxylase activity, abolished the ability of ANK to assist TMV MP movement. Furthermore, coexpression of TMV MP with ANK resulted in $80 \%$ decrease in the amount of callose whereas coexpression with the inactive ANK mutant (E313A) had no such effect. Importantly, expression of ANK alone, without TMV MP, also did not alter callose deposits. Thus, we suggest that TMV MP utilizes ANK to decreases callose accumulation to enable plasmodesma gating and its own traffic from cell to cell. Another, as yet poorly researched aspect of viral infection is regulation of host gene expression. In the case of green algae-infecting PBCV1, it encodes a histone methyltransferase that epigenetically represses host genes. We will present our data characterizing plant chromatin-modifying $\mathrm{r}$ complexes potentially involved in such repression.

Yeast as a model host to explore plant virus - host interactions P. D. Nagy

Department of Plant Pathology, University of Kentucky

Phytopathology 99:S165

Plant RNA viruses, which are important and emerging pathogens, depend greatly on host proteins. Selected host proteins are subverted to facilitate virus replication and other steps in the viral infection cycle. To identify all host factors affecting the RNA replication and RNA recombination of tombusviruses, we performed genome-wide approaches based on yeast model host developed in our lab. The studies included systematic testing of 5,500 yeast genes via deletion or down-regulation. In addition, we conducted proteomics approaches based on mass spectrometry analysis of the highly purified viral replicase complex and yeast protein arrays carrying 4,100 proteins. The systems biology approaches led to the identification of $\sim 200$ host proteins. Follow up experiments demonstrated that, surprisingly, tombusvirus replication could switch from the peroxisomal membrane to ER in the absence of peroxisomes. We also show that GAPDH (glyceraldehyde-3-phosphate dehydrogenase) and heat shock 70 proteins are components of the tombusvirus replicase, and they are re-distributed to the site of viral replication. Mechanistic studies revealed the role of GAPDH in viral RNA replication, whereas HSP70 was shown to affect the assembly of the viral replicase. The relevance of yeast studies has been confirmed using Nicotiana host. Based on the above and additional data, we propose novel roles for several host proteins in regulation of viral RNA replication and discuss novel antiviral strategies.

\section{Virus-host arms race as a shaping force of virus evolution}

V. V. Dolja

Department of Botany \& Plant Pathology, Oregon State University, Corvallis, OR 97331

Phytopathology 99:S165

Although the virus-host interactions are inherently complex, recent advances in revealing the mechanisms of the innate and adaptive immunity, and virus counterdefensive strategies provide a glimpse of the emerging holistic picture. One apparent common theme is that every single feature of a virus that makes it distinct from a cell can be targeted by a cognate host defense. But one example of this is hypermutation of the retroviral single-strand DNA by APOBEC defense system. The second common theme is that, eventually, virus mirrors each of the host defenses with a counterdefense. For instance, HIV-1 has evolved Vif to suppress hypermutation. From an evolutionary standpoint, such arms race preconditions gradual growth of the viral genome complexity that, in turn, provides a bigger and easier target for the host defenses. Accordingly, the genomes of the larger viruses contain a larger proportion of genes that function in evasion or suppression of the host defenses. This evolutionary tendency can be illustrated by closteroviruses, the largest positive-strand RNA viruses of plants that contain multiple suppressors of RNA interference and other antiviral systems. The next challenge for the evolutionary virology is to unravel the chronological context of the arms race. Important clues to this problem were provided by recent studies of the origins and evolution of retroviruses and picorna-like viruses including plant potyviruses.

\section{Mechanisms of Post-Transcriptional Control of Gene Functions in Plant-Microbe Interactions (AS, PTGS, Sumoylation and More...)}

\section{Alternative splicing in plant-microbe interactions}

P. Veronese (1), S. Heber (2)

(1) Center for Integrated Fungal Research; (2) Bioinformatics Research Center, North Carolina State University, Raleigh, NC 27695 Phytopathology 99:S165

Intron retention (IR) is the most abundant type of alternative splicing (AS) in plants. To investigate the prevalence of stress-induced AS in Arabidopsis, we performed a genome-wide IR analysis using the entire Arabidopsis dbEST EST/cDNA data set ( 1.5 million sequences). We found that the frequency of IR versus intron skipping was 2.8 times higher in libraries derived from treated (biotic/abiotic agents) samples, suggesting IR involvement in plant stress adaptation. The search yielded 439 genes showing IR specifically upon treatment. Remarkably, about $70 \%$ of these genes were annotated as having non known function, process or cellular localization. We then investigated the genes' expression pattern in response to stimulus using GENEVESTIGATOR tools. About $10 \%$ of the stress-specific AS genes did not show any differential level of expression in response to biotic stressors. We interpret these results to indicate AS undergoes regulation upon stress exposure and that this response involves appearance of novel, treatment-induced splice variants. Furthermore, AS genes often change their splicing patterns but not their overall expression level. The current lack of knowledge on the role of AS in plant biology is most likely the result of prioritizing gene functional analyses mainly on the basis of overall mRNA abundance rather than on changes in sub-populations of transcripts produced at a locus of interest.

Regulation of plant disease resistance gene function by alternative splicing

X.-C. Zhang, S. H. Kim, W. Gassmann

Department of Plant Sciences, University of Missouri, Columbia, MO 65211 Phytopathology 99:S165

Alternative transcripts are being described for a growing number of plant resistance genes, and are most prominent among the large family of genes 
encoding Toll/interleukin-1 receptor (TIR) - nucleotide binding site (NBS) leucine-rich repeat (LRR) domain-containing resistance proteins. While the mechanism of alternative splicing in this gene family varies, these alternative transcripts usually encode putative truncated TIR-NBS proteins. A first indication that these alternative transcripts provide a crucial function came from the observation that intronless cDNAs of the tobacco $\mathrm{N}$ gene were nonfunctional. We study the Arabidopsis RPS4 gene and showed that intronless RPS4 transgenes, despite being expressed, failed to complement an rps4 mutant line. However, combining full-length and artificially truncated cDNAs that mimic the prevalent RPS4 transcripts provided resistance, demonstrating directly that a combination of RPS4 transcripts is required for function. RPS4 alternative transcript levels were temporally regulated after stimulus perception, suggesting that alternative splicing is fine-tuned to optimally regulate the plant innate immune response. We will present a model for the function of alternative transcripts in regulating plant resistance gene-mediated responses, and will discuss how the study of resistance genes can lead to insights into the important process of alternative splicing in plants.

\section{A novel role for protein farnesylation in plant innate immunity}

S. Goritschnig (1,2), X. Li (1)

(1) Michael Smith Laboratories and Dept. of Botany, University of British Columbia, Vancouver, BC, V6T 1Z4, Canada; (2) Dept. of Plant and Microbial Biology, University of California, Berkeley, CA 94720 Phytopathology 99:S166

Plant innate immunity involves tightly regulated signaling pathways leading from pathogen recognition by Resistance $(\mathrm{R})$ proteins to the expression of immune responses. By using the autoimmune model snc1, which expresses a constitutively active $\mathrm{R}$ protein in Arabidopsis thaliana, we were able to dissect the signaling events downstream of $\mathrm{R}$ protein activation and to identify new players involved in plant defense. In the snc1 suppressor screen, using fast neutron, we identified modifier of snc $1,8(\operatorname{mos} 8)$, which restores wild type susceptibility to virulent pathogens in snc1. MOS8 was identified through a map-based approach and is allelic to Enhanced Response to ABA 1
(ERA1), mutations in which affect seed germination, ABA responses, flower morphology and drought tolerance. ERA1 encodes the beta subunit of protein farnesyltransferase, a bipartite enzyme required for C-terminal prenylation of specific target proteins, which is important for correct protein localization and interactions. Mutations in ERA1 render plants more susceptible to virulent bacterial and oomycete pathogens and also affect several $\mathrm{R}$ protein mediated responses. ERA1 acts additively with the known resistance regulator Nonexpressor of PR genes 1 (NPR1). Our data suggest a direct involvement of farnesylation in defense signaling. However, the protein targets of ERA1 involved in plant innate immunity have yet to be identified.

Endogenous small RNAs and host RNAi machinery added a fundamental layer of regulation in plant immunity

H. Jin

Department of Plant Pathology and Microbiology, Center for Plant Cell Biology and Institute for Integrative Genome Biology, University of California, Riverside, CA 92521

Phytopathology 99:S166

Emerging evidence suggests that host endogenous small RNAs play an important role in plant immune responses. To identify and characterize pathogen-regulated small RNAs at the whole genome level, we performed high-throughput sequencing of small RNA libraries prepared from bacteriaand fungi-challenged Arabidopsis. We identified a diverse set of endogenous small RNAs, including miRNAs, nat-siRNAs, gene-targeting hc-siRNAs, and protein-coding gene-associated siRNAs. These small RNAs have different distribution patterns and distinct biogenesis pathways. Many of these small RNAs are either up- or down-regulated by various pathogens and may subsequently regulate target genes, thus contributing to gene expression reprogramming and fine-tuning in plant immune responses. Furthermore, we found that some of the RNAi pathway components are also important for regulating plant biotic stress responses. Our results suggest that host endogenous small RNAs and host RNA-silencing machinery represent a fundamental layer of control in plant immune responses.

\section{Microbial Genomes Off the Beaten Path}

\section{Genome plasticity in the genus Mycosphaerella}

\section{S. B. GOODWIN (1), G. H. J. Kema (2)}

(1) USDA-ARS, Crop Production and Pest Control Research Unit, West Lafayette, IN 47907; (2) Plant Research International, Wageningen, the Netherlands

Phytopathology 99:S166

Most members of the genus Mycosphaerella grow very slowly in culture and have long latent periods in planta. Until recently, very little was known about their genetics or host-pathogen interactions. Genomes of two species have been sequenced: the septoria tritici blotch pathogen of wheat, M. graminicola; and $M$. fijiensis, the black Sigatoka pathogen of banana. The sequence of $M$. graminicola is complete; only one telomere and two internal gaps are missing. Among the 21 chromosomes of the 39.7-Mb genome, eight were smaller, had higher repetitive DNA contents, lower percent G+C and fewer genes compared to the essential chromosomes. These eight, representing $40 \%$ of the chromosomes and about $10 \%$ of the genome, could be missing in other isolates indicating an extraordinary degree of within-species genome plasticity. In contrast, the genome of M. fijiensis was $74 \mathrm{Mb}$ in size but had a similar gene content. The increased size was due primarily to invasion of the genome by long-terminal repeat retrotransposons. The mitochondrial genome of $M$. fijiensis also was about twice the size as that of M. graminicola. Thus, extreme genome plasticity occurs both within and among species of the genus Mycosphaerella.

Why is Ralstonia solanacearum Race 3 cold tolerant? Using post-genomic analysis to explore strain-specific traits

C. ALLEN, F. Meng, J. M. Jacobs, L. Babujee

Department of Plant Pathology, University of Wisconsin-Madison Phytopathology 99:S166

Most strains of the bacterial wilt pathogen Ralstonia solanacearum are tropical, but one group, Race 3 biovar 2 (R3b2), is adapted to cooler environments and causes disease in temperate zones and tropical highlands. We compared the growth and virulence of $R$. solanacearum strains GMI1000 (tropical, biovar 3) and UW551 (R3b2, temperate) at temperate and tropical temperatures. The two strains grew similarly in media at $20^{\circ} \mathrm{C}$ and $28^{\circ} \mathrm{C}$. At $28^{\circ} \mathrm{C}$, both strains wilted tomato plants rapidly in a naturalistic soil-soak virulence assay. In contrast, at $20^{\circ} \mathrm{C}$ UW551 was much more virulent on tomato than GMI1000, suggesting that interaction with plants is required for the temperate epidemiological trait of R3b2. To understand the mechanisms of
R3bv2 cold tolerance, we studied global gene expression patterns of the two strains at $20^{\circ} \mathrm{C}$ and $28^{\circ} \mathrm{C}$ using genomic microarrays. In rich medium, the strains' expression profiles differed significantly with respect to both strain and temperature. In the four conditions, we found differential expression of genes involved in cell wall/membrane synthesis and function, carbohydrate transport and metabolism, transcription, replication, recombination and repair, and diverse unknown functions, including some specific to R3bv2. A hitherto cryptic quorum sensing system, SolIR, and a SolIR-dependent gene, aidA, were up-regulated in $\mathrm{R} 3 \mathrm{bv} 2$ at $20^{\circ} \mathrm{C}$. aidA, which was expressed around 12fold higher at $20^{\circ} \mathrm{C}$, is not present in the GMI 1000 genome.

Rhizoctonia solani genome project; providing insight into a link between beneficial and plant pathogenic fungi

M. A. CUBETA (1), R. A. Dean (1), E. Thomas (1), P. Bayman (2), S. Jabaji (3), S. Neate (4), P. Nolte (5), S. M. Tavantzis (6), T. Toda (7), R. Vilgalys (8), P. Ceresini (9), N. Fedorova (10), W. C. Nierman (10)

(1) Plant Pathology, North Carolina State Univ., Raleigh, NC 27695; (2) Biology, University of Puerto Rico, San Juan, PR 00931; (3) Agric. and Environ. Sciences, McGill University, Quebec H9x 3V9; (4) Plant Pathology, North Dakota State Univ., Fargo, ND 58105; (5) Idaho Center for Potato Research and Extension, University of Idaho, Idaho Falls, ID 83402; (6) Biological Sciences, University of Maine, Orono, ME 04469; (7) Bioresource Sciences, Akita Prefectural University, Akita, 010-0195, Japan; (8) Biology, Duke University, Durham, NC 27708; (9) Plant Pathology, ETH Institute of Integrative Biology LFW B28 8092 Zurich, Switzerland; (10) J. Craig Venter Institute, Rockville, MD 20850

Phytopathology 99:S166

A consortium consisting of North American and international scientists in the Rhizoctonia community is actively involved in a collaborative project to obtain a high quality complete genome sequence of the soil fungus $R$. solani anastomosis group 3 (AG-3), strain Rhs1 AP. This fungus is a competitive saprobe and an important pathogen of food crops in the plant family Solanaceae. In addition to its economic importance as a plant pathogen, the fungus and its closely related species can often form beneficial associations with early diverging land plants, lichens, and orchids. Sanger and 454 Titanium pyrosequencing methods have provided approximately $16 \mathrm{X}$ coverage of the genome with average read lengths of 709 and $383 \mathrm{bp}$, respectively. Estimates of genome size vary from 52.4 to $71.5 \mathrm{Mb}$ depending on the method of analysis. Repetitive sequences in the genome have been identified and microsatellite-based genetic markers for population genetics studies are available to the community on the website. 
Streptomyces scabies: Mapping a novel path to pathogenicity

\section{R. LORIA}

Department of Plant Pathology \& Plant-Microbe Biology, Cornell University, Ithaca, NY 14853

Phytopathology 99:S167

Streptomyces scabies is the dominant pathogenic species among the dozen or more streptomycetes that cause potato scab. Emergence of locally adapted potato scab species can now be attributed to horizontal gene transfer. The newly emerged pathogen $S$. turgidiscabies Car8 carries a $660 \mathrm{~kb}$ integrative conjugative element, encoding the thaxtomin biosynthetic pathway and other virulence loci. New genomic resources, including the genome of $S$. scabies 87-22 genome, are emerging that allow us to use comparative genomics to filter putative virulence genes from these large bacterial genomes. The picture revealed by this analysis is one of continuing evolution of pathogenicity islands in this genus, with acquisition of virulence genes found in other pathogenic bacteria and fungi, including animal pathogens. The importance of the cellulose biosynthesis inhibitor, thaxtomin, as a pathogenicity determinant has been confirmed. Thaxtomin is produced exclusively by scab-causing streptomycetes, but genome sequences reveal other virulence determinants that are shared with a diverse group of pathogens. Ongoing comparative and functional genomic analysis is providing substantial insight on the mechanisms by which these economically important and fascinating pathogens manipulate plant cells and continue to evolve in agricultural systems.
Evolutionary relationship of enteric plant pathogenic bacteria M. PILAR MARQUEZ VILLAVINCENCIO, A. Charkowski Dept. Plant Pathology, University of Wisconsin-Madison Phytopathology 99:S167

Pectobacterium is an Enterobacteriaceae plant pathogen that causes soft rot disease on diverse plant species. Pectobacterium species have wide host ranges, except for $P$. atrosepticum, which infects potato and a few other solanaceous species. We have found that the sequenced strain of $P$. atrosepticum is significantly less virulent on tubers and on the model plant, Nicotiana benthamiana than $P$. carotovorum. A comparison of genome sequences of two $P$. carotovorum subspecies and $P$. atrosepticum identified genes that could account for these differences. The $P$. carotovorum genomes were generated by 454 pyrosequencing and ordered by reference to the previously published complete circular chromosome of $P$. atrosepticum genome and each other. A tiled $P$. carotovorum microarray was designed based on the draft sequence and used to identify $P$. carotovorum genes that were highly expressed when the bacteria were grown in potato tubers. A highly expressed gene cluster present in $P$. carotovorum species, but absent from $P$. atrosepticum, was identified and we are currently testing these genes to determine if they affect virulence. We found that $P$. carotovorum, $P$. atrosepticum, and $P$. wasabiae differ in which T3SS genes are encoded and our gene expression and mutagenesis experiments suggest that the $P$. carotovorum T3SS is not important for infection of potato tubers, but is important for disease in plant leaves.

\section{Molecular Mechanisms of Host Susceptibility}

Victoria blight: A convergence of plant disease susceptibility and resistance?

T. J. Wolpert, J. M. Lorang, B. M. Gilbert, C. S. Bradford II

Department of Botany and Plant Pathology and Center for Genome Research and Biocomputing, Oregon State University, Corvallis, OR

Phytopathology 99:S167

Victoria Blight is conditioned by a single dominant gene called $V b$ in oats. Virulence of the causal agent, Cochliobolus victoriae, depends on production of the "toxin", victorin. When a victorin-producing isolate encounters a host that carries the dominant allele, disease occurs. In all other cases, such as a homozygous recessive host, disease does not occur. In oats, numerous analyses have indicted that $V b$ is identical or closely linked to the $P c 2$ gene, which confers crown rust resistance. Recently, we characterized a gene in Arabidopsis that confers both victorin sensitivity and susceptibility to $C$. victoriae. This gene, called $L O V$, encodes a CC-NB-LRR protein. We also found that LOV function requires the cytosolic thioredoxin, TRX5. Current analyses are directed at understanding the role of TRX5 and victorin in mediating LOV activity and the nature of the LOV-mediated response. Given that the primary role for CC-NB-LRR proteins is to confer disease resistance, results support the possibility that $V b$ and $P c 2$ may be the same gene and indicate that a host resistance response can be exploited by $C$. victoriae to evoke disease susceptibility.

The Biotrophic Interfacial Complex and effector translocation during rice blast disease

B. VALENT (1), C. H. Khang (1), M. C. Giraldo (1), G. Mosquera (1,4), R. Berruyer (1,5), P. Kankanala (1,6), M. Yi (1), K. Czymmek (2), S.-Y. Park $(3,7)$, S. Kang (3)

(1) Kansas State University, Manhattan, KS, USA; (2) University of Delaware, Newark, DE, USA; (3) Pennsylvania State University, University Park, PA, USA; (4) Currently: International Center for Tropical Agriculture, Cali, Colombia; (5) Currently: Université d'Angers, Angers, France; (6) Currently: Edenspace Systems Corporation, Manhattan, KS, USA, (7) Currently: Seoul National University, Seoul, Korea Phytopathology 99:S167

To cause rice blast disease, Magnaporthe oryzae sequentially invades living rice cells using specialized invasive hyphae $(\mathrm{IH})$ that are enclosed in hostderived Extra-Invasive-Hyphal Membrane (EIHM). Little is known about how the fungus delivers effector proteins across the EIHM into the plant cell's cytoplasm to promote disease, or to trigger resistance in rice varieties with corresponding resistance genes. We performed coupled live cell imaging and microarray expression analyses of IH growing in first-invaded cells. The cellular analysis suggested that IH control rice membrane dynamics for growth in invaded cells and host pit fields for movement into neighboring cells. The expression analysis identified numerous novel BiotrophyAssociated Secreted (BAS) proteins as candidate effectors. Using live-cell fluorescence imaging, we identified a novel pathogen-induced structure, the
Biotrophic Interfacial Complex (BIC), which accumulates fluorescentlylabeled, secreted effectors AVR-Pita, PWL1, and PWL2 as well as some BAS proteins. Correlative light and electron microscopy identified the BIC as a complex aggregation of membranes and vesicles at a specific location in the EIHM matrix. We have shown that secreted effectors that accumulate in BICs are translocated into invaded host cells. Surprisingly, translocated effectors were also observed in uninvaded neighboring rice cells, suggesting that the fungus sends effectors to hijack host cells before entry.

\section{Negative regulators of basal defense in cereal-fungal interactions}

R. P. Wise (1,2,3), Y. Meng (2), M. J. Moscou (2,3), G. S. Fuerst (1,2), W. Xu (2)

(1) Corn Insects and Crop Genetics Research, USDA-ARS, Iowa State University, Ames, IA; (2) Department of Plant Pathology and Center for Plant Responses to Environmental Stresses, Iowa State University, Ames, IA; (3) Bioinformatics and Computational Biology, Iowa State University, Ames, IA Phytopathology 99:S167

Plants have evolved complex regulatory mechanisms to control the defense response against microbial attack. Both temporal and spatial gene expression are tightly regulated in response to pathogen ingress, modulating both positive and negative control of defense. BLUFENSIN1 (BLN1), a small peptide belonging to a novel family of proteins in barley, wheat, and rice, is highly induced by attack from the obligate biotrophic fungus, Blumeria graminis $\mathrm{f}$. sp. hordei, causal agent of powdery mildew disease. BLN1 negatively impacts plant defense, is predicted to be secreted, and contains both structural and sequence similarities to knottins, small disulfide-rich proteins characterized by a unique disulfide through disulfide knot. To discern regulatory targets of BLN1, we conducted Barley1 GeneChip analysis of $B \ln 1$-silenced plants via Barley stripe mosaic virus-induced gene silencing (BSMV-VIGS). Sixty GeneChip hybridizations were performed, based on 5 replications of 12 BSMV-VIGS/host-pathogen interactions. Mixed linear model analysis revealed 36 highly significant new genes $(\mathrm{p}<0.0001$; FDR $<5 \%)$ that are suppressed together with Bln1 (Contig12219_at; $\mathrm{p}=2.31 \mathrm{E}-07$ ), or induced when we compare BSMV:Bln1248 silenced plants to the BSMV:00 control. These candidates appear to have a role in R-gene mediated and innate immunity networks, thus, the functional identification of their precise roles will be a key step in understanding plant defense.

How oomycete effectors condition susceptibility to Phytophthora sojae B. M. Tyler (1), S. D. Kale (1), D. Dou (1,2), D. Capelluto (1), W. Qunqing (2), H. Changzhi (2), S. Li (3), B. Gu (1,4), R. Anderson (1), A. Ferreira (1), S. Tripathy (1), F. Arredondo (1), R. Hanlon (1), H. Brar (3), S. Grosic (3), W. Xiaoli (2), Y. Xiaoli (2), L. Tiuli (2), Y. Yao (2), W. Xinle (2)

(1) Virginia Polytechnic Institute and State University; (2) Nanjing Agricultural University, China; (3) Iowa State University; (4) Northwest Agricultural and Forestry University, China

Phytopathology 99:S167

Oomycete pathogens cause billions of dollars of damage to crops each year. The potato pathogen Phytophthora infestans and the soybean pathogen 
Phytophthora sojae are among the most destructive oomycete pathogens. Genome sequencing of these and other oomycete pathogens has revealed large numbers of candidate effector genes, encoding proteins with the host cell entry motif RXLR. We have shown that oomycete RXLR motif binds to the phospholipids phosphatidyl inositol-4-phosphate and phosphatidyl-3phosphate and that binding to these phosphoinositides enables the proteins to pass the plant plasma membrane into the cytoplasm. Effectors from fungal and apicomplexan pathogens also use this mechanism, which also allows entry into animal cells. Once effectors enter the plant cell they target the plant's defense response machinery. We have shown that the $P$. sojae effectors Avrlb and Avrlk can suppress effector ( $\mathrm{R}$ gene)-mediated immunity via a site in the nucleus. The binding of Avr1b to a soybean $U$ box protein may mediate suppression of effector-triggered immunity. Avrlb and Avrlk can also suppress immunity triggered by the PAMP elicitin, but the target for this action is located outside the cytoplasm. The $P$. sojae genome encodes around 400 effector candidates, and we have screened approximately half of these for the ability to suppress host defenses. Nearly all of those tested can suppress either effector- or PAMP-triggered immunity, and most can suppress both. The timing of expression of many effectors is staged so that those that suppress effector-triggered immunity are expressed earliest in order to prevent host defense responses to later effectors that suppress PAMP-triggered immunity.

Mechanisms of bacterial speck disease development in tomato: Functional role of a ubiquitin ligase and the chloroplast targeting virulence factor, coronatine

S. RAO UPPALAPATI (1), Y. Ishiga (1), T. Wangdi (2), C.-M. Ryu (1), K. S. Mysore (1), C. L. Bender (2)

(1) Plant Biology Division, The Samuel Roberts Noble Foundation, Ardmore, OK, USA; (2) Department of Entomology and Plant Pathology, Oklahoma State University, Stillwater, OK, USA

Phytopathology 99:S168

Bacterial speck disease, which is caused by Pseudomonas syringae pv. tomato, is an economically important disease on tomato. Several pathovars of $P$. syringae produce a chlorosis-inducing virulence factor coronatine $(\mathrm{COR})$, which functions as a phytohormone mimic of methyl jasmonate (MeJA) and JA-isoleucine (JA-Ile). A comparison of COR- and MeJA-regulated transcriptomes revealed that COR and MeJA share similar, but not identical activities and impact multiple phytohormone pathways in tomato. COR, by structurally mimicking JA-Ile, hijacks an ubiquitin E3 ligase of the SCFcoi1/jail complex to activate JA signaling and thereby suppress salicylic acid (SA)-mediated defense responses. Our results also demonstrate a role for COR-induced effects on photosynthetic machinery and ROS in modulating necrotic cell death. To identify new players in COR-induced chlorosis, we utilized Nicotiana benthamiana and virus-induced gene silencing (VIGS) as a genetic screen and identified a role for several chloroplast-localized genes and sgt1 (suppressor of G2 allele of Skp1) in COR signaling. Collectively, the results of virulence assays, metabolic profiling, gene expression data and VIGS-based genetic screens indicate that COR targets the JA pathway to suppress SA-mediated defense responses and the chloroplast to modulate ROS homeostasis, thus promoting symptom development in tomato.

Breakdown of basal resistance in Nicotiana benthamiana and Arabidopsis against host and nonhost pathogens

K. S. MYSORE, K. WANG, S.-K. MUTHAPPA, C.-M. RYU, L. KANG

Samuel Roberts Noble Research Foundation, Ardmore, OK 73401

Phytopathology 99:S168

Plant nonhost resistance, a form of innate immunity, is the most common form of disease resistance exhibited by plants against the majority of potential pathogens in nature. We used virus-induced gene silencing in Nicotiana benthamiana to identify genes involved in nonhost resistance. Eleven genes were identified to be involved in type I and/or type II nonhost resistances by individually silencing $\sim 4,000$ genes from a normalized NbcDNA library. One of them encodes squalene synthase ( $S Q S)$, a key enzyme catalyzing the first enzymatic step in sterol biosynthesis. Silencing $S Q S$ gene in $N$. benthamiana caused plant cell membrane leakage resulting in more nutrient accumulation in the apoplast. The Arabidopsis SQS1 RNAi lines were not only susceptible to nonhost pathogens, Pseudomonas syringae pv. tabaci and P. syringae pv. syringae, but also more susceptible to virulent pathogens, $P$. syringae $\mathrm{pv}$. tomato DC3000 and P. syringae pv. maculicola, when compared with the wild-type Arabidopsis. We also discovered that a mutation in Arabidopsis $S M T 2$, a gene encoding sterol methyltransferase (downstream enzyme in phytosterol biosynthesis), compromised nonhost resistance. Metabolite analysis indicated that, compared to the wild-type Arabidopsis, SQS RNAi lines and a smt 2 mutant produced less stigmasterol. Strikingly, the gene AtCYP710A1 converting sitosterol to stigmasterol was dramatically induced and stigmasterol was significantly increased in wild-type plants upon inoculation with nonhost pathogens. Arabidopsis cyp710a1 mutant and overexpressors of AtCYP710A1 are currently being characterized and the results will be presented. Our data suggest that cell membrane components especially membrane associated stigmasterol plays an important role in plant innate immunity against bacterial infections.

\section{The Balance is Tilting, Finding Resistance to Vascular Wilting}

Breeding for resistance - new approaches and challenges

R. J. HAYES (1), G. E. Vallad (2), L. K. McHale (3), M.-J. Truco (3), O. E. Ochoa (3), R. W. Michelmore (3), S. J. Klosterman (1), K. Maruthachalam (4), K. V. Subbarao (4)

(1) United States Department of Agriculture, Agricultural Research Service, Crop Improvement and Protection Unit, Salinas, CA 93905; (2) University of Florida, Gulf Coast Research and Education Center, Wimauma, FL 33598; (3) University of California, The Genome Center and Department of Plant Sciences, Davis, CA 95616; (4) University of California, Department of Plant Pathology, Salinas, CA 93905

Phytopathology 99:S168

Breeding resistance to soil-borne wilt diseases is challenging due to cumbersome testing methods and limited genetic variation for resistance. Verticillium wilt of lettuce caused by Verticillium dahliae can cause severe economic damage and threatens the existence of lettuce production in California; resistance is the only feasible control measure. Initial field trials identified resistance, however a decade of field selection developed resistant but commercially unusable germplasm. Research was conducted to accelerate breeding and meet the urgent need for resistant cultivars. Pathogen surveys and greenhouse assay development lead to the discovery of two races, and later demonstrated that known field-resistant cultivars were only resistant to race 1 (R1). A single gene for R1 resistance in the cultivar La Brillante was described and positioned on chromosome 5, and marker assisted breeding should produce R1 resistant cultivars within six years. Race 2 (R2) isolates are located in California, and may render R1 resistance obsolete. Screening germplasm for R2 resistance identified accessions with either reduced symptoms or disease incidence, but not complete resistance. Further, all tested germplasm can be colonized, even if a-symptomatic. A quantitative PCR assay for Verticllium in planta was developed to assess the usefulness of the reduced symptom phenotype for breeding, and populations are being created for genetic analysis and screening for transgressive segregants.
Molecular mechanisms of resistance - functions of major $\mathbf{R}$ genes D. Halterman USDA/ARS, Madison, WI

Phytopathology 99:S168

Vascular wilt pathogens have evolved a diverse arsenal of toxic proteins and compounds, termed effectors, designed to promote pathogenesis and facilitate suppression of basal host defenses. However, as is the case with most phytopathogens, certain plant hosts have developed a corresponding set of resistance $(R)$ genes that encode receptors capable activating strong defenses upon recognition of specific pathogen effectors. Research efforts over the past 20 years have resulted in the identification and cloning of $R$ genes for a wide variety of pathogens from many plant hosts. The identification of $R$ genes and their incorporation into cultivated crops becomes particularly important when dealing with pathogens such as vascular wilts, where chemical control options are typically very limited. This presentation will include an overview of genes conferring resistance to vascular wilt pathogens and an update on research results related to mechanisms of pathogen recognition and resistance activation.

Secondary metabolites and toxins - what is causing disease symptoms? A. A. Bell, J. Liu, R. D. STIPANOVIC

USDA/ARS, College Station, TX

Phytopathology 99:S168

Fusarium species produce a variety of phytotoxic metabolites. Of the races of Fusarium oxysporum f. sp. vasinfectum (Fov) that attack cotton, alfalfa, and okra, many secondary metabolites are derived via a polyketide biosynthetic pathway. The recent discovery of new pathotypes not previously found in the U.S. is of particular concern to the cotton industry. In addition, a virulent Fov biotype has been identified in Australia that can cause $>60 \%$ plant mortality. In 2002/2003, several shiploads of fumigated/live cottonseed were imported into the U.S. from Australia as feed for dairy cow. We isolated 17 Fov isolates from about 17,000 of these seeds. The most virulent belonged to race 3 based on molecular phylogenetic analysis and it was vegetatively compatible with the Australian biotype. Indel analysis of the EF gene also revealed a close relationship to the Australian biotype. While the Australian biotype has not 
been found in U.S. fields, a newly discovered Fov race 4 is of increasing concern due to losses of Pima cotton in California. Race 4 and the Australian biotypes both attack cotton seedlings, and produce prodigious quantities of fusaric acid (FA) when grown on Czapek media. We confirmed that FA is derived in part via a polyketide synthase (PKS). We are searching for the corresponding PKS genes, and investigating the role of FA in the pathogenicity of these Fov isolates. Results from these studies and generation of FA knockout mutants will be presented.

\section{Molecular interactions between Fusarium oxysporum and Arabidopsis A. Diener \\ UCLA, Los Angeles, CA \\ Phytopathology 99:S169}

Fusarium wilt of Arabidopsis is a model pathosystem for studying vascular disease. Three distinct formae speciales of Fusarium oxysporum from crucifer hosts, cabbage (f. sp. conglutinans), radish (f. sp. raphani) and stock (f. sp. matthioli), instigate disease symptoms in Arabidopsis that are indistinguishable from those observed in the natural host of each. Among Arabidopsis ecotypes, considerable variation in susceptibility is observed. We are identifying the genes and gene interactions responsible for the quantitative variation of resistance. We are also studying the enhanced resistance or susceptibility of Arabidopsis mutants, which implicates well-characterized plant processes as well as poorly characterized plant genes in disease progression. Our ability to study Fusarium genes in vascular disease has improved considerably as genetic transformation of $F$. oxysporum has become routine and because full Fusarium genome sequence is now available.
Molecular responses to quantitative bacterial wilt resistance in tomato A. Milling

University of Wisconsin, Madison, WI

Phytopathology 99:S169

Host resistance is the only practical control for bacterial wilt of tomato, caused by Ralstonia solanacearum, but wilt resistance is horizontal, polygenic and its basis is not understood. We found that tomato plants infected with $R$. solanacearum Race 3 biovar 2 strain UW551 upregulated genes in both the ethylene and salicylic acid signal transduction pathways. However, in response to $R$. solanacearum infection the horizontally wilt-resistant tomato line H7996 activated expression of these defense genes faster and to a greater degree than did susceptible cultivar Bonny Best. Interestingly, results suggest different roles for the virulence factor extracellular polysaccharide (EPS) in resistant and susceptible hosts. Wild-type UW551 induced a lower defense response in susceptible tomato than did an eps mutant, supporting the idea that EPS can shield $R$. solanacearum from recognition. In contrast, the eps mutant induced significantly lower defense responses in resistant H7996 than the wild-type strain, weakening the "cloaking" hypothesis. The eps mutant also induced noticeably less accumulation of the defensive reactive oxygen species hydrogen peroxide in resistant tomato leaves, despite attaining similar cell densities in planta. Further, cell-free purified EPS from UW551 triggered significant defense gene expression in resistant but not in susceptible tomato plants. Collectively, these data suggest that H7996 specifically recognizes EPS from $R$. solanacearum.

\section{Plant Disease Management}

\section{Carboxylic Acid Amide Fungicides (CAA) FRAC Group 40}

Molecular and genetic aspects of CAA mode of action and resistance U. GISI, M. Blum, F. Moulin, R. Fonné, H. Sierotzki

Syngenta Crop Protection, Research Biology, CH-4332 Stein, Switzerland Phytopathology 99:S169

Carboxylic acid amide (CAA) fungicides comprising the commercial compounds dimethomorph, flumorph, iprovalicarb, benthiavalicarb and mandipropamid are specifically active against pathogens of the oomycetes such as Phytophthora, Plasmopara, Pseudoperonospora and Bremia species but not against Pythium species. The biochemical mode of action was claimed to involve inhibition of membrane or cell wall biosynthesis. Resistance to CAAs was detected in field populations of $P$. viticola in Europe and $P$. cubensis in USA and some Asian countries but not in P. infestans and B. lactucae. In crosses of sensitive and CAA resistant isolates of $P$. viticola, all F1 progeny isolates were sensitive; after crossing F1 isolates, CAA resistance segregated with an average $r: s$ ratio of $1: 9$ suggesting a recessive inheritance pattern of resistance involving genes with one or both loci being heterozygous. Resistance co-segregated for all CAA fungicides but not for mefenoxam. Sequencing the four known genes involved in cellulose biosynthesis revealed mutations in cesA 3 of CAA resistant isolates suggesting that the mechanism of resistance is linked to cellulose biosynthesis which probably represents also the site of CAA action. Based on field observations, the molecular and genetic results and the different biology of the pathogens, resistance risk to CAA fungicides is estimated as low for $P$. infestans and moderate for $P$. viticola.

\section{Activity of CAA fungicides against Phytophthora infestans and Bremia lactucae}

Y. COHEN (1), A. Rubin (1), U. Gisi (2), H. Sierotzki (2), D. Hermann (2)

(1) Faculty of Life Sciences, Bar-Ilan University, Israel; (2) Syngenta Crop Protection, Stein, Switzerland

Phytopathology 99:S169

The CAA fungicides, mandipropamid (MPD), dimethomorph (DMM), benthiavalicarb (BENT) and iprovalicarb (IPRO) are effective inhibitors of spore germination of Phytophthora infestans and Bremia lactucae and hence, of infection. MPD had the highest intrinsic activity against spore germination and IPRO the lowest. Cystospores of P. infestans exposed to CAAs showed extensive internal deterioration within $1 \mathrm{~h}$. CAA did not hamper F-actin rearrangement in germinating spores of B. lactucae. Spores that were exposed to CAAs for $1 \mathrm{~h}$ and then washed with water retained their germination and infectivity. Curative application at 1 day post inoculation required higher concentrations of CAAs to prevent infection. Trans-laminar protection, although achieved with higher doses, was more effective with MPD than with the other CAAs. Natural resistance against CAAs occurs in Plasmopara viticola and Pseudoperonospora cubensis but not in $P$. infestans or $B$. lactucae. We were able to mutate sporangia of $P$. infestans for resistance against the phenylamide fungicide mefenoxam but failed to select mutants with stable resistance against CAAs. B. lactucae was mutated for resistance against CAAs but stability of resistance and pathogenic fitness of the mutants are yet unknown. In a mini-epidemic conducted in a closed plastic house, two mutant isolates survived for three months on CAA treated lettuce plants. Their persistence on untreated plants is yet unknown.

Mandipropamid and dimethomorph baseline sensitivity distribution and resistance monitoring

G. OLAYA (1), U. Gisi (2), H. Sierotzki (2), A. Tally (3)

(1) Syngenta Crop Protection, Vero Beach, FL; (2) Syngenta Crop Protection, Stein, Switzerland; (3) Syngenta Crop Protection, Greensboro, NC

Phytopathology 99:S169

The baseline sensitivities to the carboxylic acid amide (CAA) fungicides (Group 40) mandipropamid and dimethomorph of some Phytophthora and downy mildew species have been established. The mycelia sensitivity $\left(\mathrm{ED}_{50}\right.$ values) to mandipropamid of 75 isolates of $P$. capsici ranged from 0.0056 to $0.0265 \mathrm{mg} / \mathrm{L}$ with a mean of $0.014 \mathrm{mg} / \mathrm{L}$. The mycelia sensitivity of 40 isolates to dimethomorph ranged from 0.068 to $0.333 \mathrm{mg} / \mathrm{L}$ with a mean of $0.226 \mathrm{mg} / \mathrm{L}$. The sensitivity to mandipropamid for the control of late blight on detached leaves of 122 isolates of Phytophthora infestans ranged from 0.025 to $2.98 \mathrm{mg} / \mathrm{L}$. The mandipropamid sensitivity of 15 isolates of Bremia lactucae tested on lettuce seedlings ranged from 0.001 to $0.01 \mathrm{mg} / \mathrm{L}$ with a mean of $0.003 \mathrm{mg} / \mathrm{L}$. Sensitivity monitoring for the early detection of resistant isolates is in place for several CAA target pathogens. At this time no CAA resistant $P$. infestans isolates have been detected in the USA or Europe. However, resistant isolates of Pseudoperonospora cubensis were detected in the USA in 2007. Resistant isolates of Plasmopora viticola have been detected in Europe for several years but no practical product failures have been reported when CAAs were used in mixture with contact fungicides. The fungicide resistance action committee (FRAC) has classified the CAA risk for resistance development as low for $P$. infestans and moderate for $P$. viticola and $P$. cubensis. CAA sensitivity monitoring helps with the early detection of resistance and its proper management.

Biological effect of some carboxylic acid amide fungicides on growth and sporulation of three species of Phytophthora and the diseases they cause

M. MATHERON, M. Porchas

University of Arizona, Yuma, AZ

Phytopathology 99:S169

The effect of dimethomorph, a carboxylic acid amide (CAA) fungicide, was evaluated on the growth, sporangium formation, and germination of encysted zoospores of Phytophthora capsici, P. citrophthora and P. nicotianae. Of these parameters, mycelial growth was most sensitive to the fungicide, with a $50 \%$ reduction in mycelial growth $\left(\mathrm{EC}_{50}\right)$ for the three pathogens being 
achieved with concentrations in the range of $<0.1$ to $0.38 \mu \mathrm{g} / \mathrm{ml}$. The $\mathrm{EC}_{50}$ value for sporangium formation for the three Phytophthora spp. was $<1.0$ $\mu \mathrm{g} / \mathrm{ml}$. Suppression of encysted zoospore germination required somewhat higher concentrations of dimethomorph, with $\mathrm{EC}_{50}$ values for $P$. capsici, $P$. citrophthora and $P$. nicotianae of $3.9,3.3$ and $7.2 \mu \mathrm{g} / \mathrm{ml}$, respectively. Following application of dimethomorph to the outer bark surface of tangelo trees, inhibition of lesion development after placement of $P$. citrophthora or $P$. nicotianae mycelium on the bark cambium 30,60 and 90 days after fungicide application was 60, 46 and $42 \%$, respectively for $P$. citrophthora and 74, 59 and $41 \%$, respectively for $P$. nicotianae, compared to nontreated bark. In greenhouse trials highly favorable to disease development using soil naturally infested with $P$. capsici and treated with dimethomorph or another CAA fungicide mandipropamid, bell pepper plant mortality after 2 months was 42 and $48 \%$ respectively, values significantly lower than the $72 \%$ plant mortality in nontreated soil.

Dimethomorph efficacy studies and resistance management

W. KIRK (1), J. Stein $(1,2)$

(1) Michigan State University, East Lansing, MI; (2) South Dakota State University, Brookings, SD

Phytopathology 99:S170
Key application timings of fungicides (including dimethomorph) to limit further infection of potato foliage by Phytophthora infestans were determined. Programs initiated $72 \mathrm{~h}$ before and after inoculation with $P$. infestans delayed development of late blight but later timings were similar to the untreated control. When dimethomorph was tank-mixed with protectant fungicides and integrated into a chlorothalonil-based late blight control program, all programs were effective. The sensitivities of 11 isolates of $P$. infestans to dimethomorph at all stages of the asexual life cycle were examined on potato leaf disks. Zoospore encystment and cystospore germination were highly sensitive to dimethomorph. The degree of dimethomorph sensitivity in all stages of the asexual life cycle was positively and significantly correlated, except cystospore germination. Dimethomorph insensitive mutant strains of $P$. infestans were made using ethidium bromide/ultra-violet light. Mutagenesis created two strains of $P$. infestans with resistance factors $>20$, i.e. the ratio of the $\mathrm{EC}_{50}$ of the mutant strain to that of the wild-type. Regardless of the induction treatment, reduced fitness was common for all Phytophthora spp., indicating a biological cost associated with dimethomorph insensitivity. Based on these results, the development of field resistance to dimethomorph of $P$. infestans and other species is unlikely with the currently employed dimethomorph resistance management schemes.

\section{Challenges for Managing Insect Vectored Diseases}

Changes in the epidemiology of Pierce's disease in California due to the introduction of the glassy-winged sharpshooter

M. Sisterson

USDA-ARS, Parlier, CA

Phytopathology 99:S170

Pierce's disease is caused by the xylem limited bacterial pathogen, Xylella fastidiosa. This pathogen is vectored by xylem feeding insects and has been present in California for more than 100 years. Within California there are three management regions that have different key vectors: the North Coast, the Central Valley, and Southern California. On the North Coast the key vector is the native blue-green sharpshooter (Graphocephala atropunctata). In the Central Valley, there are two native vectors and one exotic vector. The two native vectors are the green sharpshooter (Draeculacephala minerva) and the red-headed sharpshooter (Xyphon fulgida). Both are widely distributed in the Central Valley. In contrast, distribution of the exotic glassy-winged sharpshooter (Homalodisca vitripennis) is limited to southern portions of the Central Valley and throughout Southern California where it is the sole key vector. Two epidemics of Pierce's disease occurred approximately 10 years after introduction of the glassy-winged sharpshooter into California. The first occurred in Southern California and was followed by an epidemic in the southern portion of the Central Valley. These epidemics resulted in losses typically not observed with native vectors. Factors hypothesized to contribute to these losses were aspects of glassywinged sharpshooter ecology, the cropping landscape in Southern California, climate, and the absence of a management program for a newly introduced vector.

\section{Expansion of Xylella fastidiosa into blueberries in Georgia and Florida P. Brannen, C. J. Chang \\ University of Georgia \\ Phytopathology 99:S170}

Koch's postulates were applied in 2006 to confirm Xylella fastidiosa as the cause of bacterial leaf scorch (BLS) of blueberry, predominantly a problem on southern highbush cultivars (Vaccinium corymbosum interspecific hybrids). Symptoms include a marginal leaf scorch, leaf drop, yellowing of stems, and eventual plant mortality. In 2008, a survey was initiated to determine the prevalence of BLS in Georgia, as well as whether field resistance is present among some $V$. corymbosum cultivars. In Aug, Sep, and Oct, BLS was identified in the field based on symptoms. Samples were taken for confirmation by ELISA, and an estimate of disease incidence was collected for each site. Of 45 farms surveyed, $71.1 \%$ were positive for BLS in at least one field; of 167 fields surveyed, $41.9 \%$ were positive. Field resistance or tolerance was observed among some cultivars, and initial results indicate that Windsor, Emerald, Millennia, Southern Belle, and V5 either had no or minimal BLS symptoms ( $<1 \%$ incidence). In contrast, Star, O'Neal, and particularly FL 86-19 had a high incidence of infection and therefore appear susceptible. Based on regression analysis relating disease incidence to plant age, $75 \%$ of FL86-19 plants will be symptomatic within 10 years of planting, whereas $\sim 30 \%$ of Star plants will be diseased within the same time frame. These data provide good evidence that the solution to bacterial leaf scorch will involve resistance breeding and selection.

Transmission and management of Cucurbit yellow vine, caused by the bacterial pathogen Serratia marcescens

A. Wayadande

Oklahoma State University

Phytopathology 99:S170

Cucurbit yellow vine disease (CYVD), caused by the phloem-inhabiting bacterium, Serratia marcescens, is a periodic threat to watermelon, squash, and pumpkin production throughout parts of the United States. Squash bugs, Anasa tristis (Hemiptera: Coreidae), are the only known primary field vectors, transmitting the bacterium with a range of $5-25 \%$ efficiency for single inoculative insects. The mode of transmission is likely propagative as nymphs retain the ability to transmit after molting to the adult stage. Feeding behavior studies using electrical penetration graph (EPG) technology show that the squash bug displays different feeding profiles on squash as compared to watermelon, but most probing activity occurs with stylets in contact with the xylem. Thus far, a specific phloem-ingestion EPG waveform has not been identified, a result consistent with a hypothesis that bacteria may be deposited in plant tissue other than phloem. Comparisons of squash bug EPG parameters on potentially resistant germplasm suggest that differences in probing activity are quantitative and not qualitative. Control of CYVD in watermelon is best achieved by controlling the vector squash bug population early in the season either by timed insecticide treatments or by the use of squash trap crops.

\section{Management of Curly top virus in vegetables \\ R. Creamer \\ New Mexico State University \\ Phytopathology 99:S170}

Curtovirus infection is due to a complex of related viruses ie. Beet curly top virus, Beet mild curly top virus, Beet severe curly top virus, that are vectored by the beet leafhopper (Circulifer tenellus). The viruses and leafhopper have very large ranges of dicot hosts and are endemic throughout much of the western USA. Disease losses are routinely reported from vegetables such as tomatoes, peppers, melons, and beans, in addition to losses in sugarbeets. In New Mexico, curly top causes substantial, but unpredictable, losses to chile peppers. Management of curly top in vegetables has traditionally included cultural and insecticide sprays. However, the inability to spray insecticides for leafhopper control for the last few years in some areas has limited control to plant resistance and cultural methods. In New Mexico, a system for predicting the magnitude and timing of curly top infection based on environmental factors is being developed from research results on the primary overwintering weed host of the virus and leafhopper populations and this has allowed growers to plan for disease. Cultural methods such as weed control and kaolin sprays have also been used successfully for disease control in peppers. Characterization of plant resistance in several vegetables will provide additional sustainable management strategies. An integrated approach to control of the insect vector is the basis for curly top disease management in vegetables. 
Managing whitefly vectors of three cucurbit viruses new to Florida

S. Webb, P. D. Roberts, P. A. Stansly, S. Adkins, W. W. Turecheck, C. S. Kousik

University of Florida

Phytopathology 99:S171

In recent years, three whitefly-transmitted viruses have become a serious problem for growers of cucurbits, especially watermelon, in Florida. Squash vein yellowing virus, an ipomovirus transmitted in a semi-persistent manner, was identified in 2005 as the causal agent of watermelon vine decline (WVD), a particularly devastating disease. Since 2007, Cucurbit leaf crumple virus, a begomovirus, and Cucurbit yellow stunting disorder virus, a crinivirus, have also been identified in cucurbits in southwest Florida. Until resistant varieties are developed, the best option for managing these viruses is more intensive management of the whitefly vector, Bemisia tabaci, biotype B. Multiple tactics are being explored because of the very real concern about development of insecticide resistance. In one study, the use of reflective mulch and a soil application of a neonicotinoid insecticide combined with foliar applications of spiromesifen reduced fruit symptoms of WVD. Evaluations of many other insecticides showed reductions in disease severity in research plots, although final disease incidence was not affected. Current efforts focus on integration and further development of management strategies and development of virus and whitefly monitoring tools. Area-wide surveys will identify "hot spots" and reservoir crops for whiteflies and viruses and will help evaluate effects of current and future control strategies on virus incidence in commercial fields.

\section{Cucurbit Downy Mildew: Re-Emergence of a Historical Disease}

The history and re-emergence of cucurbit downy mildew

G. HOLMES (1), C. Thomas (2)

(1) Valent USA Corporation, Cary, NC; (2) USDA ARS (retired), Charleston, $\mathrm{SC}$

Phytopathology 99:S171

Cucurbit downy mildew (DM), caused by Pseudoperonospora cubensis, was first described in 1868 in Cuba. It is among the most well-known downy mildew diseases in the world, attacking cucurbits wherever they are grown, especially in humid climates. It is also one of the most notorious pathogens for developing resistance to fungicides. Several research programs in Israel, the U.S.A., Japan, India and the Czech Republic have contributed to an extensive knowledge-base currently in place. Breeding efforts in cucumber in the 1950s and 60 s led to the development of resistance levels sufficient to control the disease without the use of fungicides. Although this resistance was not as effective in other parts of the world, the U.S. enjoyed approximately 35 years of effective control against the disease. This changed in 2004 when the cucumber crops from North Carolina to New Jersey and beyond were destroyed by DM. The disease is now a major problem on cucurbits throughout much of the eastern half of the U.S., especially on cucumber. This led to the re-establishment of cucumber breeding efforts for DM resistance as well as research programs in pathogen biology and epidemiology. These programs are approaching an old problem using new tools.

Chemical control of cucurbit downy mildew: A summary of field experiments in the U.S.

G. HOLMES (1), P. Ojiambo (2)

(1) Valent USA Corporation, Cary, NC; (2) North Carolina State University, Raleigh, NC

Phytopathology 99:S171

Cucurbit downy mildew (DM), caused by Pseudoperonospora cubensis, is controlled mainly through the use of host plant resistance and the application of fungicides. Currently, host plant resistance must be accompanied by fungicide application in order to achieve adequate levels of disease control. Each year fungicide performance against DM is evaluated under field conditions in several locations throughout the eastern half of the U.S., where the disease is most common. These experiments are generally funded by the agricultural chemicals industry and performed by extension specialists at landgrant universities. A portion of these field evaluations are published as Fungicide and Nematicide Tests (known as Plant Disease Management Reports since 2006). For example, from 1999 to 2007, 121 reports on DM were published from 17 states in the U.S. on 8 cucurbit hosts, $34 \%$ of which used cucumber as the host crop. A total of 1440 treatments (mean $=12$ treatments/experiment) were evaluated. These reports are representative of the collective experience of industry and academia on chemical disease control, yet there is little attempt to systematically summarize the information they contain to gain a broad view of fungicide performance. Although fungicide performance may vary by location, year and host there is great value in summarizing performance from many experiments. Meta-analysis will be discussed as a tool for this purpose.

\section{Fungicide resistance in cucurbit downy mildew}

G. OLAYA (1), P. Kuhn (1), A. Hert (1), G. Holmes (2), S. Colucci (3)

(1) Syngenta Crop Protection, Vero Beach, FL; (2) Valent USA Corporation, Cary, NC; (3) North Carolina State University, Hendersonville, NC Phytopathology 99:S171

Since 2004 downy mildew caused by Pseudoperonospora cubensis has become an increasing problem in the production of several cucurbit crops in the United States. The development of resistance to various site-specific fungicide classes has limited the diversity of fungicides available for control of $P$. cubensis. Resistance to the phenylamide class of fungicides (e.g., metalaxyl and mefenoxam) was first reported in Israel in 1980 and in the USA was observed in 1987 in Florida. Phenylamide sensitivity surveys conducted in the USA over the past 3 years have shown that resistant populations have become widespread across the main cucurbit production areas. Resistance has also been reported in $P$. cubensis to QoI (quinone outside inhibitors) fungicides, first in Europe, then in Japan and then in the USA. Recent resistance monitoring surveys in the USA on the QoI fungicides azoxystrobin and pyraclostrobin have shown a high frequency of resistant isolates. In 2007, isolates of $P$. cubensis resistant to the CAA (carboxylic acid amides) fungicides dimethomorph and mandipropamid were detected in the USA. To date, resistance has not been reported to other fungicides with different modes of action currently used to control downy mildew such as zoxamide, fluopicolide, cyazofamid, propamocarb and cymoxanil. The resistance risk for zoxamide, propamocarb and cymoxanil is considered low to medium, for cyazofamid medium to high and for fluopicolide is unknown.

Forecasting long distance movement of Pseudoperonospora cubensis and the Cucurbit ipmPIPE

P. OJIAMBO (1), L. Kanetis (1), G. Holmes (2)

(1) North Carolina State University, Raleigh, NC; (2) Valent USA Corporation, Cary, NC

Phytopathology 99:S171

The dynamics of cucurbit downy mildew, caused by Pseudoperonospora cubensis, were analyzed in 22 states in the eastern U.S. in 2008 based on disease reports collected as part of the Cucurbit ipmPIPE downy mildew surveillance program. Independent experiments were also conducted in the summer at Raleigh, NC, to quantify the effects of exposure to solar irradiance on the survival of $P$. cubensis sporangia. The rate of temporal disease progress averaged 1.1 new cases per day and was higher in sentinel plots than in nonsentinel cucurbit plots. Disease cases occurred sporadically before the start of June but increased rapidly thereafter. The median nearest-neighbor distance of spread was about $110 \mathrm{~km}$, with $14 \%$ and $20 \%$ of the distances being below $40 \mathrm{~km}$ and $210 \mathrm{~km}$, respectively. The average rate of disease spread on cucumber was about $7.5 \mathrm{~km}$ per day. A linear model, provided a significant $\left(\mathrm{R}^{2}=72.1 \%, P<0.0001\right)$ quantitative description of the effect of solar irradiance dose on the percentage of $P$. cubensis sporangia that germinated. Based on this linear function, a solar and UV dose of $23.5 \mathrm{MJ} / \mathrm{m}^{2}$ and 1.2 $\mathrm{MJ} / \mathrm{m}^{2}$, respectively, will completely inhibit sporangia germination and this dose can be accumulated in as few as 10 to $11 \mathrm{~h}$ of exposure. The linear function of sporangia survival and exposure to solar radiation will be incorporated into an aerobiological model to provide cucurbit growers in the U.S. and Canada with more accurate downy mildew forecasts.

Genetic and pathogenic relatedness of Pseudoperonospora cubensis and $P$. humuli: Implications for detection and management

D. H. GENT (1), M. N. Mitchell (2), G. J. Holmes (3)

(1) USDA-ARS, Dept. Botany and Plant Path., Oregon State Univ., Corvallis, OR 97330; (2) Dept. Botany and Plant Path., Oregon State Univ., Corvallis, OR 97330; (3) Valent USA Corporation, Apex, NC 27502

Phytopathology 99:S171

A stable nomenclature for plant pathogens is critical for pathogen identification, development of disease management tactics, and plant quarantine issues. Downy mildew pathogens typically display low morphological complexity and species concepts increasingly rely on inferences of reproductive isolation based on molecular evidence. However, a stable nomenclature for many downy mildew pathogens remains elusive. Recent efforts to clarify phylogenetic and systematic relationships between Pseudoperonospora cubensis and $P$. humuli based on sequence data of the internal transcribed spacer (ITS) region of the ribosomal DNA and morphological characteristics have 
suggested these pathogens are synonymous. Extensive sequencing of the ITS, cytochrome oxidase cluster, beta-tubulin, and NADH gene regions provided higher resolution of the genetic relatedness of these pathogens, and revealed conserved polymorphisms among the 30 isolates tested that reliably differentiate $P$. cubensis and P. humuli, as confirmed by phylogenetic analyses. Host range studies conducted on universally susceptible cucurbit hosts and hop cultivars also demonstrated that these organisms have distinct pathogenic capabilities. Together, these data suggest that biologically relevant characteristics of these pathogens integral for detection and management of downy mildew on hop and cucurbit hosts may be obfuscated by reducing $P$. humuli to the status of a taxonomic synonym of $P$. cubensis.

Epidemiology of downy mildew: A regional and molecular approach B. DAY, M. Hausbeck

Michigan State University, East Lansing, MI

Phytopathology 99:S172

The occurrence of a downy mildew, incited by Pseudoperonospora cubensis, in Michigan represents a significant threat for cucurbit growers in general and cucumber growers in particular, as well as pickle processers and allied industries. To address the immediate short-term needs of the industry, a statewide disease warning system for downy mildew has been established. During the growing season, the atmospheric sporangia concentrations in five Michigan counties are monitored and results posted on a webpage. Growers use this information in conjunction with weather conditions and confirmed disease outbreaks in neighboring regions as a guide for applying fungicides. Fungicide efficacy trials have been conducted in collaboration with cooperators. To develop a successful, sustainable long-term management strategy, molecular characterization of the pathogen is necessary. Using genome sequencing and bioinformatic approaches, we have identified a suite of effector proteins from P. cubensis, and have characterized these based on in planta localization, putative function, and in part, contribution to overall pathogen virulence. In total, our analysis has focused on determining the role of RxLR and QxLR effectors from P. cubensis. In short, our data suggests an evolutionary divergence, as well as a possible functional divergence, when compared to effectors from other downy mildews. Functional characterization of RxLR and QxLR effectors will be discussed.

\section{Finding an Exotic Pest-What Do I Do Now?}

\section{A national perspective of the detection of and response to exotic pests} O. El-Lissy or R. Bulluck

USDA APHIS PPQ

Phytopathology 99:S172

APHIS Plant Protection and Quarantine (PPQ) works with Federal agencies, State, tribal and local governments, industries, and stakeholders to implement coordinated actions designed to contain, control, or eradicate invasive plant pests newly introduced into the United States. In addition to biological and ecological considerations, PPQ and cooperators evaluate several other key factors, including environmental, economic, and international trade implications, in selecting the most appropriate response strategies. This presentation summarizes the framework currently being used in response to invasive pest outbreaks in the United States.

\section{The role of the Technical Working Group in new pest detections \\ R. Bulluck, P. Berger \\ USDA APHIS PPQ CPHST \\ Phytopathology 99:S172}

The USDA Animal Plant Health Inspection Service Plant Protection and Quarantine (PPQ) is authorized to respond to plant health emergencies. The Center for Plant Health Science and Technology (CPHST) provides scientific support to PPQ for these plant health emergencies. One of the roles of CPHST is to provide leadership in the development and implementation of Technical Working Groups (TWG) to facilitate the transfer of useful information to regulatory personnel in a timely and efficacious manner. This presentation will describe how TWGs are formed and the role that scientists play in the TWG.

The role of the NPDN in the detection of and response to exotic pests

K. Cardwell (1), M. Draper (1), C. S. Thomas (2), R. M. Bostock (2), J. Stack (3), R. Hammerschmidt (4), G. Hudler (5), R. Charudattan (6)

(1) USDA CSREES, Washington, DC; (2) University of California, Davis; (3) Kansas State University, Manhattan, KS; (4) Michigan State University, E. Lansing, MI; (5) Cornell University, Ithaca, NY; (6) University of Florida, Gainesville, FL

Phytopathology 99:S172

The National Plant Diagnostic Network (NPDN) was formed to support and coordinate plant diagnostics among diagnostic laboratories in the U.S. Member laboratories and a network of first detectors serve a passive surveillance role by recognizing newly emerging and unusual outbreaks as revealed by field observation and diagnostic confirmation. The NPDN works closely with the USDA APHIS-PPQ, the Forest Service and state departments of agriculture to establish chain-of-custody and chain-of-communication standard operating procedures (SOP). These procedures cover the processes of confirmation of a suspect regulatory sample and the notification of those results through appropriate channels. The NPDN has collaborated with APHIS in conducting over 60 exercises of the communications SOP in all 50 states. APHIS, USFS, FBI, CIA, state and local law enforcement, and the NPDN also have partnered in full-scale incident command and other types of exercises on the response following a detection. The NPDN plays a critical role in providing triage and surge capacity support, and provides diagnostic expertise during an outbreak of a regulatory or non-regulatory but high consequence plant pest or disease. Critical to the success of the Network is engagement of associated laboratories early in the process to plan for and conduct early detection and accurate diagnoses and to assist in the response and recovery activities.

\section{The detection of and response to exotic pests in Florida}

W. Dixon

Florida Department of Agriculture and Consumer Products, Department of Plant Industries

Phytopathology 99:S172

Florida's agricultural, horticultural and native plant resources are under an ever increasing attack and burden by a diverse array of exotic plant pests. The globalization of exotic plant pests has resulted in an unprecedented invasion that threatens the very core of Florida's plant foundations. The exotic pest challenge has led to the formation and implementation of a substantive array of "weapons" that are wielded by Florida's regulatory agricultural body, the Florida Department of Agriculture and Consumer Services. Many strategies are used by the department to foster early detection of a newly established exotic pest and once found, a much larger process is initiated to deal with the new invader. Key to Florida's success in detection and response are regulatory authority, a well-seasoned work force and response infrastructure, logistical resources, informational outreach and a strong relationship with its stakeholders at the public, private agency and institutional levels. This presentation describes the many facets of the Florida program directed to the ever growing onslaught of exotic pests that have reached its shores.

\section{The detection of and response to exotic pests in California}

K. Kosta

California Department of Food and Agriculture

Phytopathology 99:S172

Finding an exotic pest in a nursery setting can cause a financial burden on growers, especially if the pest becomes established. This presentation will provide an overview of the role that grower play in the event that a new pest or pathogen is detected.

Finding an exotic pathogen: An industry perspective

L. Schmale

Society of American Florists

Phytopathology 99:S172

A grower's reaction to finding a new pest is not necessarily the same as a scientist's reaction would be! Will there be a quarantine? Will I lose my entire crop this year? What will my banker say? If I just let this one go, will it really matter? Agriculture wants to be protected from new pests and pathogens ... and is often the front line of defense. What are the options for encouraging industry cooperation and participation in that effort? How can growers and industry be enlisted as collaborators, rather than adversaries? And how can we work better together, to find science-based, yet practical solutions to new (and old) problems? 


\section{Methyl Bromide Alternatives Research: Plant Pathology Outcomes}

The ozone hole: Anthropogenic sources of methyl bromide and recent data on atmospheric methyl bromide levels

J. Butler, S. Montzka

National Oceanic and Atmospheric Administration, Boulder, CO Phytopathology 99:S173

Methyl bromide $(\mathrm{MeBr})$ is classified as a Class 1 ozone depleting substance (ODS) under the Montreal Protocol on Substances that Deplete the Ozone Layer and the U.S. Clean Air Act and, therefore, use has declined over the past decade. $\mathrm{MeBr}$ has been the focus of scientific and political controversy that stems from the role of $\mathrm{MeBr}$ in stratospheric ozone depletion and its toxicity to humans, contrasted with its value as an agricultural fumigant. Updated measurements show that anthropogenic ODSs have declined by $12 \%$ in the troposphere from their peak values in 1992-1994. This decline is due in large part to the shorter-lived gases such as $\mathrm{MeBr}$. $\mathrm{MeBr}$ abundance decreased in the troposphere by over 18\% from 1997-2008. This decline is greater than was originally forecasted but is attributed to decreased anthropogenic uses. Whereas tropospheric abundance data are encouraging, stratospheric bromine levels have yet to show a decline. $\mathrm{MeBr}$ is responsible for slightly less than half the bromine reaching the stratosphere today and is very efficient in depleting ozone. The Montreal Protocol does seem to be working. Outside of the polar regions, the decline of stratospheric ozone depletion has not continued and the ozone layer has shown some signs of recovery. Atmospheric scientists appreciate the role agricultural scientists have contributed to finding $\mathrm{MeBr}$ alternatives in crop production.

Current status of chemical alternative technologies for managing soil borne diseases

J. W. Noling

University of Florida, IFAS, Citrus Research \& Education Center, Lake Alfred, FL

Phytopathology 99:S173

Field research continues to focus on a co-application approach of different fumigants, herbicides, and other alternative tactics to achieve pest control efficacy and crop growth response similar to that of methyl bromide. Different application rates, technologies and grower practices are under evaluation in anticipation of potential risk mitigation tactics to reduce buffer zone distances and personal protective equipment requirements being proposed by EPA fumigant reassessments. Both chisel and drip applied fumigant application technologies are being evaluated in conjunction with high barrier, virtually impermeable mulch films to reduce air emissions and fumigant use rates. Drip fumigation procedures under evaluation continue to focus on factors affecting both water and gas phase movement of the different fumigants in soil, including chemical injection period, fumigant concentration, and numbers of drip tubes per bed. Problems with fumigant application and unsuitable environmental conditions appear to be responsible for significant yield and pest control inconsistencies with alternative fumigants. Treatment costs and returns to investment will likely be important economic considerations determining grower use decisions and transition strategy to the alternative fumigants.

Towards reduced dependence on fumigants for management of Prunus replant problems: Opportunities and challenges

G. T. Brown

USDA-ARS, Crops Pathology and Genetics Research Unit, University of California, Davis

Phytopathology 99:S173

In California, successive orchard generations of almond, peach and other Prunus spp. are subject to replant problems that suppress tree survival, growth, and productivity. Prunus replant disease (PRD; associated with a microbe complex, can affect virtually all of the acreage) and root-parasitic nematodes (RPN; can affect $<1 / 3$ of acreage) are the dominant replant problems, and both are managed with preplant soil fumigation. Spot treatment technology using GPS-controlled shanks or buried drip emitters to deliver fumigant to planting sites was developed and controlled PRD with reduced fumigant rates ( 8 to $15 \%$ of broadcast rates). The "spatial economy" of spot treatments is amenable to diverse non-fumigant treatments; spot treatments with fungicides, soil amendments, and steam are being examined. Partial remediation of PRD was achieved with fallowing and crop rotation, but the treatments were much less effective than fumigation. The potential for RPN populations to build along with root systems reduces likelihood that spot treatments can effectively control them. For RPN, reducing dependence on fumigants probably will require improved, broad rootstock resistance to ring, root knot and lesion nematodes integrated with long-term cultural and/or biological strategies for suppressing the pest populations. Advances in microbial ecology will be central to comprehensive understandings of PRD etiology and sustainable management of all replant problems.

Development of a regional transitions program: From discovery research to extension in strawberry production

F. J. Louws

Dept. Plant Pathology, North Carolina State University, Raleigh, NC Phytopathology 99:S173

Execution of a regional multi-disciplinary $\mathrm{MeBr}$ alternatives program generated multi-tiered outcomes. Stakeholders (growers, fumigant applicators and suppliers, county-level extension and other consultants, land-grant specialists and decision makers) were engaged in identification of priority issues and evaluation of alternatives in order to develop an infrastructure of knowledge and experience. Research and extension goals were realized through: Phase I experiments that evaluated new products, methods of applications or novel farming systems on research stations; Phase II projects that were primarily discovery on-farm-research experiments; Phase III projects that were large scale regional on-farm trials. Initial research efforts documented that one of the main production constraints was Black root rot, due to a complex of fungi including diverse Pythium species and Rhizoctonia fragariae strains belonging to several anastomosis groups. Molecular tools were developed to monitor key pathogens. Alternatives developed included tactic substitutions for growers who sought chemical-based alternatives; tactic diversification for growers who complimented fumigation with IPM tools and tactic development for growers who sought alternative farming systems that were biologically-based including use of cover crops and compost. Technical and economic analysis provided growers with decision tools and regional train-the-trainer programs enhanced extension impacts.

Advances in microbial ecology and farming systems as a replacement for methyl bromide to manage soil borne diseases

D. O. Chellem

USDA, ARS, U.S. Horticultural Research Laboratory, Fort Pierce, FL Phytopathology 99:S173

Several unrelated developments have contributed to an undercurrent of renewed interest in biologically based approaches for managing soil borne diseases in crop production systems traditionally reliant upon methyl bromide soil fumigation. From a commodity perspective, difficulties competing in global markets when production costs remain local have led to the examination of value added products such as certified organic or pesticide free. Concomitantly, increased regulatory pressure restricting the application of broad spectrum soil fumigants has raised doubts over their long-term availability. From a scientific perspective, advances in the technology and methods used to delineate microbial communities (genomic fingerprinting) and in the nonparametric multivariate statistical methods used to characterize their community structure and link them to environmental variables have made microbial ecology studies more accessible to applied plant pathologists. From an individual farming system perspective, advances in GPS technology used to mark and track discrete field locations coupled with the increasing use of locally generated organic soil amendments has created new opportunities to implement and monitor field experiments jointly with grower cooperators. Many challenges remain including the linkage of soil microbial community attributes to ecosystem function within the context of plant disease suppression.

\section{Perceptions of Risk, Risk Aversion, and Barriers to Adoption of Decision Support Systems and IPM}

A brief history of Plant Disease Risk Assessment: Successes and challenges

E. De Wolf

Kansas State University, Manhattan, KS

Phytopathology 99:S173
Plant disease epidemiology provides a foundation for developing the management strategies that reduce the impact of plant diseases on global food production. Predicting the risk of plant disease epidemics is a natural application of the knowledge gained through epidemiology. During the past 15 years, more than 54 journal articles have addressed the development and application of disease prediction models. These reports indicate that considerable progress has been made in developing new models, adapting models to new environments, and verifying model performance as part of practical disease management. However, additional efforts are needed to 
quantify the impact of risk assessment models on the decision process and odds of making appropriate management decisions. Sustaining the deployment of prediction models remains a significant challenge. Models appear to have a natural life cycle of development, verification, application and atrophy. Given this natural cycle, it seems unlikely that long-term deployment of prediction systems is the best indicator of success. More useful measures of success may be related to the educational objectives of a modeling effort. Using this criterion, the success of a model could be quantified by how effectively it helps decision makers acquire the skills needed to identify useful indicators of disease risk and take appropriate action without the future aid of the model.

\section{Barriers to IPM adoption in developed and developing countries P. Jepson \\ Oregon State University, Corvallis, OR \\ Phytopathology 99:S174}

Intensive, participatory IPM extension programs seem universally to advance IPM adoption. Quantitative analysis of outcomes including effects on crop yields and the impacts of pesticides on human health and the environment all reveal significant benefits of the IPM programs that farmers adopt. These benefits however rarely amplify to larger scales and rates of IPM adoption may decline over time. Barriers to adoption may include limitations to the upscaling inherent in current models for extension, low availability and use of monitoring data to reinforce the benefits of adoption, weaknesses in the development and validation of pesticide alternatives and other IPM practices, mass marketing of other models for pest management and economic constraints. This paper will review evidence for a suite of potential barriers and discuss ways forward.

\section{The sociology of uncertainty, risk, and change}

N. McRoberts, C. Hall

Scottish Agricultural College, Edinburgh, U. K.

Phytopathology 99:S174

Bayesian decision theory allows subjective probabilities to be used to model individual decision-makers' perceptions of risk. We review how such perceptions are influenced by a range of social factors including, socio-demographic factors, cultural (contextual) factors, associated benefits, psychometric paradigm dimensions of risk, the role of the media, initial impressions, and trust in different sources of information. Specifically among farmers, a range of studies have investigated the factors that influence perceptions of risk and levels of risk aversion, perceptions that influence decision-making on topics such as technology adoption and management practices. Factors which have been found to be important include: farmer age and education, and farm business characteristics such as farm size, ownership structure, gross farm income, solvency, and enterprise type. As a specific case study, we report on a postal questionnaire conducted with barley farmers in Scotland. Two variables were found to be related to whether or not farmers would consider using decision support tools for disease management. These were the region of Scotland in which they were farming and whether or not they expected to pass on the farm to the next generation of their family. We discuss these findings in relation to previous studies of farmer decision-making and the recent interest in Bayesian decision theory in plant disease management.

\section{The cost of making decisions in plant disease management}

L. V. Madden (1), G. Hughes (2), N. McRoberts (3)

(1) Ohio State University, Wooster, OH; (2) University of Edinburgh, Edinburgh, U. K.; (3) Scottish Agricultural College, Edinburgh, U. K.

Phytopathology 99:S174

In making decisions about possible epidemic outbreaks (or the need for control interventions), there are, at a minimum, two possibilities: either predicting an epidemic or predicting no epidemic. Each decision can be correct or incorrect, which leads to four possible outcomes. With results from a sample of epidemics and non-epidemics, one can thus determine the: true positive proportion (proportion of true epidemics correctly predicted; sensitivity or TPP), true negative proportion (proportion of true non-epidemics correctly predicted; specificity or TNP), false positive proportion (FPP), and false negative proportion (FNP). These proportions, which are estimates of conditional probabilities of correct and incorrect decisions, define the accuracy of a predictor. Given the (fixed) costs of incorrect decisions and the prior probability of an epidemic (estimated, for example, by the overall prevalence of epidemics in a given region), the expected cost of disease prediction (EC) can be estimated. Using a regret graph of Hilden and Glasziou and the skill/value function of Briggs and Ruppert, which are based on EC, one can determine if disease prediction is more or less cost effective as always predicting an epidemic or always predicting a non-epidemic. The skill/value function can further be used to choose the operating point of a predictor (i.e., the threshold of an indicator variable for the risk of an epidemic) which minimizes the cost of using the decision tool.

The challenge of assessing uncertainty and risk in weather-based decision support tools

W. F. Pfender (1), D. H. Gent (1), C. Thomas (2), W. F. Mahaffee (1), L. B. Coop (3), A. Fox (4)

(1) USDA-ARS, Corvallis, OR; (2) National Plant Diagnostic Network, Davis, CA; (3) Integrated Plant Protection Center, Oregon State University, Corvallis; (4) Fox Weather, LLC, Fortuna, CA

Phytopathology 99:S174

Many disease management decision aids rely on weather inputs to calculate an indicator for disease hazard. Uncertainty in the weather inputs may be propagated from raw data through indicator and model calculations to management decision recommendations. Sources of uncertainty in weather data may include sensor placement, time resolution, spatial interpolation and weather forecasting. The extent to which errors in weather inputs affect the quality of the final management outcome depends on a number of aspects of the disease management context, including the use of thresholds in the disease indicator, combined with whether management consists in a single dichotomous decision or in a multi-decision process extending over the cropping season. Quantitative risk analyses used for dichotomous decisions are problematical in multi-decision management, not only because of the perennial difficulty of assigning prior probabilities for disease events, but also because the total management effort (of which the decision aid is a part) is composed of events overlapping in time. In practice the accuracy of the disease hazard indicator is periodically assessed by reference to actual disease development, and management is adjusted for maximum benefit/cost. Effects of uncertainty in weather-based, multi-decision disease management aids will be illustrated with a simulation model for stem rust in ryegrass seed fields, and powdery mildew indices for grape and other perennial crops.

Development of management strategies for ray blight of pyrethrum: A case study of successful diffusion

S. Pethybridge (1), F. Hay (2), D. Gent (3), P. Esker (4), F. Nutter, Jr. (5), C. Wilson (2), T. Groom (1)

(1) Botanical Resources Australia - Agricultural Services Pty. Ltd., Ulverstone, Tasmania, Australia; (2) Tasmanian Institute of Agricultural Research, University of Tasmania; (3) USDA-ARS, Corvallis, OR; (4) University of Wisconsin, Madison, WI; (5) Iowa State University, Ames, IA Phytopathology 99:S174

Ray blight, caused by Phoma ligulicola var. inoxydablis is an important disease affecting pyrethrum production in Tasmania, Australia. Since regular and severe spring epidemics were first noted in 1999, research programs have developed and refined management strategies for this disease. Current recommendations for disease management were released to industry in 2002. Currently, over $90 \%$ of growers have adopted these recommendations for ray blight management. The recommendations consist of improved seed treatments to reduce seed-borne inoculum, and two to three foliar applications of a suite of fungicides coinciding with initial stem elongation. Key to the successful uptake of these recommendations were on-farm trials clearly demonstrating the benefits of fungicide application. These results were also expressed, following yield comparisons, to growers in financial return per hectare with calculation taking into account the costs associated with the fungicides and their application. Complementary to on-farm demonstration trials was effective communication of these findings using grower workshops, the extensive field extension network of the pyrethrum industry, and informative extension bulletins. All of these secondary tools were directed at the benefits of rapid implementation of management for ray blight as measured by return upon investment (i.e., fungicide application costs).

\section{Primum Non Nocere: Risk Assessment for Biological Control}

Beyond efficacy: Challenges in the selection of safe bacterial biological control agents

L. THOMASHOW (1), D. M. Weller (1), D. V. Mavrodi (2)
(1) USDA-ARS, Root Disease and Biological Control Research Unit, Washington State University, Pullman, WA; (2) Department of Plant Pathology, Washington State University, Pullman, WA

Phytopathology 99:S174

The search for new biological control agents often begins with screening in vitro for activity against target pathogens, followed by greenhouse or field 
assays. Physiological, biochemical, and phylogenetic analyses frequently are not undertaken until much later, after considerable investment already has been made in the candidate agent, and only then are many promising new isolates found to carry "baggage" due to their real or perceived affiliation with known plant or animal pathogens. Here we consider representatives of three complex genera (Pseudomonas, Burkholderia, and Bacillus) and the features that make them attractive as BCAs. We review current phylogenetic relationships within each of these genera and identify features that may prove useful in evaluating risks associated with representative strains.

\section{Minimizing risk associated with applications of microbes for biological control} D. P. Roberts

USDA-ARS, Sustainable Agricultural Systems Laboratory, Beltsville, MD Phytopathology 99:S175

Certain effective biological control agents with unique biotechnological traits are also opportunistic human pathogens. These microorganisms typically are producers of antimicrobial metabolites, resistant to multiple antibiotics, and highly competitive and versatile with regard to resources such as nutrients. These traits are desired in biological control agents but also may allow colonization of immunocompromised or otherwise challenged human subjects. Excellent examples come from the Burkholderia cepacia complex where isolates with effective disease suppression properties were registered for agricultural use by the EPA and marketed for suppression of plant disease. Subsequent concerns regarding impacts of the use of these strains in agricultural settings led to their removal from the market. Strategies are needed and being developed to harness unique biotechnological traits from these concern organisms for disease suppression while reducing the risk to human health.

Fusarium spp. as biocontrol agents

T. Odintsova (1), L. Shcherbakova (2), T. Egorov (3), R. W. Jones (4), D. R. FRAVEL (4)

(1) Vavilov Institute of General Genetics, Moscow, Russia; (2) Russian Research Institute of Phytopathology, Moscow Region, Russia; (3) Shemyakin \& Ovchinnikov Institute of Bioorganic Chemistry, Moscow, Russia; (4) USDA, ARS, Beltsville, MD

\section{Phytopathology 99:S175}

Fusarium spp. are among the most effective and consistent biocontrol agents for use against diseases caused by soilborne plant pathogenic fungi, particularly Fusarium wilt diseases. Biocontrol strains of Fusarium are presumed nonpathogenic because disease symptoms do not occur on hosts tested. Concerns have been raised about the possibility that biocontrol strains might either be pathogenic on hosts not yet identified or that through widespread application the biocontrol strain might become pathogenic over time. Genetic sequence data and functional genomics provide information for informed decisions about the risks involved in the use of Fusarium as a biocontrol agent. Sequence information is providing insight into the relationships among pathogenic, biocontrol and saprophytic strains of Fusarium. Functional genomics can identify genes associated with pathogenicity, or with biocontrol ability. Functional genomics also provides detailed information on mechanisms of action of biocontrol agents. Knowledge of mechanisms is useful in assessing risk as well as mitigating risk. Our laboratories recently sequenced $25 \mathrm{~N}$-terminal amino acids of a protein produced by the biocontrol strain $F$. oxysporum CS-20 which elicits resistance in tomato. The sequence contained many basic amino acid residues and is cysteine rich. Use of an elicitor rather than a living organism may eliminate the need to release a living biocontrol agent into the environment.
U.S. EPA's approach to risk assessment and regulation of biopesticides

G. Tomimatsu

Biopesticides and Pollution Prevention Division, Office of Pesticide Programs, U.S. Environmental Protection Agency, Washington, DC

Phytopathology 99:S175

Biopesticides may be distinguished from conventional chemical pesticides by their specificity to target species, natural occurrence, unique modes of action, or low volume use. For the organic farmer, they offer very attractive and environmentally-benign pest control options in IPM strategies. The U.S. pesticide registration process is rigorous and complex; it involves comprehensive review and assessment of science and economic data or information to support federal pre-market approval and periodic evaluations of labeled uses for manufacturers, distributors and users in the agricultural, industrial, structural, municipal, commercial, residential and recreational sectors. The Office of Pesticide Programs in the U.S. Environmental Protection Agency uses the standard tiered risk assessment paradigm of analyzing hazards and exposures to assess pesticidal risks to human health and to the environment. Within this tiered structure, potential risks are determined first from estimates of acute hazard and limited exposures under worst-case scenarios. Studies at the lower tiers are essentially screening tests-simple in design, but broad in scope. Higher tier testing may encompass field testing and sub-chronic or repeated dose exposures. A risk assessment is developed from a synthesis of results from tiered testing, intended uses and the open literature to fulfill data requirements addressing the primary disciplines of product characterization (i.e., microbial product analysis or biochemical product chemistry) and manufacturing, mammalian health and ecological or environmental effects. The presentation will provide an overview of a risk assessment and the registration process for biopesticides, based on over 30 years of regulatory experience.

Improving the risk assessment of beneficial plant pathogens for biological control of weeds: Yellow starthistle and Russian thistle pathogens

W. L. BRUCKART (1), K. D. Warner (2)

(1) USDA, ARS, Foreign Disease-Weed Science Research Unit, Ft. Detrick, MD; (2) Santa Clara University

Phytopathology 99:S175

The objectives of risk assessment are to learn about whether a candidate agent would be safe to use in the environment where release is planned, and to present such information in a clear, understandable format to regulators, stakeholders, and the public. Plant pathogens evaluated for biological control of weeds are, by definition both plant pests and pesticides, and for each of these categories there is a unique set of regulations. Risk assessment, therefore, is central to development of plant pathogens for weed management, particularly if the candidate is of foreign origin. Both objectives were achieved when permit was issued in 2003 for the release of Puccinia jaceae, a rust fungus collected in Turkey, for biological control of yellow starthistle (Centaurea solstitialis), an invasive plant of major importance in the Western U.S. Risk assessment approaches that led to this achievement had been defined over 30 years ago. Recently, statistical and molecular tools have become readily available to scientists in biological control that should facilitate development, analysis, interpretation, and communication of data concerning candidate agent safety. The application of molecular information and the use of mixed model analysis are being applied currently to risk assessments of Russian thistle (Salsola tragus) pathogens.

\section{Professionalism/Service/Outreach}

\section{Can You Hear Me Now? Expanding Plant Pathology Coverage With Diverse Delivery Tools}

Entering the digital world: How to go from being a newbie to an internet maven

J. H. LaFOREST, C. Bargeron, D. Moorhead, G. K. Douce

Center for Invasive Species and Ecosystem Health, University of Georgia, Tifton, GA

Phytopathology 99:S175

For many people, entering the world of computers is intimidating, scary and confusing. This is extremely problematic when a person's job requires them to share information since electronic resources are widely used and frequently requested. Fortunately, there are many resources, helpful groups and patient individuals that can make the entry into the Digital World relatively painless. This talk will highlight the path and some of the helpful tools that will take you from being a rookie on the computer to a wizard on the World Wide Web. It will also provide insight into one of the first steps of developing your online presence. The Bugwood Image Database will be featured along with other resources for sharing and managing images online.

Online outreach: Phytophthora training for nursery growers

J. L. PARKE (1), J. Pscheidt (1), R. Regan (1), J. Hedberg (2), N. Grunwald (3)

(1) Oregon State University, Corvallis, OR; (2) Oregon Department of Agriculture, Salem, OR; (3) USDA-ARS Horticultural Crops Research Lab, Corvallis, OR

Phytopathology 99:S175

Phytophthora spp. cause some of the most important diseases of nursery crops nationwide. The quarantine pathogen $P$. ramorum, the cause of ramorum blight and sudden oak death, is of special concern. In partnership with the Oregon Department of Agriculture, we created an online course to teach 
growers how to reduce the incidence of Phytophthora diseases in their nurseries. This free, non-credit course includes three modules that focus on 1) biology, symptoms and diagnosis, 2) disease management, and 3) Phytophthora ramorum. Both English and Spanish language versions of the course are available. After completion of the course, nursery growers can take an optional online exam for a fee. If they pass the exam, they earn a certificate of mastery from Oregon State University Extended Campus and qualify for pesticide recertification credits. The course may be accessed at http:// ecampus.oregonstate.edu/phytophthora. The development and efficacy of online training courses for grower education will be discussed.

\section{Adobe connect: What can it do for you? \\ G. Snyder \\ Dept of Communications, Kansas State University, KS \\ Phytopathology 99:S176}

Save time, travel, and communicate with people across the globe by using a simple Web browser and Webcam. Adobe Connect is a full features on-line video conferencing system. K-State is utilizing Connect for live meetings, research collaboration, eLearning, on-line presentations, seminars (Webinars), and even accredited courses. Connect allows you to use live video, audio, the ability to view PowerPoint presentations, post agendas, share documents, and offers interactive features such as polls, whiteboards and active chat. This session highlights several examples from the K-State Research and Extension Connect system. It will also cover many of Connect's features, offer tips, resources, and ideas on how to get started.

ipmPIPE: Legume PIPE new option for generating, summarizing, and disseminating real-time pest data to stakeholders

H. F. SCHWARTZ (1), M. A. C. Langham (2), S. A. Tolin (3), J. Golod (4), J. LaForest (5), K. F. Cardwell (6)

(1) Colorado State University, Fort Collins, CO; (2) South Dakota State University, Brookings, SD; (3) Virginia Tech, Blacksburg, VA; (4) Pennsylvania State University, University Park, PA; (5) Bugwood Network, University of Georgia, Tifton, GA; (6) USDA-CSREES, Washington, DC Phytopathology 99:S176

The Integrated Pest Management Pest Information Platform for Extension and Education (ipmPIPE) began as a dynamic, integrated national warning system for soybeans (and other legumes) that would promote efficient and coordinated IPM decision making for Soybean Rust and Soybean Aphid management. In 2007, the Risk Management Agency (RMA) requested that the ipmPIPE help determine causes of disease and insect losses in other legumes including fresh and dry peas and beans, chickpeas, lentils, lima beans, and cowpeas. Thus, the Legume ipmPIPE evolved from the ipmPIPE to address multiple pests on related legume hosts. Specialists from nearly 30 states devised sampling protocols and developed diagnostic assays for legume diseases including viruses in 2007. National mapping of this information on a public website began in 2008. Legume ipmPIPE enhances the role of extension specialists in IPM by providing near real-time access to observations, model output, pest management information, and diagnostic images at http://legume.ipmpipe.org. Communication tools also allow specialists to customize information for dissemination to state and regional crop consultants and growers. The diversity of pathogens, pests and hosts are uniquely suited to demonstrate the value of the ipmPIPE as a "one-stop shop" for legumes where educators and stakeholders can easily obtain information on pathogens and pests identified in a specific area or general region.

\section{eXtension.org - how to use it to deliver your information}

T. Meisenbach

eXtension Initiative, Rancho Mirage, CA

Phytopathology 99:S176

eXtension takes the traditional technology transfer role of Cooperative Extension to a new level with an opportunity to reach millions of Americans who use the Internet for information and education every day. Faculty and staff in universities throughout the nation are finding the collaborative opportunities offered by eXtension's wiki environment an excellent base for developing and delivering content on myriad topics from beef cattle to fire ants to consumer horticulture to organic agriculture and more. Multi-state, multi-disciplinary teams or communities of practice work together to create "best of the best" educational resources with science- and research-based content enhanced by Web 2.0 tools. And, America's borders do not limit the reach of eXtension. Nearly 20 percent of all eXtension traffic comes from outside the United States. eXtension provides training for Cooperative Extension faculty and staff and collaborators in new technologies to enhance learning, explores delivering educational experiences through Second Life, an interactive environment finding great success in the corporate training world, and uses Moodle for development of courses for professional development and public consumption. eXtension's Frequently Asked Questions and Ask an Expert features allow consumers to search a database of more than 8,000 peerreviewed questions and connect directly to experts for more specific answers when needed.

\section{Prepare for your Future: Career Opportunities After Graduate School - Option 1. Industry}

\section{Dispelling the myths of working in industry}

\section{P. Kuhn}

Syngenta Crop Protection, Inc.

Phytopathology 99:S176

Of the career paths open to recent graduates in plant pathology, positions in the private sector may be given less consideration than options in the public sector (academia, USDA, etc.). In part, this may reflect a higher comfort level with the more familiar settings of universities or state/federal laboratories, but probably in many cases also a lack of firsthand knowledge of what is involved in working in industry. The disinclination to consider careers in the private sector may be reinforced by peers and advisers when they present an unfavorable perspective of life on the other side of the fence. To compound this state of affairs, graduates of plant pathology may also associate working in the private sector with a number of myths that are discouraging. This presentation will explore some popular misconceptions, giving candidates a more informed view of what a position or career in the private sector involves and of the associated advantages.

\section{Acquiring the skills to get the job you want}

B. Olson

Dow AgroSciences LLC

Phytopathology 99:S176

Graduate and post graduate research in plant pathology provides scientists with the basic understanding of the science and knowledge of plant health, scientific method, experimental design, data interpretation and analysis. In addition to an academic degree there are several non-technical skills and attributes individuals need to develop and demonstrate over the course of their research to ensure successful careers. These attributes are important building blocks to an individuals' personal and professional effectiveness throughout their career. The non-technical skills are transferable from one job or project to another and serve as strong discriminating factors when evaluating candidates from a large pool of well qualified researchers. These attributes are rarely taught or discussed in graduate school and instead are each individual's responsibility to develop. These include: leadership and initiative; creativity and problem solving; communication; research productivity and quality; teamwork; and accountability. Often in industry these attributes are evaluated during the candidate interview process using a tool known as behavioral interviewing. Regardless of the position an individual may have in academia or industry the non-technical skills developed by an individual will be transferable to all of their various roles and responsibilities and will allow them to be effective, productive, and respected scientists.

\section{Putting it together - getting the job you want with the right resume} R. Kaiser

Valent BioSciences Corp.

Phytopathology 99:S176

Landing the job you want in today's economic environment isn't easy, but it can be done with planning and perseverance. Step 1 is a serious examination of your skills and aspirations. Step 2 is developing a marketing plan that sells your unique skills and personality to potential employers. You should list three key strengths and develop supporting evidence (three examples for each strength) that demonstrate how you have produced results using these strengths. Developing your resume' as a short advertisement of your achievements is Step 3. Future employers pay for results, not just knowledge or skills. Your resume should reflect your abilities in leadership, communication and problem solving by giving examples of your achievements. Your employer will teach you any new necessary skills, but in the selection process they look for candidates with a track record of producing results. Steps 4 and 5 are utilizing networking techniques and 
preparing for the interview. This presentation will focus on Steps 1-3 and help candidates recognize their strengths and develop strong results-orientated statements.

\section{A year in the life of a field scientist \\ R. Bounds \\ Syngenta Crop Protection, Inc. \\ Phytopathology 99:S177}

Industry field scientists are in integral part of research and development efforts to deliver new technologies to agricultural producers. The activities of field scientists, from project planning to experiments to results, will be described from the perspective of an agrochemical industry field scientist.

\section{A year in the life of an agricultural consultant}

C. Becker

BAAR Scientific LLC, Romulus, NY

Phytopathology 99:S177

Consulting in agriculture is an increasing employment option. Extensive applied experiences and an advanced degree are the typical requirements for the resume. The diversity of options include pest management, contract research, nutrient management, yield optimization, and marketing. Scouting for pest management requires little capital input, but also generates limited financial returns. Whereas contract research may yield increased income potential, however, it require extensive agricultural equipment, followed by extensive marketing of your companies services. Also personal experiences with contract research have showed extreme diversity with agricultural projects every year. In addition to drawing from education and experiences in the applied sciences, most professionals consulting in agriculture need to understand business and insurance issues, must communicate with a diverse audience, and benefit from efficient management of information. Experiences from 6 years of conducting knowledge based pest management in grapes and conducting contract research on the diverse crops in the Northeastern U.S. will be discussed.
Pathology roles in disease resistance discovery and implementation

P. Himmel

Seminis Vegetable Seeds, a division of Monsanto

Phytopathology 99:S177

'An inoculum cook at the mercy of plant breeders in an environment lacking innovative research' is perhaps the most common misconception of the role a plant pathologist plays in a vegetable seed company. Competition between seed companies that requires strict confidentiality and legal protection of research exacerbates this misconception. Disease resistance is an important component of commercial vegetables and often determines whether or not a variety can be released into key markets. Staying ahead of the evolving disease landscape requires innovation, focus and teamwork between pathologists, plant breeders, geneticists and molecular biologists. Today, there are opportunities in both molecular and applied pathology to discover, develop and deploy new disease resistances and speed deployment of existing resistances. Essential to these diverse pathology roles is the ability to communicate with growers as well as our non pathology colleagues in research, seed production, sales and marketing. A clear understanding of disease resistance helps set realistic performance expectations for the vegetable varieties we sell. A composite of pathology roles and responsibilities in research and seed production will be presented.

\section{Developing your career in industry}

L. Fought

Bayer CropScience LP

Phytopathology 99:S177

Obtaining a job in industry marks the beginning of a lifetime of learning and professional development opportunities. The skills developed prior to entering industry serve as the basis for continued growth in an environment that depends greatly on innovation, commitment, and personal standards of excellence. A career in industry may not take a straight path, and there are many opportunities to stretch and strengthen skills and learn new ones. A sampling of the opportunities available for career development in industry will be presented.

\section{Regulation of Pests and Pathogens-Where Are We?}

\section{Update on APHIS PPQ 7 CRF 330 regulatory changes}

J. L. White, S. Wager-Page

USDA APHIS, Riverdale, MD

Phytopathology 99:S177

USDA, APHIS, Plant Protection and Quarantine is committed to improve customer service for plant pathogen and nematode permitting (form 526). EPermits, our on-line application process, has improved service significantly by reducing lost paperwork, prompting applicants to reauthorize expiring permits, and electronically copying existing permits for the reauthorization process. Efforts to streamline permits for domestic pests this year has focused on fungi and nematodes. The first widely prevalent fungi list by state was submitted by APS (http://prevalentfungi.org/). PPQ consulted with all States and territories on whether permits for widely prevalent fungi could be expedited (i.e., organisms and conditions are preapproved by the States). Forty-five States agreed to expedite many widely prevalent fungi. These States had agreed previously to expedite certain viruses and bacteria. The list of States participating, the organisms, and the standard permitting conditions are available at http://www.aphis.usda.gov/plant_health/permits/organism/ wpp/index.shtml. APS and PPQ expect that the widely prevalent nematode list by State will be completed by the end of 2009 and the expedited list by July 2010. PPQ envisions that changes in epermit software will allow organisms on the expedited list to be fully used without applicant knowledge of the organisms on the list or participating States. PPQ plans to propose these revisions to the plant pests and microbial biocontrol regulations (7CFR330) in the near future. This will address whether certain widely distributed pest or biocontrol agents will require an e-permit.

\section{The APS Public Policy Board: Pulse on Policy Issues}

\section{APS and public policy}

K. Eversole

Eversole Associates

Phytopathology 99:S177

Public policy impacts virtually all aspects of the diverse scientific enterprise from providing education and training for careers in science to funding research projects to applying results from fundamental research to the field. While many scientists believe that it is difficult if not impossible for them, personally, to have an impact on calls for proposals, regulations, funding decisions, or even Presidential budget requests and Congressional appropriations, exactly the contrary is the reality. One person can make a difference and a group of scientists have a variety of mechanisms by which to influence the policies that affect them. The APS has a diverse tool kit for understanding the interrelationship between public policy and the science of plant pathology as well as for providing advice, suggestions, and assistance to improve the conditions under which scientists must operate. An overview of some of the methods for approaching public policy will be presented along with several examples of how individual scientists can influence public policies that affect the conduct of science.

\section{The APS Early Career Internship}

A. Records

Texas A\&M University, College Station, TX, USA

Phytopathology 99:S177

The APS Public Policy Board (PPB) Early Career Internship presents a rare opportunity for a graduate student, post-doctoral associate, or junior professional to learn how science policies are shaped. As the second PPB intern, I worked with the PPB for a year, gaining hands-on experience in public policy and learning about APS initiatives. Specifically, I became most involved in the Genomics initiative, because funding for plant and plantpathogen genome sequencing has had a significant impact on my research and that of so many plant pathologists. The highlight of the internship was the annual governmental outreach meeting in Washington, DC, where I joined the PPB in talks with key policy makers and visits to several federal agencies. I will present an account of my internship experience, with special focus on the meetings in Washington, DC. In addition, I will discuss the impact that the APS PPB internship has had on my professional development and direction. 
The future of plant pathology education

J. MacDonald

UC Davis

Phytopathology 99:S178

In a recent survey of plant pathology students, graduate program heads, and employers, concerns surfaced about the shrinking ability of universities to provide students with educational experiences related to the applied or fieldoriented aspects of plant pathology. Graduate program heads also expressed concerns about shrinking numbers of students with an interest in studying plant pathology. These two concerns actually extend well beyond plant pathology, having surfaced in virtually every discipline related to the plant sciences... and beyond that to most of the agricultural sciences. Indeed, at the November, 2008 meeting of the American Association of Agricultural Scientific Societies, which represents approximately 50,000 scientists from academia, government and industry, "education concerns" were listed among the groups five priorities for focused attention. For its part, the APS Public Policy Board and the ad hoc Committee on the Future Education of Plant Pathologists, hosted a national workshop on The Future of Education in Plant Pathology and Related Disciplines in March, 2009. This workshop brought together leaders of plant pathology and other plant science-related disciplines, students, and representatives of government and private sector employers. The workshop sought to identify the educational challenges facing our disciplines, what employers need for the future, and strategies for working together to address what is coming to be viewed as a looming crisis in national and international food systems. This presentation will summarize the major outcomes of the workshop and the anticipated next steps.

\section{The culture collection resource of the future}

S. Gold

University of Georgia

Phytopathology 99:S178

The PPB has undertaken an initiative, in partnership with the USDA-ARS and USDA-APHIS, to establish a plan for a National Plant Microbial Germplasm System (NPMGS). This is intended to be a culture collection system for the long-term and stable preservation of important plant associated microbial resources. Two workshops to develop this plan will have been carried out by the time of the 2009 APS meeting. Participants in these workshops include scientists from APS, industry, university and government. The first workshop was held in November 2007 and produced an outline document defining the critical components of the system. The second, to be held in January 2009, will focus on perfecting this plan and producing an executive summary document for distribution to policy makers. The second workshop will include international participants involved in major culture collection systems around the world with the intent of gaining from their experiences and determining how best to integrate a U.S. system with other major collections. The structure of the system as currently envisioned involves a central hub repository and a system of taxonomic expert spoke centers. The central repository will capture orphaned collections and store backups from spoke centers. A NPMGS steering committee will be established charged with developing policies regarding (among others) inclusion, distribution and funding for the system. Copies of the NPMGS executive summary plan will be available.

\section{Plant pathology contributions to food safety}

J. Barak

University of Wisconsin

Phytopathology 99:S178

Bacterial pathogens, both plant and human, colonize crop plants and can share environmental niches. The colonization of plants by enteric animal pathogens causes a unique public health concern, and recent impacts of fresh producelinked epidemics of foodborne illness have reached the tens to hundreds of millions of dollars for each industry implicated. Plant pathologists, who bring collective knowledge and experience to unravel the synergy between the plant and human pathogens on plants, have begun to address the biology of these interactions, revealing mechanisms used by the bacteria to attach to and colonize plants, as well as factors that impact the nature of such interactions. An APS-Colorado State University workshop, "Human Pathogens on Plants," in October 2008 served as a stimulating interface for plant pathologists, food safety specialists, and industry and agency representatives to learn about ongoing research in each others' disciplines, to understand the overlapping contributions from each discipline, to discuss and prioritize future research efforts, and to identify ways in which our diverse communities can work together to enhance and direct that research in a meaningful way. Joint efforts planned as outcomes of the workshop will include white papers directed at policy makers and funding agencies, and a future APS workshop to continue these productive multi-disciplinary linkages.

\section{Perspectives from the APS-OSTP Fellow}

\section{J. Sherwood}

University of Georgia

Phytopathology 99:S178

The Office of Science and Technology Policy (OSTP) is in the Executive Office of the President and serves to advises the President on issues in science and technology on domestic and international affairs; on major policies, plans and programs of the Federal Government; and leads interagency efforts to develop and implement sound science and technology policies and budgets. With support from the Public Policy Board of APS, the APS Foundation and the University of Georgia, Dr. Sherwood had the opportunity to work in OSTP for the six month period of November 2008 through beginning of May 2009. This was a significant time in regards to potential impacts on policy in regards to agricultural research as there was a significant transition in leadership for the Federal Government and in policy as the National Insitute for Food and Agriculture was becoming established, and the Agriculture and Food Research Initiative was implemented under the new Farm Bill. Dr. Sherwood will speak on his experiences and activities during this period, and possible impacts on the field of plant pathology.

\section{Reflections from the Early Career PPB Intern}

M. Abril

Louisiana State University

Phytopathology 99:S178

I have had a unique opportunity to serve as the third APS Public Policy Board (PPB) Early Career Intern this year. This experience has allowed me to be involved first hand in issues that have direct impact on current and relevant issues in agriculture at the national level. I have participated in several discussions addressing critical issues that directly impact agriculture through monthly conference calls with my fellow Board members. My first course of action was to become familiar with the current APS initiatives that include Biosecurity, Culture Collections, Education, Food Safety, Industry, Genomics, General Agricultural Funding, and Regulatory Issues. From there, my personal interest let me to join the Education Initiative and to participate actively on a symposium that will assess the current status of plant pathology educational programs nationwide scheduled concurrently with the APS Annual Meeting to be held next year in Portland, OR. I have also been engaged in making decisions about numerous current concerns in the field of plant pathology from the demise of faculty and research positions to Farm Bill Implementation. The APS PPB internship available to APS members (graduate students, post-docs, or members with 10 years of receiving a degree) members within 10 years of receiving their degree offers an invaluable experience to those interested in getting first-hand insight of policy making at the national level. Having the opportunity to be directly involved on the process of decision-making on relevant aspects concerning my field of interest has certainly rendered this experience gratifying and rewarding. The internship has made me aware of the impact to the economy of the country of funding allocations for advances in science and technology. Attention to biotechnical research applied to agriculture should be considered a priority to all parties involved, since it represents an opportunity to improve the nation's resources for generations to come. Furthermore, now I am aware of the crucial role that scientific societies such as APS have with respect to providing leadership to address immediate needs in agriculture that are of a national scope, such as the development of resistant plant cultivars and the training of plant pathologists.

\section{Working With Genetically Engineered Plant Pathogens in the Modern Regulatory Environment}

\section{Shipping genetically engineered pathogens}

D. Stiger

Federal Aviation Administration, Portland, OR

Phytopathology 99:S178
The presentation will cover an overview of United States Department of Transportation hazardous materials regulations concerning shipping of infectious substances. The new classification criteria and packaging requirements will be covered and then compared to the international standards for shipping of infectious substances by air. In addition, the session will cover the extensive difference between United States transportation regulations and international transportation regulations of Genetically Modified MicroOrganisms (GMMOs) and Genetically Modified Organisms (GMOs). 
Culture collections: An important partner in establishing and enforcing regulations on research with genetically engineered plant pathogenic micro-organisms

K. McCluskey

UMKC, Kansas City, MO

Phytopathology 99:S179

Culture collections have a unique perspective on the regulatory requirements for working with genetically engineered micro-organisms. While many researchers never face the questions of how to achieve regulatory compliance, culture collections by their very nature encounter these questions frequently. Because the scientific understanding of genetic manipulations has increased in recent years, regulations have needed to evolve to promote a culture of compliance in academic and commercial research laboratories. As the significant majority of strains in genetic research are now genetically engineered, nearly every researcher will be regulated by government agencies regarding the sharing of research strains. Culture collections can serve to promote both awareness and development of those regulations. 